Review

\title{
Advances in Development of Antimicrobial Peptidomimetics as Potential Drugs
}

\author{
Natalia Molchanova, Paul R. Hansen * (D) and Henrik Franzyk * \\ Department of Drug Design and Pharmacology, Faculty of Health and Medical Sciences, \\ University of Copenhagen, Jagtvej 162, DK-2100 Copenhagen, Denmark; natalia.molchanova@sund.ku.dk \\ * Correspondence: prh@sund.ku.dk (P.R.H.); henrik.franzyk@sund.ku.dk (H.F.); Tel.: +45-3533-6680 (P.R.H.); \\ +45-3533-6255 (H.F.)
}

Received: 11 July 2017; Accepted: 22 August 2017; Published: 29 August 2017

\begin{abstract}
The rapid emergence of multidrug-resistant pathogens has evolved into a global health problem as current treatment options are failing for infections caused by pan-resistant bacteria. Hence, novel antibiotics are in high demand, and for this reason antimicrobial peptides (AMPs) have attracted considerable interest, since they often show broad-spectrum activity, fast killing and high cell selectivity. However, the therapeutic potential of natural AMPs is limited by their short plasma half-life. Antimicrobial peptidomimetics mimic the structure and biological activity of AMPs, but display extended stability in the presence of biological matrices. In the present review, focus is on the developments reported in the last decade with respect to their design, synthesis, antimicrobial activity, cytotoxic side effects as well as their potential applications as anti-infective agents. Specifically, only peptidomimetics with a modular structure of residues connected via amide linkages will be discussed. These comprise the classes of $\alpha$-peptoids ( $N$-alkylated glycine oligomers), $\beta$-peptoids ( $N$-alkylated $\beta$-alanine oligomers), $\beta^{3}$-peptides, $\alpha / \beta^{3}$-peptides, $\alpha$-peptide $/ \beta$-peptoid hybrids, $\alpha / \gamma \mathrm{N}$-acylated $\mathrm{N}$-aminoethylpeptides (AApeptides), and oligoacyllysines (OAKs). Such peptidomimetics are of particular interest due to their potent antimicrobial activity, versatile design, and convenient optimization via assembly by standard solid-phase procedures.
\end{abstract}

Keywords: antimicrobial peptides; peptidomimetics; peptoids; antibiotics

\section{Introduction}

Antimicrobial resistance (AMR) is a global health-care problem causing the death of nearly 700,000 people each year [1], and predictions indicate that this number may reach up to 10 million deaths annually by 2050 . The annual cost of AMR is estimated at $€ 1.5$ billion in the EU and US $\$ 5$ billion in the USA [2]. According to the Infectious Diseases Society of America (IDSA), the most worrying bacteria comprise the multidrug-resistant (MDR) ESKAPE pathogens Enterococcus faecium, Staphylococcus aureus, Klebsiella pneumoniae, Acinetobacter baumannii, and Enterobacter species, which together cause the majority of US hospital infections. Furthermore, resistance to the last-resort antibiotics colistin and carbapenems for treatment of difficult Gram-negative infections is spreading rapidly. For example, shortly after the emergence of a mobilized colistin resistance gene (mcr- 1 ) in bacteria from pigs in China in 2015, it was rapidly distributed across Europe and to Canada and USA [3]. The mcr-1 gene is the first polymyxin resistance-inducing gene capable of horizontal transfer, implying that it may spread among different bacteria, such as Escherichia coli, P. aeruginosa and K. pneumoniae. In 2016, after the initiation of screening for bovine and porcine colistin-resistant $E$. coli, a new resistance gene termed mcr-2 was identified in Belgium mcr-2 [4]. Carbapenem antimicrobial resistance, mediated by transferable carbapenemase-encoding genes and efflux pumps, has been found on all continents [5]. Also, a recent review of currently available data reports on alarming rates of carbapenem resistance in Pseudomonas spp. and Acinetobacter spp. [6]. 
Multidrug resistance in Gram-positive bacteria such as methicillin-resistant Staphylococcus aureus (MRSA), vancomycin-resistant enterococci (VRE), and Clostridium difficile remains a challenge in infectious diseases. Community-associated MRSA strains, which cause serious skin and soft tissue infections in otherwise healthy individuals, have emerged [7]. Infectious diarrhea in hospitalized patients caused by Clostridium difficile [8], and a high incidence of VRE colonisation among children with hematological/oncological diseases [9], both constitute severe health issues.

Human medicine is mainly concerned with AMR emerging in human pathogens, and thus it is often overlooked that companion animals (dogs, cats, horses etc.) and food-producing animals (cattle, pigs, sheep, chickens etc.) are also treated with related antibiotics. Therefore, the veterinary area may also contribute to development of resistant bacterial pathogens. In fact, two thirds of the consumption of antibiotics in the EU and $70 \%$ of their usage in the US occurs in the animal farming industry [10]. In many countries, even colistin is administered to pigs, veal calves, and poultry to treat and prevent diarrhea caused by E. coli and Salmonella spp. [11]. Administration of tetracyclines to food animals have resulted in the spreading of the livestock-associated methicillin-resistant S. aureus CC398 (LA-MRSA CC398) [12].

Furthermore, pet animals are often treated with the same types of antibiotics as humans, thereby enhancing the risk of AMR development in humans [13]. The importance of proper antibiotic use in small animals is crucial considering that $25 \%$ of European households own a pet. Antimicrobial treatment in dogs and cats is most commonly used against skin and wound infections, typically caused by Staphylococcus pseudintermedius, otitis externa caused by P. aeruginosa, and urinary tract infections (UTI) that can be caused by several bacteria including E. coli [14]. In 2009, the first case of human infection with methicillin-resistant $S$. pseudintermedius (MRSP) was reported [15]. Infections caused by MRSP (the main reason for antibiotic prescription in dogs) are challenging to eradicate, but MRSP is still considered a rare pathogen in humans, albeit with an increasing number of cases reported each year [16].

Emergence of AMR is often ascribed to overuse/misuse of antimicrobial drugs, as well as the pharmaceutical companies' lack of success in meeting this challenge [17]. A contributing factor is the fact that development of antibiotics has a high risk profile due to single short-term prescriptions and restrictions on their use, and hence antibiotics often generate low returns [18]. In recent years, the AMR crisis has been addressed by several global organizations, attempting to raise global awareness [19]. Finally, a number of recent regulatory incentives for antibiotic drug development have been proposed as reviewed by Sinha [20].

\subsection{Antimicrobial Resistance}

Antimicrobial resistance may be intrinsic, adaptive or acquired. Intrinsic resistance implicates an ability of the pathogen to resist the antibacterial treatment due to inherent structural or functional properties, while adaptive resistance refers to an ability of the bacteria to adapt to non-lethal conditions by rapidly altering their transcriptomes in response to a stressful environment (e.g., selection pressure exerted by subinhibitory levels of antibiotics). Acquired resistance develops through acquisition of genes or as a result of a gene mutation, and it is the only form of resistance that can be transferred both horizontally and vertically [21]. Horizontal gene transfer implicates the exchange of genes between distinct species, while vertical gene transfer represents a transmission of DNA from the parent organism to its offspring [22]. There are several different main types of antibiotic resistance mechanisms: (i) Prevention of access of the antibiotic to its target by either reduced permeability of the membrane or by increased efflux [23]; (ii) Change in antibiotic target by mutations not affecting its functionality, but preventing interaction with the antibiotic [24]; (iii) Post-translational modification of the target [25]; (iv) Direct modification/degradation of antibiotics through enzyme-catalyzed transformations (e.g., hydrolysis of $\beta$-lactam antibiotics) [26]. 


\subsection{Development of Antibiotics in Recent Years}

For more than 70 years antibiotics have constituted a successful cure to life-threatening infectious diseases. Meanwhile bacteria evolved and became resistant, but antibiotic research was not highly prioritized by most of the pharmaceutical companies [27]. Today, the antibiotic pipeline is drying out, and efficacy of current antibiotics to combat MDR Gram-negative bacteria is rapidly declining. According to FDA, between 2012 and 2017 only nine antibiotics were approved, of which none was first-in-class against Gram-negative pathogens [28]. Notably, most newly approved antibiotics belong to known classes of antibiotics, and hence there is a high risk of rapid resistance development. For example, an MRSA strain resistant to linezolid was isolated only a year after its introduction to the market [29]. There is a steady state of antibiotics entering and leaving clinical trials [30]. In phase III clinical trials there are only eight drugs with broad-spectrum activity, while phase II trials comprise ten broad-spectrum drugs of which only one targets Gram-negative pathogens, whereas there is only one broad-spectrum antibiotic in phase I trial [28]. Additionally, in phase I-III there are six $\beta$-lactam/ $\beta$-lactamase inhibitor combinations of known drugs that target Gram-negative bacteria. The lack of treatment options especially against MDR Gram-negative pathogens highlights the need for novel antimicrobial treatment strategies.

\subsection{Antimicrobial Peptides (AMPs)}

Antimicrobial peptides (AMPs), also often termed host-defense peptides (HDPs), have for the last two decades been considered as possible candidates for novel antibiotics due to their key role in the innate immune system in all multicellular organisms [31]. Thus, AMPs have been found not only in animals, but also in plants, fungi and even in bacteria. Today, all reported naturally occurring and synthetic AMPs are collected in databases, e.g., Data Repository of Antimicrobial Peptides (DRAMP), which contains more than 4500 sequences of antimicrobial peptides [32]. AMPs are typically divided into four groups based on their secondary structure [33]: (i) $\alpha$-helical AMPs (e.g., the cathelicidins); (ii) $\beta$-sheet-containing AMPs, often with two or more disulfide bonds present (e.g., $\alpha$ - and, $\beta$-defensins); (iii) AMPs with a $\beta$-hairpin or loop conformation stabilized by the presence of a single disulfide bond and/or cyclisation of the peptide chain (e.g., thanatin); (iv) short AMPs with extended conformations (e.g., indolicidin).

Generally, AMPs contain 10-50 amino acids of which approximately half typically are hydrophobic, and most AMPs possess a net positive charge [34], although a few anionic AMPs are known [35]. Most AMPs are amphipathic, and this is believed to facilitate a selective electrostatic interaction with the negatively charged bacterial membranes, thereby causing perturbation of the lipid bilayer structure [36].

Despite increased attention to AMPs and the constant development of new biophysical techniques, the understanding of their mechanism of action at the molecular level remains to be elucidated in detail. The combination of cationic and hydrophobic residues promotes a strong electrostatic interaction with the negatively charged surface layer of bacteria that consist of lipids such as phosphatidylglycerol (PG), cardiolipin (CL) as well as lipopolysaccharides (LPS) in case of Gram-negative bacteria, or lipoteichoic acid (LTA) in case of Gram-positive bacteria. Additionally, hydrophobic interaction with bacterial envelopes induces folding of the AMPs that contributes to the antibacterial properties of these peptides. The high abundance of neutral phosphatidylcholine/cholesterol/sphingomyelin lipids confers a zwitterionic surface to mammalian cell membranes, which leads to a weaker attraction between cationic peptides and host cells, which is the origin of the cell selectivity observed for many AMPs. The bacterial membrane is considered as the main target for AMPs, since several studies have demonstrated that AMPs disrupt bacterial membrane integrity, thereby causing leakage of cell content followed by cell death [37]. A number of models of AMP disturbance of bacterial membranes have been reported, and these comprise: the carpet model [38]; aggregation [39]; molecular electroporation [40]; toroidal pore formation [41]; sinking raft [42]; barrel-stave model [43]; interfacial activity [44]; and lipocentric pore formation [45]. 
Although the bacterial membrane is the main AMP target, intracellular targets such as nucleic acid synthesis (e.g., buforin II), RNA synthesis (e.g., Bac5 and Bac7), protein synthesis (indolicidin), enzymatic activity (pyrrhocoricin), ATP efflux (histatins), or cell wall synthesis (nisin) have been reported [46].

\subsection{AMPs as Therapeutic Agents}

AMPs often display broad-spectrum antibacterial activity, including MDR pathogens, with a rapid onset of killing, and thus with relatively low risk of resistance development that make them desirable drug candidates. However, objective assessment of their therapeutic potential exposes a large difference between peptides claimed active in scientific articles and their realistic performance in clinical trials. Within the last three decades, despite numerous attempts, only four natural AMPs have found their way onto the market, none of them being linear peptides. Currently, no synthetic AMP has been approved by the FDA.

Several peptide antibiotics that have been introduced to the clinical use, e.g., bacitracin, polymyxin, gramicidin, and tyrothricin, are produced by Bacillus species [47]. Tyrothricin, the first AMP to be used clinically, consists of tyrocidine (main component) and gramicidin. Tyrocidine is a mixture of cyclic decapeptides that due to hemolytic properties exclusively are used as a topical agent [48]. Tyrocidine A and gramicidin S are broad-spectrum cyclodecapeptides that also only are applicable for topical use due to hemolytic side effects $[49,50]$. The cyclic lipopeptides polymyxin $B$ and polymyxin $\mathrm{E}$ (also known as colistin) have been used for treatment of Gram-negative infections, and currently they constitute the last-line therapy for MDR Gram-negative infections [51]. Use of polymyxins is limited due to nephro- and neurotoxicity; however, via a prodrug formulation as the corresponding sulfomethylated compound acute toxicity is reduced. Bacitracin is a mixture of cyclic polypeptides used in combination with polymyxin and neomycin (Neosporin ${ }^{\mathrm{TM}}$ ) for topical treatment of eye and skin infections, however, bacitracin also exhibits nephrotoxicity [52,53]. Nisin is another natural (34-residue) AMP produced by Lactococcus lactis, which is effective against Gram-positive bacteria, in particular mastitis pathogens. Due to its low toxicity, nisin has been licensed in 48 countries for use as a food preservative especially in dairy products [54]. Finally, another cyclic lipopeptide, daptomycin, is utilized for treatment of infections caused by MDR Gram-positive pathogens [55].

In Tables 1 and 2, selected AMPs currently undergoing clinical and preclinical trials as well as compounds recently failed during different stages are listed. Notably most AMPs failing preclinical studies during the last phase typically suffered from high susceptibility to degradation or from unexpected in vivo toxicity. Therefore, pharmaceutical companies have shifted focus from development of peptide drugs for systemic administration toward agents for topical use.

The majority of AMPs in current clinical development targets skin infections caused by Gram-positive bacteria. The magainin analog pexiganan is currently in phase III clinical trials for treatment of diabetic foot ulcers, though it was not approved by FDA in 1999 after completion of phase III. One of the most well-known host-defense peptides LL-37 is undergoing phase II for treatment of leg ulcer. After failing in phase III for possible treatment of catheter-related infections, the indolicidin analog omiganan is undergoing phase III for treatment of rosacea. However, there are several candidates exhibiting activity against Gram-positive and Gram-negative bacteria with alternative administration routes. For example, a cationic fragment of human lactoferricin hLF1-11 is aimed for intravenous treatment of bacterial infections in immunocompromised patients after stem cell transplants. Additionally, three AMPs, NVB-302, surotomycin and ramoplanin, are being developed for oral administration in order to treat infections caused by Clostridium difficile. The development of protegrin analog POL7080, the only AMP targeting Gram-negative infections, has been terminated during phase II after Roche discontinued their involvement. However, POL7080 was studied to investigate drug-drug interaction with amikacin and recently completed Phase I (January 2017) [56]. Polymyxin derivative SPR741, which acts as a potentiator in combination with antibiotics active against Gram-positive pathogens, has shown success in preclinical studies aimed at treating infections 
caused by Gram-negative bacteria, and it has entered Phase I clinical studies in January 2017 [57,58]. In addition, there are four AMPs in preclinical stage that exhibit activity against Gram-negative bacteria. The most recent advances in development of AMPs in clinical trials have been decribed more thoroughly in reviews by Greber \& Dawgul [59], Kosikowska \& Lesner [60] and Sierra et al. [61].

Table 1. AMPs in clinical trials (Phase I-III).

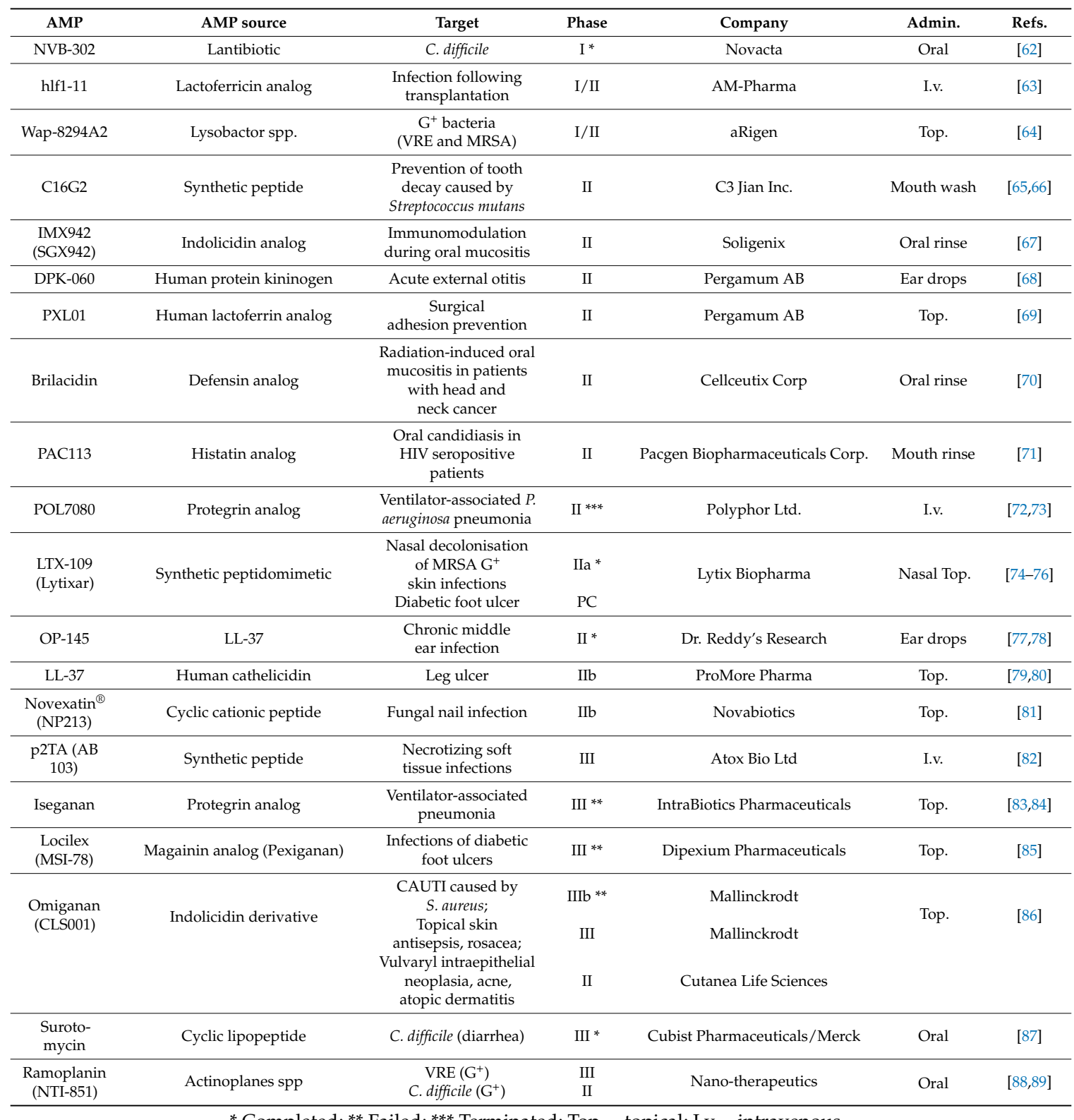

* Completed; ${ }^{* *}$ Failed; ${ }^{* * *}$ Terminated; Top.--topical; I.v.-intravenous.

Table 2. AMPs in preclinical trials.

\begin{tabular}{ccccccc}
\hline AMP & AMP Source & Target & Phase & Company & Admin. & Refs. \\
\hline MU1140 & $\begin{array}{c}\text { Streptococcus mutans } \\
\text { (lantibiotic) }\end{array}$ & G $^{+}$bacteria (MRSA, C. difficile) & PC & Oragenics & Not specified & {$[90,91]$} \\
\hline HB1345 & Lipopeptide & Broad-spectrum antibiotic, acne & PC & Helix Biomedix & Top. & [92] \\
\hline $\begin{array}{c}\text { Novarifyn } \\
\text { (NP432) }\end{array}$ & Synthetic antimicrobial & $\begin{array}{c}\text { MRSA, } \text { P. aeruginosa, C. difficile, } \\
\text { A. baumannii, E. coli }\end{array}$ & PC & Novabiotics & Top. & [93] \\
\hline
\end{tabular}


Table 2. Cont.

\begin{tabular}{ccccccc}
\hline AMP & AMP Source & Target & Phase & Company & Admin. & Refs. \\
\hline $\begin{array}{c}\text { Arenicin } \\
\text { (AP139) }\end{array}$ & Lugworm Arenicol marina & $\mathrm{G}^{-}$bacteria, UTI & PC & $\begin{array}{c}\text { Adenium } \\
\text { Biotech }\end{array}$ & Not specified & {$[94,95]$} \\
\hline AP138 & Arenicin analog & MRSA implant infections & PC & Adenium & Not specified & {$[96]$} \\
\hline AP114 & Arenicin analog & C. difficile & PC & Adenium & Not specified & {$[96]$} \\
\hline $\begin{array}{c}\text { Avidocin } \\
\text { and purocin }\end{array}$ & Modified R-type bacteriocin & $\mathrm{G}^{+}$and G bacteria & PC & AvidBiotics & Oral & {$[97,98]$} \\
\hline \multicolumn{7}{c}{ Top.-topical. } \\
\end{tabular}

As an alternative to AMPs, rational design involving incorporation of non-standard amino acids has been explored as a strategy for obtaining compounds with AMP-like properties, where AMPs serve as starting pharmacophores of which length, backbone, side chains, hydrophobicity, charge and amphipathicity may be subjected to optimization. The resulting peptide mimics (or peptidomimetics as they will termed hereafter) often possess improved bioavailability and metabolic stability while retaining activity and selectivity profiles resembling those of AMPs. The term peptidomimetic usually refers to any sequence that is designed to mimic a peptide structure and/or function, but in which the backbone is not based on $\alpha$-amino acid residues alone. To date, numerous strategies have been explored-from incorporation of a single unnatural amino acid residue to alternative backbone structures in order to discover potent peptidomimetic-based drug leads exhibiting high cell selectivity and improved bioavailability [99].

The most promising antimicrobial peptidomimetics that are readily optimized due to their modular structure include: $N$-alkylated glycines (peptoids), $\beta$-peptoids $(N$-alkylated $\beta$-alanine oligomers), $\beta$-peptides, $\alpha$-peptide $/ \beta$-peptoids, $\alpha / \gamma N$-acylated $N$-aminoethylpeptides (AApeptides) and oligoacyllysines (OAKs). An advantage of such peptidomimetics (Figure 1 ) is that solid-phase synthesis allows for convenient preparation of large arrays of analogs by simple replacement/insertion of alternative residues by way of commercial and/or synthetic amino acid analogs. Also, these peptidomimetics possess enhanced in vivo stability and often exhibit lowered toxicity as compared to $\alpha$-helical AMPs.

Resistance to AMPs and Peptidomimetics

Despite the interest in AMPs as antibiotic drugs only a few studies on resistance development have been reported. The general belief has been that resistance to AMPs is difficult to acquire since AMPs mainly target the bacterial membrane. However, studies have shown that bacteria can develop resistance to AMPs [100-102]. For example, Habets et al. demonstrated that experimentally evolved resistance to pexiganan provided S. aureus with cross-resistance to the defensin, human neutrophil peptide-1 [103]. A special concern is the possibility of bacteria becoming resistant to peptides of our own immune system after being exposed to unrelated therapeutic AMPs [104]. In their extensive review, Nawrocki et al. describe various mechanisms of AMP resistance for Gram-positive bacteria. Among all, Gram-positive bacteria have been a common source for AMPs, therefore there is a high likelyhood of resistance development in these pathogens that can be tranfrerred to non-producing strains [105]. Also, AMPs have been mostly targeting infections caused by Gram-positive bacteria, thereby increasing the risk of resistance development. Additionally, resistance mechanisms in Gram-negative bacteria evolved towards AMPs have been well described in a minireview by Gruenheid \& Moual [106]. 

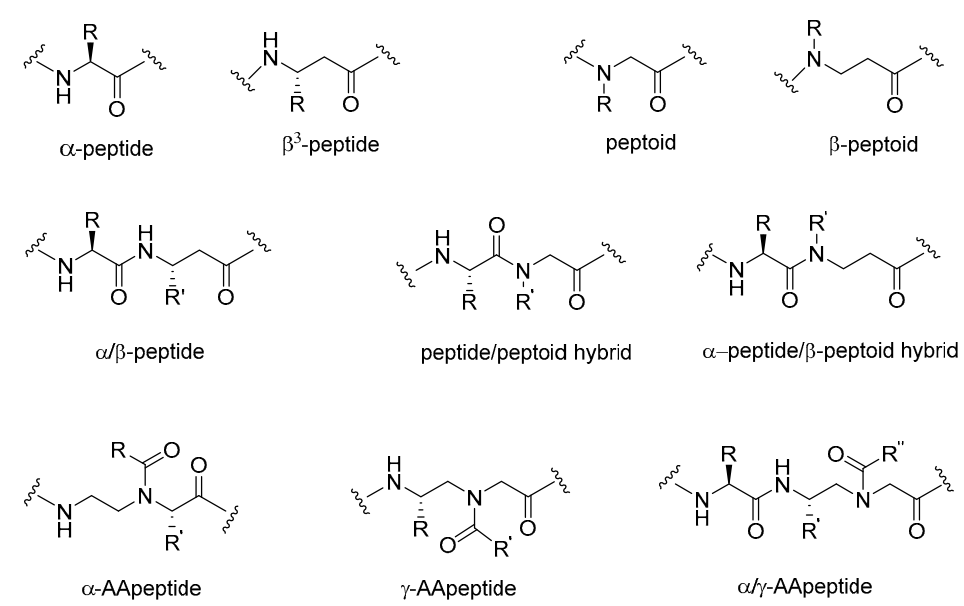

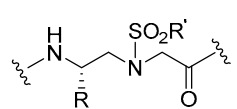

Sulfono-y-AApeptide

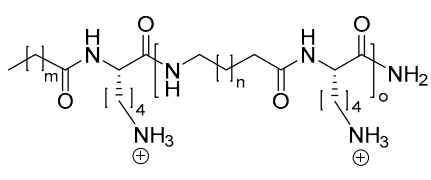

$\alpha$-oligoacyllysines ( $\alpha$-OAKs)

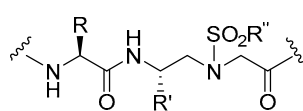

$\alpha$-sulfono- $\gamma$-AApeptide

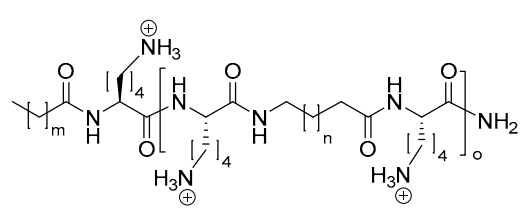

$\beta$-oligoacyllysines ( $\beta$-OAKs)

Figure 1. Basic structures of peptidomimetics discussed in the present review.

In one study it was shown that innate host-defense peptides are less efficient against AMP-resistant S. aureus thereby compromising the native immune response [107]. Hence, use of AMP drugs may prove to cause cross-resistance to human defensins and cathelicidins, but a better understanding of bacterial resistance to AMPs combined with new therapeutic strategies may overcome this problem [108].

For peptide/peptoid peptidomimetics it has been shown that resistant strains may be selected for by long-term continuous exposure in adaptive evolution experiments [109,110]. Hence, resistance is a key challenge also for peptidomimetics of AMPs when these are to be used more widespread as drugs.

\subsection{Screening for Antimicrobial Activity and Cytotoxicity of Peptidomimetics}

\subsubsection{Determination of Minimal Inhibitory Concentration}

Determination of the minimal inhibitory concentration (MIC value) constitutes a key step in the evaluation of in vitro activity of potential new antimicrobial drug leads, and it is defined as the lowest concentration of an antimicrobial compound that inhibits the visible growth of a microorganism after overnight incubation (16-20 h). The resulting MIC value may be reported in either micromolar $(\mu \mathrm{M})$ or $\mu \mathrm{g} / \mathrm{mL}$ depending on the specific context. In medicinal chemistry the unit $\mu \mathrm{M}$ in often preferred as it allows for a direct comparison of the activity exerted by a concentration based on the number of molecules (typically measured in micromoles) rather than the amount in microgram it contains per volume. Micromolar concentrations are related to $\mu \mathrm{g} / \mathrm{mL}$ as follows:

$$
\mu \mathrm{g} / \mathrm{mL}=[(\text { molecular weight including counterions }) / 1000] \times \mu \mathrm{M}
$$

The Clinical and Laboratory Standard Institute (CLSI) and the European Committee on Antibiotic Susceptibility Testing (EUCAST) provide guidelines for MIC testing to ensure use of uniform and 
improved methodologies in various laboratories around the world [111]. Among a number of techniques, agar dilution and broth dilution are the most commonly used methods. For broth dilution, a two-fold dilution series of an antimicrobial drug in liquid growth media is inoculated with bacteria. Depending on the combined volume of test solution and bacterial inoculum, the method is defined as macrodilution ( $\geq 2 \mathrm{~mL}$; performed in tubes) or microdilution ( $\leq 500 \mu \mathrm{L}$; performed in microtiter plates; Figure 2). A number of parameters may differ when a protocol for MIC determination is adapted in various laboratories.

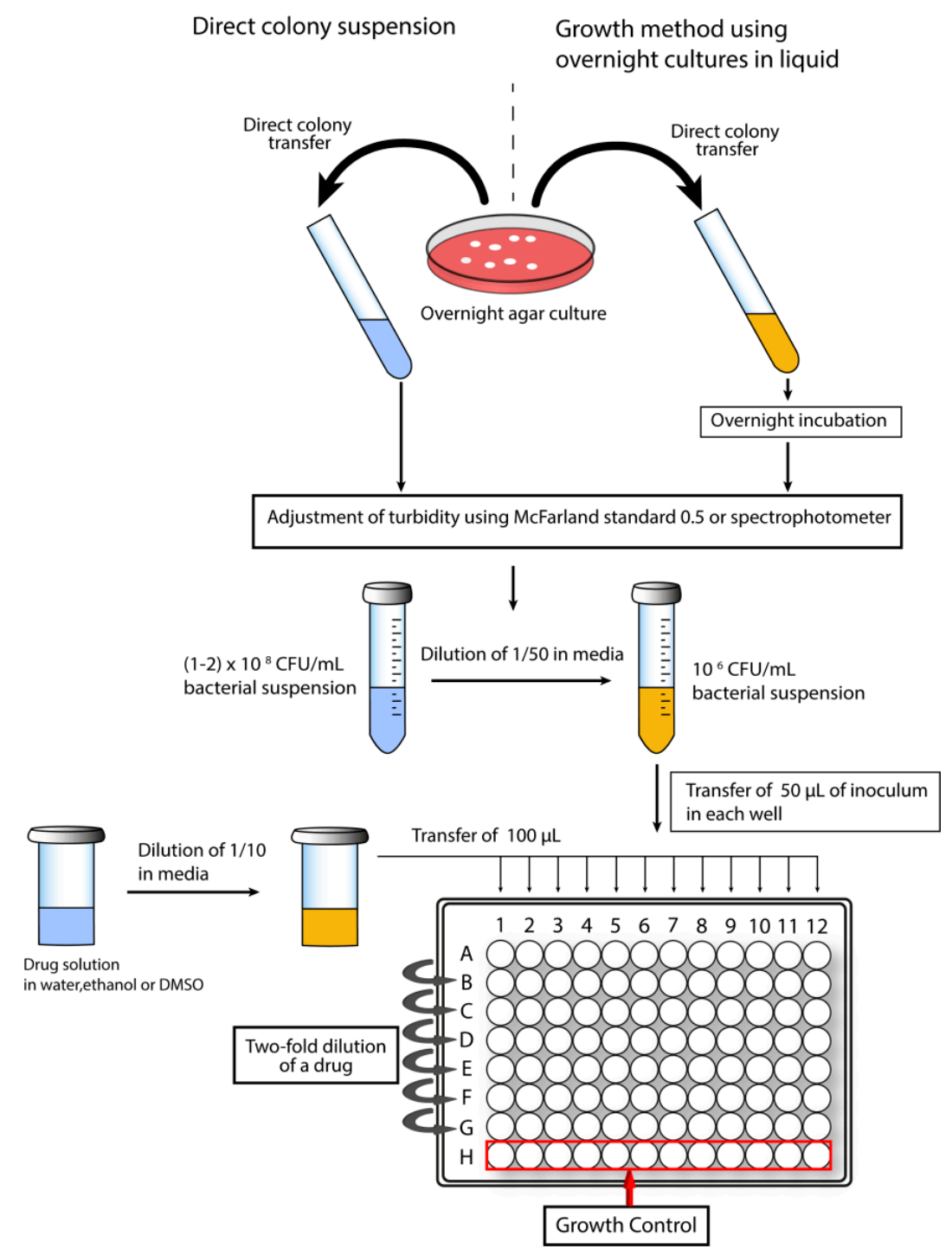

Figure 2. Determination of minimal inhibitory concentration by the broth microdilution method.

Reproducibility of results relies on following the guidelines strictly. However, quite often a modified version of the recommended standard protocol is used in work reported in the literature. Change of parameters, e.g., type of media, incubation time, and concentration of bacterial inoculum, may give rise to misleading results. The ensuing inconsistency of literature data makes comparison of different antimicrobials quite difficult. Recently, some practical issues in how to carry out susceptibility testing of AMPs have attracted attention in the research community. The tendency of cationic AMPs to bind to polystyrene or glass surfaces was taken into consideration by Hancock et al. resulting in a modified CLSI-based protocol [112]. In this modified protocol, $0.02 \%$ acetic acid and $0.4 \%$ BSA (bovine serum albumin) are added to non-cation-adjusted medium (i.e., without addition of salts 
with divalent cations) in order to prevent binding of AMPs to the microtiter plates, and this may also improve solubility of peptides. This potential problem was investigated further by Gram and co-workers who showed that it was only critical when MICs are below $1 \mu \mathrm{M}$ [113].

\subsubsection{Time-Kill Kinetics}

The time-kill assay is the most appropriate method to assess pharmacodynamics of an antibacterial drug in vitro, as it reveals how fast bacteria are killed when exposed to either the MIC or slightly higher concentrations of an antimicrobial compound (Figure 3). At different time points the number of viable cells is counted by performing serial dilutions on an aliquot removed from the treated culture. Afterwards the concentration of surviving cells expressed as CFU $/ \mathrm{mL}$ is plotted against time. In addition, the time-kill assay can be used to study drug interactions such as synergy and antagonism, as defined by $2 \log _{10}$ decreased CFU / $\mathrm{mL}$ and $2 \log _{10}$ increased CFU/mL, respectively, as compared to that found the most active single compound at a chosen time point. Cationic membrane-active AMPs are known to exhibit fast killing, while for AMPs with intracellular target typically an initial delay is seen [114].

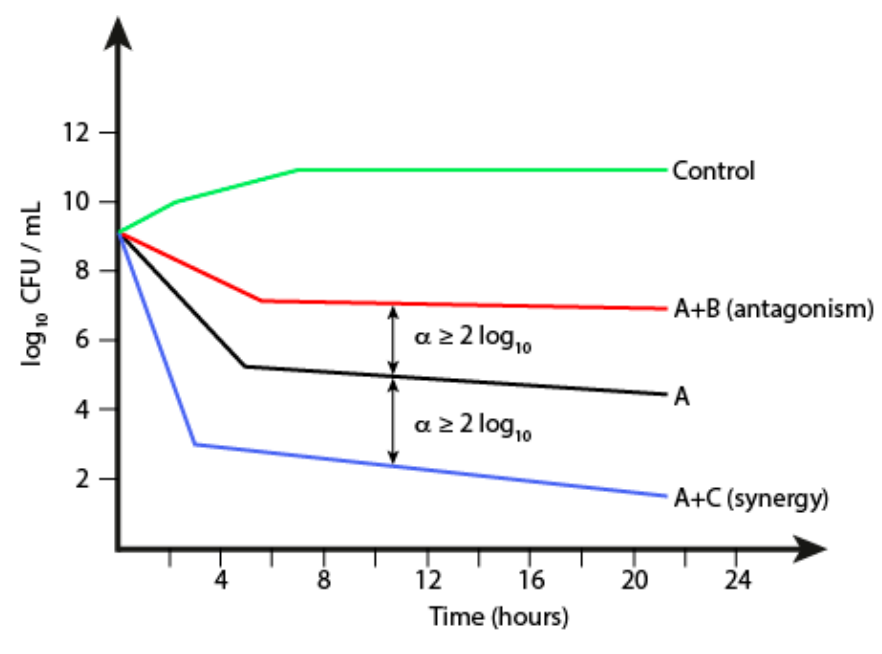

Figure 3. Schematic representation of a time-kill kinetics experiment.

\subsubsection{Synergistic Effects in Combination Therapy}

Antimicrobial combination therapy involves simultaneous use of two or more antibiotics, often with different mode of action, which may lead to synergy [115]. A synergistic effect implies that a combination of antibiotics show substantially higher activity than each antibiotic individually. Two widely used methods for testing of synergy between antimicrobial drugs are the checkerboard and time-kill methods. The time-kill method is used to compare the rate and efficiency of bacterial killing exerted by each drug alone and in combination. The checkerboard method (Figure 4) is often used for screening purposes, while the time-kill assay can provide a more detailed picture of a synergistic effect. The checkerboard method resembles the method for MIC determination, and provides information on which antibiotic combinations inhibit bacterial growth [116]. The latter method is usually performed by multiple dilutions of two different drugs in a microtiter plate that creates a checkerboard pattern, hence the name. Calculation of the fractional inhibitory concentration index (FICI) is used to analyze the results of the checkerboard assay by estimating the degree of synergistic effect. FICI is calculated as the sum of the individual fractional inhibitory concentrations (FICs) for each drug (where MIC A and MIC $B$ denote the MIC of each drug alone, and MIC $A_{A+B}$ and MIC $B_{A+B}$ denote the concentrations of $\mathrm{A}$ and $\mathrm{B}$ in the drug combination):

$$
\mathrm{FICI}=\left(\mathrm{MIC} \mathrm{A}_{\mathrm{A}+\mathrm{B}} / \mathrm{MIC} \mathrm{A}\right)+\left(\mathrm{MIC} \mathrm{B}_{\mathrm{A}+\mathrm{B}} / \mathrm{MIC} \mathrm{B}\right)
$$


The FIC for each drug is defined as the MIC of the combination divided by the MIC of the drug alone. Thus, the more efficient the synergy is, the lower the FICI will be. For a FIC index $<0.5$, the combination of antibiotics has a synergistic effect, while a FIC index of 0.5-1.0 indicates that the effects of the drugs are additive. When FIC is between 1 and 4, the combination effect is indifferent, whereas a FIC $>4$ indicate an antagonistic combination.

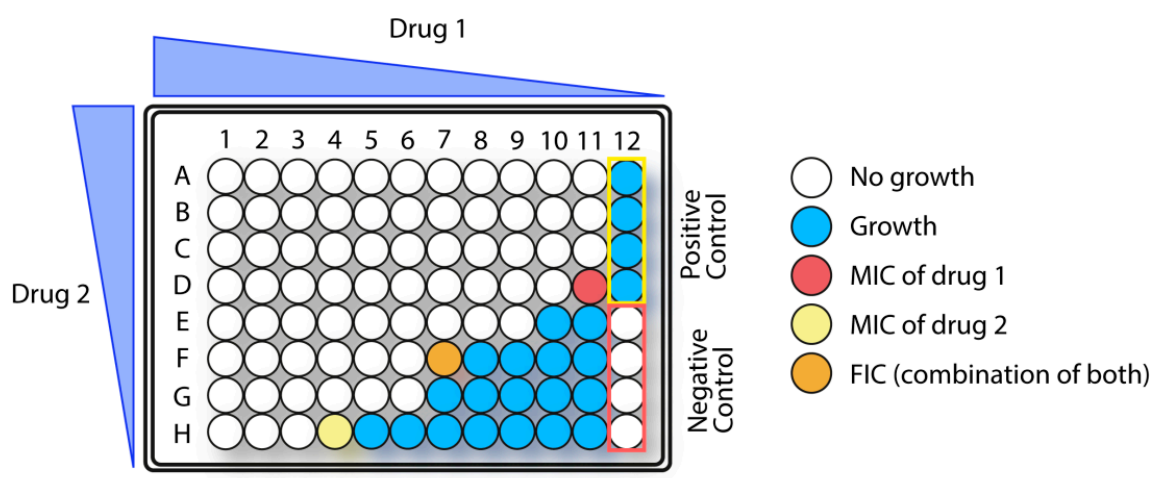

Figure 4. Example of a checkerboard testing of two drugs.

\subsubsection{Biofilm Eradication}

Bacterial growth within biofilms is associated with high tolerance to antibiotics and rapid development of resistance due to slow or incomplete killing. The key characteristic of biofilms is their ability to adhere to a surface, establishing a matrix of extracellular polymers. This feature allowed Ceri et al. to grow biofilms on peg lids [117]. A key step in the peg lid insertion method is the removal of pegs that allows for control measurement (e.g., microscopy), which cannot be performed by using direct cultivation in microtiter plates. In 2006 Harrison published the Calgary Biofilm Device (CBD) protocol that was slightly modified later in 2010 [118]. In brief, the peg lid is inserted into a 96-well microtiter plate containing bacterial inoculum in each well (A) (Figure 5). The peg lid with established biofilm is rinsed after incubation for $48 \mathrm{~h}$ (or more) to remove loosely adherent cells (C), and then it is inserted into another 96-well microtiter plate, containing serial dilutions of antibacterial drug (D). The peg lid is washed again (E), followed by staining with crystal violet or removal of surviving biofilm from the individual pegs (e.g., sonication, incubation in a growth medium) (F,G). Aliquots from each well are plated, incubated and CFU is counted to determine the minimal biofilm eradication concentration (MBEC) (H).

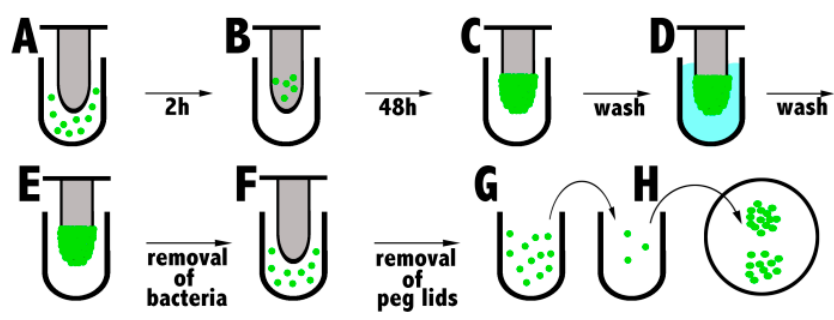

Figure 5. Diagram of experimental procedure for peg lid biofilm assay.

\subsubsection{Cytotoxic Activity}

Cell selectivity, i.e., relative preference for killing bacteria over host cells, is a critical property of an antimicrobial drug. There are two commonly used ways to assess cellular toxicity of a compound. Testing for hemolytic activity (HA) is a standard inexpensive fast screening method by which the degree of lysis of red blood cells (RBCs) is measured after exposure of RBCs to the drug. This property indicates the propensity of test compounds to disrupt mammalian RBCs by measuring the amount of 
hemoglobin released from the lysed RBCs. HA is usually presented as an effective concentration of the compound resulting in $10 \%\left(\mathrm{HC}_{10}\right)$ or $50 \%\left(\mathrm{HC}_{50}\right)$ lysis of erythrocytes. $\mathrm{HA}$ is measured by incubation of serial compound dilutions in phosphate-buffered saline (PBS) with a suspension of freshly drawn red blood cells in PBS at $37^{\circ} \mathrm{C}$ for a fixed time period (typically 1-8 h) in 96-well microtiter plates, where melittin and PBS often serve as positive and negative control, respectively [119]. Release of hemoglobin is measured on a spectrophotometer at $414 \mathrm{~nm}$. Assessment of hemolysis is useful for screening purposes only, as a non-hemolytic compound may still be toxic toward other cell lines. However, it is a powerful tool that allows for a fast in vitro identification of highly toxic compounds. One of the disadvantages of this method is the often inconsistent choice of blood source. Due to absence of an internationally standardized protocol, research groups occasionally use blood of different origin e.g., human, rat, rabbit, sheep, horse etc., leading to incomparable results. Even when the choice is between different types of human blood, some issues must be considered in order to avoid any side interactions that can influence the final result. Therefore, type- 0 blood is often considered the most appropriate option, since it lacks the saccharide antigens that can be found in types A and B. The noise level of the absorbance reader $(\sim 4 \%)$ also constitutes a disadvantage, because it restricts sensitivity of the method and complicates interpretation of data below $8 \%(2 \times$ noise level $)$.

Determination of the effects of a compound on the viability of a panel of human cells is recommended as a standard protocol to provide a solid base for estimating its toxicity profile [120]. The viability assay is conducted by exposing cells grown in 96-well plates to a serial dilution of a drug in the medium followed by incubation under shaking at $37{ }^{\circ} \mathrm{C}$. Tetrazolium dyes are used to stain healthy cells and to provide convenient conditions for spectrophotometric analysis. The MTT ((3-[4,5-dimethylthiazol-2-yl]-2,5-diphenyltetrazolium bromide) assay is one of the most common tools for detection of cytotoxicity or cell viability in vitro [121]. MTT is a water-soluble tetrazolium salt, which is converted into an insoluble purple formazan when exposed to metabolically functional mitochondria. Formazan cannot penetrate the cell membrane, and therefore it accumulates in healthy cells. The MTT assay is a highly sensitive method, however, insolubility of formazan in the cell medium may be a complication that can be solved by adding a solubilizing agent prior to measurement. An alternative tetrazolium dye, MTS (3-(4,5-dimethylthiazol-2-yl)-5-(3-carboxy-methoxyphenyl)-2-(4-sulfophenyl)-2H-tetrazolium), has been created to yield soluble formazan products, and when used the protocol is termed a 'one-step' MTT assay [122]. This method is successfully used to assess cytotoxicity of AMPs and peptidomimetics.

Other approaches for assessing the data quality in predictive toxicology have been described by Pohjala et al. [123] including the lactate dehydrogenase (LDH) assay, the water-soluble tetrazolium salt (WST-1) assay, and an assay measuring the intracellular level of ATP. Also LDH and gamma glutamyl transferase (GGT) release assays can be used for an in vitro prediction of drug-induced nephrotoxicity [124].

\section{Peptidomimetics}

The focus of this review is to highlight the developments in the last decade regarding the synthesis, discovery and potential applications of antimicrobial peptidomimetics (Figure 1) comprising the classes of $\alpha$-peptoids ( $N$-alkylated glycine oligomers), $\beta$-peptoids ( $N$-alkylated $\beta$-alanine oligomers), $\beta^{3}$-peptides, $\alpha / \beta^{3}$-peptides, $\alpha$-peptide $/ \beta$-peptoid hybrids, $\alpha / \gamma N$-acylated $N$-aminoethylpeptides (AApeptides) and oligoacyllysines (OAKs). These classes of antimicrobial peptidomimetics are of particular interest owing to the convenient synthesis of the corresponding building blocks and their assembly by using standard solid-phase procedures. Other types of promising antimicrobial peptidomimetics not discussed in the present review comprise arylamide and phenylene ethynylene oligomers [125-127], small synthetic antimicrobial peptidomimetics (SMAMPs or SAMPs) [128-130], pyrazole, poly-lysine and histidine-derived ultra-short antimicrobial peptidomimetics [131-133], macrocyclic peptidomimetics [134], binaphthyl-based, functionalized oxazoles, biaryl amino acid templates in cyclic $\beta$-hairpin cationic antimicrobial peptidomimetics [135], thiazole 
peptidomimetics [136], 1,4-dihydropyridine cationic peptidomimetics [137], and peptidomimetics containing 3-aminobenzoic acid [138]. Several such small-molecule mimetics have been reviewed by Ghosh \& Haldar [139]. For an authoritative review on general design and properties of peptidomimetics see Liskamp et al. [140].

\subsection{Peptoids}

Peptoids are oligomers of $N$-substituted glycines and differ from $\alpha$-peptides in that the side chains are attached to the backbone $N^{\alpha}$ position instead of at the C- $\alpha$ atom (Figure 6). Since peptoids often retain the biological activity of the parent peptide and are stable to proteases, they hold promise as therapeutics [141]. For recent reviews on peptoids see [142-146]. A historical account detailing the initial discovery and early developments in the peptoid field was published by Zuckerman [147]. Besides being promising antimicrobial agents, peptoids with activity against fungi [148], Candida biofilm [149], tuberculosis [150], the neglected tropical disease leishmaniasis [151], and cancer cells [152] have been reported. Peptoids have also found applications within supra- and macromolecular engineering [153], biomaterials [145], protein peptoid mutagenesis [154], and as fluorescent analogs for study of delivery to the cell nucleus [155], Huntington's disease [156], positron emission tomography (PET) [157], glycopeptoids [158], DNA-binding peptoids [159], and carboxyalkyl peptoid PNAs [160].

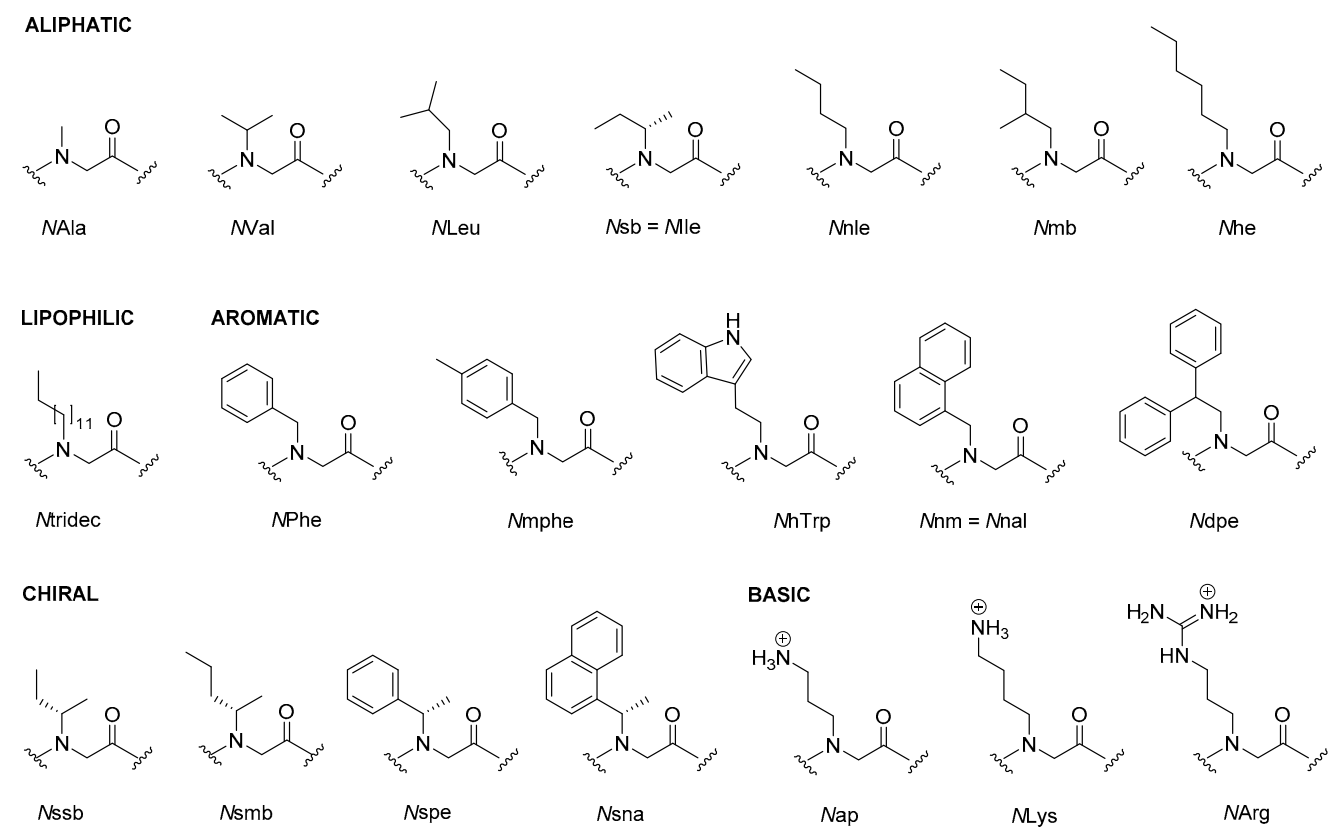

Figure 6. Structure of commonly used peptoid building blocks. NAla: N-methylglycine; NVal: $\quad N$-isopropylglycine; NLeu: N-isobutylglycine; Nsb: $N$-(sec-butyl)glycine; Nnle: $N$-(butyl)glycine; Nmb: N-(2-methylbutyl)glycine; Nhe: $N$-hexylglycine; Ntridec: $N$-tridecylglycine; NPhe: $\quad N$-phenylmethylglycine; $\quad N m$ phe: $\quad N$-(4-methylphenyl)methylglycine; $\quad N h T r p:$ (N-(2-indolethyl)glycine; Nnm: $N$-(naphtalen-1-ylmethyl)glycine; Ndpe: diphenylethylglycine; Nssb: N-(S)-(sec-butyl)glycine; Nsmb: (S)-1-methylbutylglycine; Nspe: N-(S)-(1-phenylethyl)glycine; Nsna: (S)-(1-(naphthalen-1-yl)ethyl)glycine; Nap: $N$-(3-aminopropyl)glycine; NLys: $N$-(4-aminobutyl)glycine; NArg: $\quad N$-(3-guanidinopropyl)glycine. Note: NArg is obtained by reacting Nap with pyrazole-1-carboxamide on solid phase [161]. Adapted and expanded from Mojsoska et al. [162].

\subsubsection{Synthesis}

Peptoid synthesis is carried out by solid-phase synthesis (SPS) via the monomer or submonomer approaches. In the original monomer strategy [163] (Scheme 1A), a protected peptoid building block is synthesized by nucleophilic displacement of an alkyl halide by an appropriate amine (Route 1), 
or reductive amination (Route 2) followed by $N$-protection with Fmoc-OSu. The fully protected building block is then used in standard Fmoc-based SPS (Scheme 1B). However, the monomer strategy is laborious and time-consuming when several different building blocks are required. Shortly after, the submonomer approach was introduced by Zuckerman et al. [164], thereby avoiding the need for synthesis of protected building blocks (Scheme 1C). Here, peptoid synthesis is achieved entirely by solid-phase steps: bromoacetic acid is activated with $N, N$-diisopropylcarbodiimide (DIC) and then reacted with a resin-bound amine in DMF; subsequent nucleophilic displacement with a primary amine gives the desired peptoid residue. This activation/substitution cycle is repeated until the target sequence is obtained. Finally, the peptoid is cleaved from the resin by using TFA.

Three other less widely used submonomer strategies are known (Scheme 1D-F). A solid-phase submonomer strategy based on reductive alkylation of resin-bound Gly with the appropriate aldehyde to obtain the desired $N$-alkylated glycine derivative was reported by Tal-Gan et al. [165] (Scheme 1D). More recently, $N$-substituted $o$-nitrobenzenesulfonamide derivatives were used as alternative building blocks in the submonomer synthesis of peptoids as proposed by Vézina-Dawod et al. [166] (Scheme 1E). Finally, a four-step photolithographic synthesis of peptoids, using the [( $\alpha$-methyl-2-nitropiperonyl)oxy]carbonyl (MeNPOC) group has been demonstrated by Li et al. [167] (Scheme 1F).

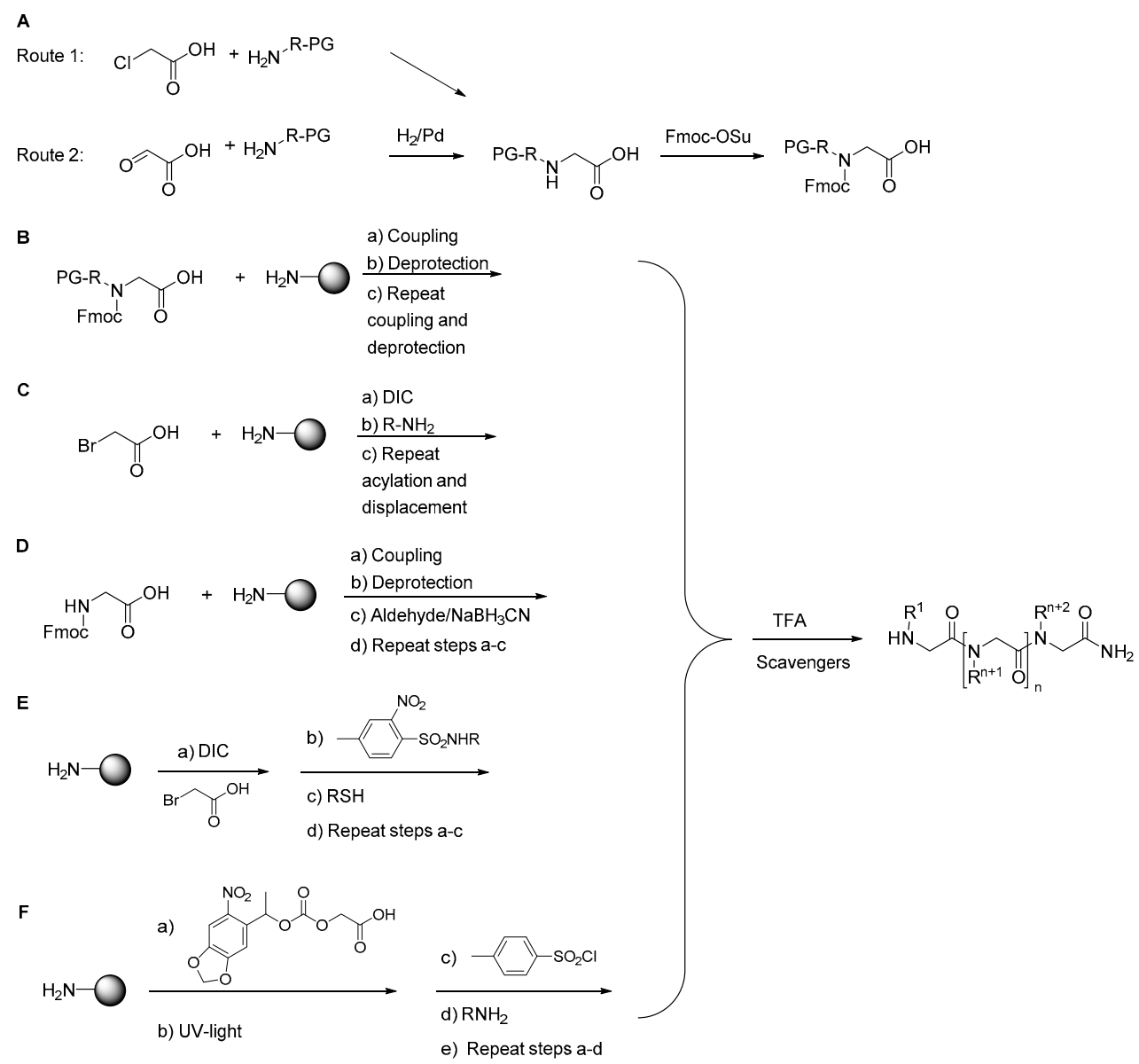

Scheme 1. Overview of peptoid synthesis. Two different methods for preparing protected peptoid building blocks (A) for solid-phase synthesis (B); Submonomer approach developed by Zuckerman et al. (C); Submonomer reductive amination of Gly (D); Peptoid synthesis using $N$-substituted o-nitrobenzenesulfonamide derivatives (E); Photolithographic peptoid synthesis (F); Adapted from Simon et al. [163] and Gangloff et al. [153]. 
Zuckermann's submonomer synthesis is most often performed on a Tenta Gel Rink amide resin using a two-step procedure. In the first step, acylation is typically performed by mixing the resin with bromoacetic acid (1.2 M; 20 equiv) in DMF and DIC (20 equiv) for $20 \mathrm{~min}$. In the second step, nucleophilic $\mathrm{S}_{\mathrm{N}} 2$ displacement of the bromide is carried out with various primary amine solutions (1.0-2.0 M; 20-40 equiv) in DMF or N-methyl-2-pyrrolidone (NMP) during agitation for $90 \mathrm{~min}$. Following synthesis, the product is cleaved from the resin with TFA $/ \mathrm{H}_{2} \mathrm{O} /$ triisopropylsilane (95:2.5:2.5). Peptoid chains up to 50 residues can be synthesized in reasonable yield by using this approach [145]. Since 230 primary amines have been used in peptoid synthesis [142], and more than 1000 are commercially available this approach allows for the creation of a vast diversity. Besides bromoacetic acid, chloroacetic acid [168] and iodoacetic acid (via a Finkelstein reaction) [169] have been used. These are particular useful when heterocyclic aromatic amines are to be displaced [168] or for the chemoselective incorporation of functionalities into peptoids [169].

\subsubsection{Other Synthetic Developments}

An approach enabling convenient synthesis of linear and cyclic peptoids that contain both arginine- and lysine-type residues within the same sequence has been reported. In this strategy pyrazole-1-carboxamide was used for on-resin guanidinylation of amines liberated upon N-Dde deprotection, while final lysine residues remained Boc-protected [161]. Furthermore, René et al. [170] described the synthesis of Fmoc-protected $N$-substituted glycine building blocks corresponding to a selection of functionalized natural amino acids like tyrosine, tryptophan, cysteine and serine. Finally, Caumes et al. [171] have described a gram-scale solution-phase synthesis applicable to $\beta$ - and $\alpha, \beta$-tetrapeptoids as well as $\alpha$-peptoids. A strategy for the on-resin synthesis of antimicrobial macrocyclic peptides (3- to 13-mers) using the submonomer approach for cyclisation was described by Oddo et al. [172].

\subsubsection{Side Reactions}

Not all primary amines are suitable for peptoid synthesis [142,173]. These include 2-methoxyethylamine and 2-phenylethylamine, which form $N$-substituted diketopiperazines; 4-(2-aminoethyl)morpholine and $N^{\mathrm{Im}}$-tritylhistamine, which have a nucleophilic group that also may react with the main-chain bromoacetyl group; 2,4,6-trimethoxybenzylamine and $p$-guanidino-substituted $\alpha$-methylbenzylamine which is unstable during TFA cleavage. Peptides and peptoids are often acetylated at the N-terminus to improve biological activity; Kim et al. [174] reported that $\mathrm{N}$-acetylated peptoids may spontaneously truncate under standard TFA cleavage conditions. They found that the problem could be circumvented by using a cleavage cocktail of TFA $/ \mathrm{CH}_{2} \mathrm{Cl}_{2} / \mathrm{H}_{2} \mathrm{O} / \mathrm{TIS}$ (50:42:5:3) for $1 \mathrm{~h}$. Finally, it should be mentioned that HOBt and HOAt reduce the yield significantly when employed as additives in solid-phase submonomer synthesis [147].

\subsubsection{Antimicrobial Activity}

Antimicrobial peptoids were first reported by Goodson et al. $[175,176]$ who identified a number of trimer peptoids from a combinatorial library of 845 members. Compound CHIR29498 (Figure 7) was the most active against a panel of resistant Gram-positive and Gram-negative bacteria with MICs ranging from 5 to $40 \mu \mathrm{M}$ and displaying $40 \%$ hemolysis at $150 \mu \mathrm{M}$. Mice infected i.p. with $10^{8}$ CFU of S. aureus followed by i.p. injection of CHIR29498 $(10 \mathrm{mg} / \mathrm{kg})$ were protected five days after infection [175]. 


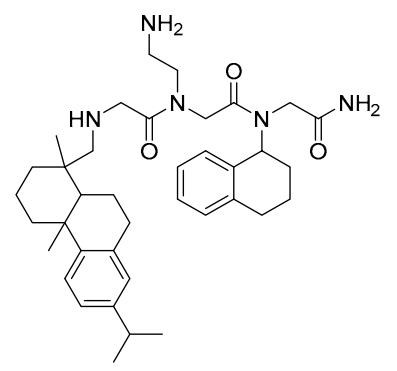

Figure 7. Structure of CHIR29498.

\subsubsection{Structure-Activity Studies of Peptoids}

A structure-activity study of 22 cationic and amphipathic antimicrobial peptoids was reported by Mojsoska et al. [162]. Starting from known antimicrobial peptides (GN-2, -4 and -6), the authors described the transformation into peptoids, and investigated the effects of increasing hydrophobicity, single monomer substitution and variation of chain length. The most active compound H-NLys-NhTrp-NLys-NLys-NhTrp-NhTrp-NLys-NhTrp-NPhe- $\mathrm{NH}_{2}$ showed an MIC of 8, 16 and $2 \mu \mathrm{g} / \mathrm{mL}$ against MRSA, E. coli and P. aeruginosa, respectively, as well as an $\mathrm{HC}_{50}$ of $104 \mu \mathrm{g} / \mathrm{mL}$. Two peptoids showed high cell selectivity and a bactericidal mode of action against $E$. coli. This was further investigated in a follow-up study which suggested that these peptoids act via a mechanism involving both membrane disruption and intracellular targets [177].

Chongsiriwatana et al. [178] reported a structure-activity study based on an array of 15 peptoids derived from $\mathrm{H}-(\mathrm{NLys}-\mathrm{N} \text { spe- } N \text { spe })_{4}-\mathrm{NH}_{2}$ and $\mathrm{H}-(\mathrm{NLys}-\mathrm{Nssb}-\mathrm{Nspe})_{4}-\mathrm{NH}_{2}$ by varying chirality, length, hydrophobicity, overall charge and amphipathicity. The authors observed: (i) the mechanism does not involve stereospecific interactions, which also has been shown for most AMPs; (ii) optimal hydrophobicity with highest antimicrobial potency was seen for 12-mers (while increased hydrophobicity conferred high hemolytic activity); (iii) helicity is required for hemolytic activity but not for antimicrobial activity; (iv) highly charged $(\geq+3)$, moderately hydrophobic and helical peptoids exhibit high cell selectivity. Ten of the 15 peptoids showed MICs against B. subtilis and E. coli similar to those of melittin and pexiganan.

A structure-activity study involving 44 peptoids was reported by Bolt et al. [179]. The compounds were six to twelve residues in length with a net charge ranging from +2 to +4 . Generally, the peptoids were considerably more active toward the Gram-positive bacteria S. aureus and S. epidermidis than against the Gram-negative bacteria tested. Several peptoids displayed activity (Table 3) against E. coli (MIC of $6 \mu \mathrm{M}$ for five compounds) and P. aeruginosa (MIC of $13 \mu \mathrm{M}$ for three compounds). However, these compounds were also toxic against two mammalian cell lines HaCaT and HepG2 (EC 50 below $50 \mu \mathrm{M})$. In agreement with previous studies, the authors observed that antimicrobial activity was correlated with length: 12 residues $>9$ residues $>6$ residues. Furthermore, fluorine-substituted analogs displayed increased antimicrobial activity, and achiral sequences were more active and less hemolytic than peptoids with a higher content of chiral monomers.

Using a number of in silico, in vitro, and in vivo techniques, Czyzewski et al. [180] reported a QSAR model based on 27 peptoid sequences, which accurately correlated structure of antimicrobial peptoids with their antimicrobial activity. The most active compound was $\mathrm{H}-(\mathrm{NLys}-\mathrm{Nspe}-\mathrm{Nspe})_{4}-\mathrm{NH}_{2}$ (discussed above), which exhibited MICs $\leq 8 \mu \mathrm{g} / \mathrm{mL}$ for 19 out of the 20 MDR strains tested, and it was more active than the AMPs MSI-78 and MX-226. In a murine model with invasive S. aureus, the peptoid was able to reduce bacterial counts two log orders in the peritoneum at a concentration of $4 \mathrm{mg} / \mathrm{kg}$ without causing any medium-term toxicity.

Bang et al. reported the conversion of a Trp-rich peptide, H-KLWKKWKKWLK-NH ${ }_{2}$, into the corresponding protease-stable peptoid without loss of potency or increase in hemolytic properties [181]. Interestingly, the killing kinetics of the Trp-rich peptide and the peptoid analog were compared at 
$8 \mu \mathrm{M}(1$ or $2 \times \mathrm{MIC})$ against E. coli and S. aureus, and it was found that the bactericidal rate of the peptoid $(60 \mathrm{~min})$ was slower than that of the peptide $(30 \mathrm{~min})$, indicating different killing mechanisms.

Synergy between peptides and peptoids against Gram-negative bacteria has been reported by Chongsiriwatana et al. [182] who studied combinations of seven peptoids and the AMPs pexiganan and melittin. Against E. coli, 7 of 36 combinations (e.g., H-Nspe-Nspe-[NLys-Nspe-Nspe] $]_{5}-\mathrm{NH}_{2}$ and pexiganan) yielded FICIs $\leq 0.25$, indicating highly synergistic interactions with at least an 8 -fold decrease in the MIC of each compound in the presence of the other. The $\mathrm{HC}_{50}$ of the most active combinations ranged from $8 \mu \mathrm{M}$ to $>200 \mu \mathrm{M}$. The trend was that relatively hydrophilic oligomers exhibited synergism with hydrophobic oligomers, and it was suggested that synergy was due to distinct but complementary mechanisms.

Barron et al. [183] investigated the antimicrobial activity of H-(NLys-Nspe- $N$ spe $)_{n}-\mathrm{NH}_{2}(\mathrm{n}=1-4)$ and lipidated analogs carrying alkyl chains of 5, 10 or 13 carbons. The most active compound was H-Ntridec-NLys-Nspe-Nspe-NLys- $\mathrm{NH}_{2}$ which exhibited MICs of $10.8 \mu \mathrm{g} / \mathrm{mL}$ against $P$. aeruginosa and K. pneumonia and $5.4 \mu \mathrm{g} / \mathrm{mL}$ against MRSA. The hemolytic activity $\left(\mathrm{HC}_{50}\right)$ was $224 \mu \mathrm{g} / \mathrm{mL}$. The peptoids H-(NLys-Nspe-Nspe $)_{4}-\mathrm{NH}_{2}$ and H-Ntridec-NLys-Nspe-Nspe-NLys- $\mathrm{NH}_{2}$ were also shown to reduce the viability of P. aeruginosa (PA 14) biofilms at their MICs (12.5 $\mu \mathrm{M}$ and 12.5-25 $\mu \mathrm{M}$, respectively), whereas antibiotics, such as kanamycin, showed comparable results at much higher concentrations [184]. Guanidinylation and tail effects in cationic antimicrobial trimeric lipopeptoids were studied by Findlay et al. [185] who synthesized 19 compounds consisting of combinations of NhArg, NLys, Gly and a fatty acid or fluorinated fatty acid (9-20 carbon atoms) at the N-terminus. Most peptoids exhibited moderate activity against Gram-positive bacteria (MICs of 8-64 $\mu \mathrm{g} / \mathrm{mL}$ ) and weak activity against Gram-negative strains (MICs of 16-512 $\mu \mathrm{g} / \mathrm{mL}$ ). As expected, these lipopeptoids were also very hemolytic.

\subsubsection{Libraries}

Lipophilic antimicrobial peptoids have been identified by testing of peptoids in a so-called peptoid library agar diffusion assay (PLAD) [186]. Resin beads containing two identical peptoid strands ( $\alpha$ and $\beta$ ) are imbedded into soft agar together with the test microorganism (Figure 8). Overnight incubation with a reducing agent, e.g., $\beta$-mercaptoethanol, releases the $\beta$-strand peptoid. The other strand is cleaved with cyanogen bromide at the C-terminal methionine. The product is then analyzed by mass spectrometry to identify the active peptoid. In a follow-up study, the authors identified a peptoid which exhibited MICs of $25 \mu \mathrm{g} / \mathrm{mL}$ and $6.3 \mu \mathrm{g} / \mathrm{mL}$ against $A$. baumannii and E. faecalis, respectively, while it showed $30 \%$ hemolysis at $100 \mu \mathrm{g} / \mathrm{mL}$ [187]. The PLAD strategy has also been applied for identification of a peptoid with antifungal activity against Cryptococcus neoformans [148].

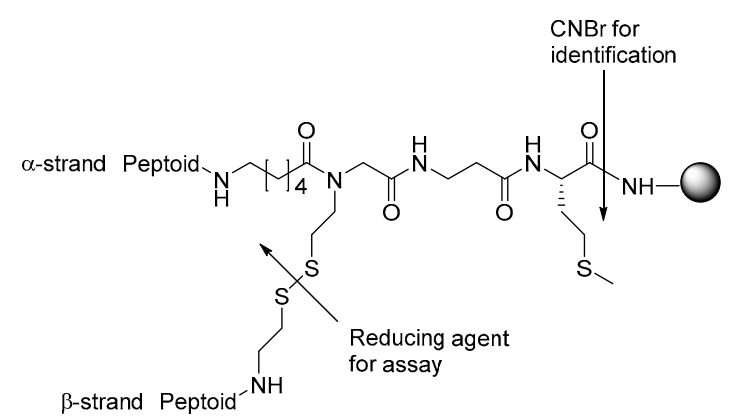

Figure 8. General structure of the Peptoid Library Agar Diffusion (PLAD) system. The identical peptoid sequences are cleaved separately: (i) with a reducing agent (e.g., a thiol) for screening of antimicrobial activity, and (ii) with $\mathrm{CNBr}$ to identify the active compound by mass spectrometry. 


\subsubsection{Cyclic Peptoids}

Huang et al. [188] investigated the effect of head-to-tail cyclisation on the antimicrobial activity of short peptoid sequences that contain cationic and hydrophobic side chains. Fifteen cyclic peptoids (6-10 residues), were compared to the corresponding acetylated linear peptoids. It was found that cyclisation and increasing length generally improved antimicrobial activity. The most pronounced example was $\mathrm{Ac}(\mathrm{Nap}-\mathrm{NPhe})_{5}$ and $\mathrm{c}(\mathrm{Nap}-\mathrm{NPhe})_{5}$, which against $B$. subtilis, E. coli and S. aureus showed MICs of 15.6 vs. $0.5 \mu \mathrm{g} / \mathrm{mL} ; 31.3 \mathrm{vs}$. $7.8 \mu \mathrm{g} / \mathrm{mL}$; and $62.5 \mathrm{vs} .7 .8 \mu \mathrm{g} / \mathrm{mL}$, respectively. The $\mathrm{HC}_{50}$ was not affected by chain length or cyclisation ( $>250 \mu \mathrm{g} / \mathrm{mL}$ for all compounds). In a follow-up study, the authors reported on 26 cyclic peptoids based on pentamer and hexamer scaffolds, containing cationic aminopropyl groups and a number of hydrophobic residues. Ten cyclic peptoids showed moderate MICs ranging between $15.6-250 \mu \mathrm{g} / \mathrm{mL}$ against clinical isolates of MRSA, while nine peptoids were very active (MICs $\leq 3.9 \mu \mathrm{g} / \mathrm{mL}$ ). These peptoids target and damage the MRSA cytoplasmic membrane through formation of pores as demonstrated by electron microscopy experiments [189]. The same research group also studied the membrane interactions of linear and cyclic versions of the antimicrobial peptoids (Nap-Ndp) ${ }_{3}$ (Table 3) and (Nap-Nnm) $)_{3}$ by using scanning electron microscopy on bacterial cells, and high-resolution X-ray scattering and epifluorescence microscopy on Langmuir layers [190]. They found that cyclisation increases the membrane activity of antimicrobial peptoid oligomers, and suggested this to be related to the reduced conformational flexibility of the cyclic peptoids.

Table 3. Antimicrobial activity and cytotoxicity of representative peptoids.

\begin{tabular}{|c|c|c|c|c|c|}
\hline \multirow{2}{*}{ Compound } & \multicolumn{5}{|c|}{ MIC Values Cytotoxicity } \\
\hline & S. aureus & E. coli & P. aeruginosa & $\mathrm{EC}_{50} \mathrm{a} / \mathrm{HC}_{50} \mathrm{~b}$ & Refs. \\
\hline $\mathrm{H}-\left(\mathrm{NhArg}-\mathrm{Nspe}-\mathrm{Nspe}_{4}\right)^{-\mathrm{NH}_{2}}$ & $1 \mu \mathrm{M}$ & $6 \mu \mathrm{M}$ & $13 \mu \mathrm{M}$ & $12 \mu \mathrm{M}^{\mathrm{a}}$ & [179] \\
\hline $\mathrm{H}-(\mathrm{NLys})_{4}(\mathrm{NhTrp})_{4}-\mathrm{NIle}-\mathrm{NH}_{2}$ & $8 \mu \mathrm{g} / \mathrm{mL}$ & $8 \mu \mathrm{g} / \mathrm{mL}$ & $4 \mu \mathrm{g} / \mathrm{mL}$ & $128 \mu \mathrm{g} / \mathrm{mL}^{\mathrm{c}}$ & {$[162,177]$} \\
\hline $\mathrm{c}(\text { Nap-Ndpe })_{3}$ & $3.9 \mu \mathrm{g} / \mathrm{mL}$ & ND & $7.8 \mu \mathrm{g} / \mathrm{mL}$ & $>250 \mu \mathrm{g} / \mathrm{mL}^{\mathrm{b}}$ & [190] \\
\hline
\end{tabular}

a concentration which is toxic to $50 \%$ of HEPG 2 cells; ${ }^{\mathrm{b}}$ concentration giving rise to $50 \%$ hemolysis; ${ }^{\mathrm{c}}$ concentration which generates $10 \%$ hemolysis of red blood cells.

\subsection{Peptides Displaying Substitution(s) with Peptoid Residues and Peptide-Peptoid Hybrids}

The Shin group. has been a major contributor to the exploration of the effects of introducing one or more $\alpha$-peptoid residues into $\alpha$-helical peptides [191-194]. A key aim in these investigations was to improve the pharmacological profiles of hemolytic AMPs towards lower toxicicity while retaining antibacterial activity [191-194]. Similar to Pro, a peptoid residue constitutes a potential inducer of a $\beta$-turn and possess an ability to break an $\alpha$-helix, since peptoid residues lack the amide proton required for stabilization via intramolecular hydrogen bonds. Typically, the insertion point of peptoid residue(s) is in the middle region of the sequence, thereby partially disrupting the $\alpha$-helical conformation, which often gives rise to a change in mode of action from membrane permeabilization toward bacteria penetration to reach putative intracellular target(s) [192-195]. Likewise, replacement of Pro residues in Trp/Pro-rich AMPs appears to constitute a promising approach for development of cell-selective AMPs with intracellular mechanisms [196]. In most cases the modification with $\alpha$-peptoid residues confers broad-spectrum antibacterial activity against common Gram-negative and Gram-positive pathogens [191-198]. With few exceptions preparation involves solid-phase peptide synthesis (SPPS) where Fmoc-protected peptoid building blocks are used at the appropriate positions.

\subsubsection{AMPs Displaying Substitution(s) with Peptoid Residues}

Analogs of the plant-derived 20-residue 1b-AMP1, containing two disulfide bonds, were designed as readily synthesized linear peptides lacking the N-terminal Glu as well as the four Cys residues, but displaying a D-Pro or peptoid residue (NAla or NLys) instead of L-Pro in the central position of the sequence (WGRRGWXGRRYVRW- $\mathrm{NH}_{2}, \mathrm{X}=$ Pro or peptoid) [199]. All analogs exhibited approx. 
4-fold enhanced activity (MICs in the range 2-16 $\mu \mathrm{M}$ ) against both Gram-negative (E. coli, P. aeruginosa, and S. typhimurium) and Gram-positive (S. epidermidis and S. aureus) bacteria. Circular dichroism (CD) spectroscopy inferred that the modifications with peptoid residues induced a $\beta$-turn conformation in the presence of bacterial membrane-mimicking dodecyl phosphocholine (DPC) micelles. The analogs had weak ability to induce fluorescent calcein leakage from negatively charged liposomes that mimic bacterial membranes. Moreover, the analogs induced significant depolarization of the membrane potential in intact $S$. aureus, while the original 1b-AMP1 showed no effect in this assay. Collectively, these results suggest a mode of action involving formation of transient pores rather than membrane disruption [199].

Piscidin 1 from a hybrid of striped bass is an antibacterial and cytotoxic $\alpha$-helical peptide (22 residues) for which analogs with peptoid residues (FFHHIFRXIVHVGKTIHRLVTG, $X=P$, NAla, NLeu or NLys) were designed $[193,197]$. The hydrophobicity of the NAla- and NLeu-substituted analogs was higher than that of the NLys-containing analog, but all peptides retained high antibacterial activity (MICs of 1-8 $\mu \mathrm{M}$ ) against a panel of Gram-negative and Gram-positive bacteria, and were devoid of hemolytic activity at a concentration of $100 \mu \mathrm{M}$, whereas the original AMP was hemolytic at $3 \mu \mathrm{M}$.

The tertiary structures of the Pro- and NLys-containing analogs (i.e., Pis-1[PG] and Pis-1[NkG], respectively) in the presence of DPC micelles were determined by NMR spectroscopy. While Pis-1[PG] had a rigid bent structure at the central Pro, Pis-1[NkG] was found to exist as two conformers with a flexible hinge structure at NLys [193]. Confocal laser-scanning microscopy revealed that all fluorophore-labelled peptoid-containing analogs penetrated the bacterial membrane and accumulated in the cytoplasm, whereas Pis-1[PG] localized to the surface and displayed extensive membrane depolarization of S. aureus $[193,197]$. The different conformations induced by Pro and Gly replacement by a peptoid residue may account for the distinct killing mechanisms of the resulting analogs. Thus, introduction of an NLys residue provided simultaneous conformational flexibility and increased cationicity in the hinge region, which facilitated penetration of the bacterial cell membrane and conferred the highest bacterial cell selectivity to Pis-1[NkG] [193,197]. Moreover, the most hydrophobic NLeu-substituted analog exhibited inhibition of LPS-induced nitric oxide production at a concentration of $2 \mu \mathrm{M}$ [197].

Papiliocin is a 37-residue AMP from larvae of the butterfly Papilio xuthus, while magainin 2 is a 23-residue AMP isolated from the skin of the African clawed frog Xenopus laevis. Papiliocin-magainin 2 hybrid AMPs (18 residues: RWKIFKKIXKFLHSAKKF-NH ${ }_{2}, \mathrm{X}=\mathrm{P}$ or NLys) were constructed by linking the N-terminus (residues $1-8$ ) of papiliocin and the N-terminus (residues 4-12) of magainin 2 via a central hinge region induced by either a Pro or an NLys residue (designated PapMA and PepMA-k, respectively) [198]. PapMA had high antimicrobial activity but was cytotoxic to mammalian cells, whereas PapMA-k retained broad-spectrum high antimicrobial activity against a panel of Gram-negative and Gram-positive species (MICs in the range 2-16 $\mu \mathrm{M}$ ), but was less hemolytic and cytotoxic ( $\mathrm{IC}_{50} \sim 40 \mu \mathrm{M}$ toward RAW264.7 and murine fibroblasts (NIH 3T3 cells)) than PapMA $\left(\mathrm{IC}_{50} \sim 10 \mu \mathrm{M}\right)$. In addition, MICs in the range $2-8 \mu \mathrm{M}$ were found against clinical isolates of MDR P. aeruginosa, E. coli, A. baumannii, MRSA, and S. typhimurium. NMR experiments revealed that the structures of PapMA and PapMA-k were consistent with $N$ - and C-terminal helices connected via a hinge residue, which for NLys gave rise to a dynamic equilibrium between cis and trans conformers. Fluorescent dye leakage experiments with liposomes mimicking bacterial membranes as wells as confocal microscopy of fluorescent analogs interacting with E. coli indicated that the mechanism of PapMA is membrane permeabilization, whereas PapMA-k is a bacteria-penetrating peptide with a putative intracellular target. Thus, the flexible structure as well as the positively charged NLys residue appear to play important roles in the bacterial cell selectivity of PapMA-k. By using lipopolysaccharide-stimulated RAW264.7 macrophages, both hybrids were found to display anti-inflammatory activities, e.g., inhibition of production of nitric oxide and expression of pro-inflammatory cytokines at concentrations of 5-10 $\mu \mathrm{M}$ [198]. 
Gobbo et al. have investigated how replacement of Arg and/or Leu residues with an analogous peptoid residue in the Pro-rich insect AMP apidaecin Ib (GNNRPVYIPQPRPPHPRL) affected the properties [200]. Generally, introduction of NArg residues resulted in reduced antimicrobial activity, however, modification in positions 4 or 12 led to non-hemolytic analogs (at least up to $300 \mu \mathrm{M}$ ) with only 2-fold higher MICs (16-32 $\mu \mathrm{M})$ against several Gram-negative bacteria. Peptoid substitution in the C-terminal Arg-Leu positions prevented the rapid enzymatic degradation seen for native apidaecin $1 \mathrm{~b}$ that produced inactive truncated analogs. Unfortunately, these peptoid-containing analogs lacked antibacterial activity; similarly, a tris-NArg-substituted analog lacked activity. Although peptoid-peptide hybrids are more resistant to proteolysis and devoid of any significant cytotoxic activity, shifting of the Arg $\rightarrow$ AArg replacement from the N-terminus towards the C-terminus progressively reduced the antibacterial activity of the analogs. Incubation experiments with $E$. coli cells infer that loss of antibacterial activity of apidaecin diplaying a C-terminal 17-NArg residue is a consequence of its inability to translocate into bacterial cells, supporting the involvement of a membrane peptide transporter (e.g., SbmA) [200]. SPPS of peptoid-peptide hybrids having an NArg residue was found to be facilitated by submonomer assembly of the $N$-protected aminoalkyl glycine residue, followed by completing the sequence with an on-resin guanidinylation to give the final peptoid-peptide hybrid [200].

Melittin is a highly cytotoxic AMP $\left(\mathrm{IC}_{50}\right.$ of 2 and $4 \mu \mathrm{M}$ against human cervical carcinoma (HeLa) cells and NIH 3T3 cells, respectively) with potent broad-spectrum antimicrobial activity (MICs of $0.5-4 \mu \mathrm{M})$. In order to reduce cytotoxicity an analog (ME-w; GIGAVLKVLTTGLPALIS-NhTrp-IKRKRQQ-NH ${ }_{2}$ ) displaying a homo-Trp peptoid residue (NhTrp) was designed [191]. ME-w exhibited similar antimicrobial activity as melittin, but accompanied by lower hemolytic properties and reduced cytotoxicity against HeLa and NIH-3T3 cells ( $\mathrm{IC}_{50}$ of 35 and $56 \mu \mathrm{M}$, respectively). Tryptophan fluorescence and CD spectroscopy revealed that the NhTrp-substituted analog had a much lower tendency to assemble into helical tetramers, which may explain the lower cytotoxicity [191].

Melittin contains a leucine zipper motif, consisting of every seventh amino acid (being Leu or Ile) that are aligned in a similar position in a helical wheel projection. In an attempt to generate cell-selective analogs, the residues in this zipper sequence were replaced by either NAla, NLeu, NPhe, or NLys (to give Me-a, Me-l, Me-f or Me-k) [195]. CD spectroscopy indicated that such substitutions disrupt the $\alpha$-helical structure in the presence of zwitterionic phospholipid vesicles. Also, Me-l, Me-f and Me-k proved incapable of self-association in an aqueous environment with high ionic strength, which may be correlated to their non-hemolytic behavior even at $100 \mu \mathrm{M}$, whereas native melittin is hemolytic already below $1 \mu \mathrm{M}$. Likewise, when tested towards HeLa and NIH 3T3 cells melittin inhibited growth at $10 \mu \mathrm{M}$, while ME-a, ME-1, and ME-k did not exhibit any cytotoxicity even at $100 \mu \mathrm{M}$. Broad-spectrum antibacterial activity against Gram-negative and Gram-positive species was observed for ME-f (MICs of 1-8 $\mu \mathrm{M}$ ) and ME-k (MICs of 2-4 $\mu \mathrm{M}$ ) corresponding to a 2 -fold lower potency as compared to that of native melittin. The peptoid-containing analogs were shown to possess little or no ability to induce membrane disruption or membrane depolarization. Substitution of the leucine zipper motif in melittin with peptoid NLeu or NLys residues confers increased selectivity for bacterial cells by impairing self-association, and this modification changes the mode of antibacterial action from membrane disruption to a putative intracellular mechanism, and thus analogs displaying three NLeu or NLys residues appear to be therapeutically useful lead compounds [195].

In order to convert the non-cell-selective Leu/Lys-rich model peptide KLW into an AMP with high preference for killing bacterial cells its two Phe residues were replaced by NPhe moieties to give the 18-mer KLW-f (KWKKLLKKfLKLfKKLLK-NH $2 ; \mathrm{f}=$ NPhe) [192]. In contrast to the distinctly $\alpha$-helical KLW, the CD spectrum of peptoid-containing KLW-f inferred a disordered structure due to the helix-breaking properties of the peptoid residues inserted in these middle positions. KLW-f exhibited high antimicrobial activity (MICs of 0.5-2.0 $\mu \mathrm{M}$ ) against both Gram-negative (e.g., E. coli and P. aeruginosa) and Gram-positive (e.g., S. aureus) bacteria. At a concentration of $100 \mu \mathrm{M}, \mathrm{KLW}-\mathrm{f}$ 
was devoid of hemolytic properties and cytotoxicity towards HeLa and NIH 3T3 cells. In addition, KLW-f caused no or little dye leakage from bacterial membrane-mimicking vesicles, indicating that its mode of action does not rely on permeabilization or disruption of bacterial membranes. Furthermore, KLW-f showed a significant inhibition of LPS-induced NO production from mouse macrophages (RAW264.7 cells) at $10 \mu \mathrm{g} / \mathrm{mL}$ [192]. These findings suggest that KLW-f may constitute a potential lead compound in the development of antisepsis therapeutics and/or antimicrobial agents.

Similarly, double introduction of L-Pro, D-Pro, D-Leu or NLeu residues into the hydrophobic face of the $\alpha$-helical non-cell-selective antimicrobial peptide $\mathrm{L}_{8} \mathrm{~K}_{9} \mathrm{~W}_{1}\left(\mathrm{KWKKLLKKXLKLXKKLLK-NH}{ }_{2}\right.$; $X=L e u$ ), designed to possess a perfectly amphipathic structure, had significant effects on conformation, cell selectivity and mechanism of action [194]. The resulting analogs lacked $\alpha$-helical structure and displayed increased selectivity toward bacterial cells; in particular, $\mathrm{L}_{8} \mathrm{~K}_{9} \mathrm{~W}_{1}$-D-Pro (X = D-Pro in the above sequence) and $\mathrm{L}_{8} \mathrm{~K}_{9} \mathrm{~W}_{1}-\mathrm{NLeu}(\mathrm{X}=\mathrm{NLeu})$ had potent broad-spectrum antibacterial activity (MICs of 0.5-2 $\mu \mathrm{M}$; including MRSA and MDR P. aeruginosa), but were non-hemolytic even at $100 \mu \mathrm{M}$. Interestingly, at 5- to 10-fold higher concentrations than their MIC the analogs containing an L-Pro, D-Pro or NLeu residue interacted weakly with negatively charged phospholipid vesicles that mimics bacterial membranes and caused weak depolarization of S. aureus membranes [194]. Thus, $\mathrm{L}_{8} \mathrm{~K}_{9} \mathrm{~W}_{1}$-L-Pro, $\mathrm{L}_{8} \mathrm{~K}_{9} \mathrm{~W} 1-\mathrm{D}-\mathrm{Pro}$ and $\mathrm{L}_{8} \mathrm{~K}_{9} \mathrm{~W}_{1}-\mathrm{NLeu}$ may be promising candidates for novel therapeutic agents due to their high cell selectivity and activity against MDR strains.

In addition, three hemolytic non-helical Trp/Pro-rich AMPs were examined with respect to the effect of Pro $\rightarrow$ NLys substitution on their cell selectivity and mode of action. All Pro residues in tritrpticin (TP: VRRFPWWWPFLRR-NH ${ }_{2}$ ), symmetric TP analog (STP: KKFPWWWPFKK-NH ${ }_{2}$ ) and indolicidin (IN; ILPWKWPWWPWRR-NH ${ }_{2}$ ) were simultaneously replaced with NLys residues to give the analogs TPk, STPk and Ink [196]. The NLys-substituted peptides (i.e., TPk, STPk and Ink) exhibited broad-spectrum antibacterial activity (MICs in the range $0.5-8 \mu \mathrm{M})$ against E. coli, $P$. aeruginosa and S. aureus including MDR strains, and displayed no hemolytic activity at $200 \mu \mathrm{M}$ corresponding to at least 2- to 8-fold higher cell selectivity than the parent Pro-containing AMPs. In contrast to the original Pro-containing AMPs the NLys-substituted peptides induced only weak depolarization of the membranes of intact $S$. aureus at their MIC. This suggest that also for non-helical Pro-rich AMPs incorporation of NLys residues confers a mode of action that most likely involves interference with essential intracellular processes [196].

Table 4 shows the activity profiles for some of the most active AMPs displaying peptoid residues.

Table 4. Antimicrobial activity of representative AMPs containing peptoid residues.

\begin{tabular}{cccccc}
\hline \multirow{2}{*}{ Compound } & \multicolumn{5}{c}{ MIC (in $\mu \mathrm{M})$ Hemolysis } \\
\cline { 2 - 5 } & S. aureus & E. coli & P. aeruginosa & HC $_{50}$ & Ref. \\
\hline Pis-1[NkG] ${ }^{\text {a }}$ & 4 & 2 & 4 & $>200$ & {$[197]$} \\
KLW-f $^{b}$ & 1 & 2 & 1 & $>100$ & {$[192]$} \\
$\mathrm{L}_{8} \mathrm{~K}_{9} \mathrm{~W}_{1}-\mathrm{NLeu}^{\mathrm{c}}$ & 2 & 2 & 1 & $>100$ & {$[194]$} \\
STPk $^{\mathrm{d}}$ & 1 & 1 & 2 & $>200$ & {$[196]$} \\
\hline
\end{tabular}

a Pis-1[NkG] = FFHHIFR-NLys-IVHVGKTIHRLVTG; ${ }^{\text {b }}$ KLW-f $=$ KWKKLLKK-NPhe-LKL-NPhe-KKLLK-NH ${ }_{2}{ }^{c}$

$\mathrm{L}_{8} \mathrm{~K}_{9} \mathrm{~W}_{1}-\mathrm{NLeu}=\mathrm{KWKKLLKK-NLeu-LKL-NLeu-KKLLK-NH}{ }_{2} ;{ }^{\mathrm{d}} \mathrm{STPk}=$ KKF-NLys-WWW-NLys-FKK-NH ${ }_{2}$

Recently, an array of AMPs, for which indications for intracellular target had been reported, was examined for their ability to act as a translocation vehicle for an antisense peptide nucleic acid (PNA) targeting fatty acid synthesis [201]. While TPk lacked capability of bacterial delivery of PNA, the antisense PNA oligomer conjugate with KLW-L9, 13-a (KWKKLLKK-NAla-LKL-NAla-KKLLK-NH2) displayed moderately enhanced activity as compared to the AMP itself independently of the expression of the SbmA peptide transporter [201]. 


\subsubsection{Peptide-Peptoid Hybrids}

By integrating chemometrics and cheminformatics methods with in vitro susceptibility test a number of antibacterial peptide-peptoid hybrids were identified [202]. Descriptors for a panel of natural amino acids (e.g., Trp, Leu, Lys and Arg) and peptoid residues abundant in AMPs and antibacterial peptoids, respectively, were derived by principal component analysis of constitutional, topological, geometrical, and physicochemical properties. These were then used to model the correlation between structural features and antibacterial activity of known 9-mer AMPs. High-throughput virtual screening of a combinatorial library based on ten natural amino acids and eight peptoid residues allowed selection of potential antibacterial compounds, for which the potency against $S$. aureus and $P$. aeruginosa was determined in vitro. Two 8-mer peptide-peptoid hybrids (IK-Nssb-NLys-VRK-Nssb-NH $\mathrm{NH}_{2}$ and NLys-NLys-W-Nsmb-IKRW-NH ${ }_{2}$ ) were found to possess antibacterial activity with MIC values in the range $3-12 \mu \mathrm{g} / \mathrm{mL}$ against the two strains. Molecular dynamics simulations revealed that IK-Nssb-NLys-VRK-Nssb- $\mathrm{NH}_{2}$ folds into a typical amphipathic helix that promotes membrane disruption, while NLys-NLys-W-Nsmb-IKRW- $\mathrm{NH}_{2}$ was devoid of secondary structure [202].

An array of twenty lysine-peptoid hybrids (5-10 residues), based on the hydrophobic Nnal-Nmphe-Nnal-Nnle- $\mathrm{NH}_{2}$ hemolytic lead compound, was designed by incorporating a varying number of cationic Lys residues (1-6) distributed along the sequence in several display modes in order to explore the SARs within this subclass of peptidomimetics [203]. These hybrids were found to exhibit antimicrobial activity against clinically important bacteria including E. faecium (VRE strain), S. aureus (e.g., MRSA), and P. aeruginosa (ATCC 27853), whereas they were inactive against K. pneumoniae [204]. The general trends were that longer compounds displaying four or more lysines were most active, and that these were most potent against Gram-positive species. Several peptidomimetics displaying high activity against S. aureus strains and VRE (MICs 1.6-6.25 $\mu \mathrm{M}$ ) were identified, with Nnal-Nmphe-Nnal-Nnle-KKKKK-NH 2 (LP5) being the most active. The two most potent low-hemolytic compounds toward P. aeruginosa were KKKK-Nnal-Nmphe-Nnal-Nnle- $\mathrm{NH}_{2}$ and KKKKK-Nnal-Nmphe-Nnal-Nnle-NH $\mathrm{N}_{2}$ [204]. In a recent study LP5 was shown to retain activity under settings resembling host physiological conditions with respect to salinity, $\mathrm{Mg}^{2+}$ concentration and $\mathrm{pH}$. However, in the presence of serum, LP5 lost activity. Moreover, at high salinity or lowered $\mathrm{pH}$, the peptidomimetic exhibited reduced activity. Interestingly, exposure of $S$. aureus to subinhibitory concentrations of LP5 affected the expression of the major virulence factors of S. aureus [205]. Table 5 shows the activity profiles for some of the most active peptide-peptoid hybrids.

Table 5. Antimicrobial and hemolytic activity of representative peptide-peptoid hybrids.

\begin{tabular}{|c|c|c|c|c|}
\hline \multirow{2}{*}{ Compound } & \multicolumn{4}{|c|}{ MIC (in $\mu \mathrm{M}$ or $\mu \mathrm{g} / \mathrm{mL}$ ) Hemolysis } \\
\hline & S. aureus & P. aeruginosa & HA $^{\mathrm{a}}$ & Ref. \\
\hline IK-Nssb-NLys-VRK-Nssb-NH2 & $3.1 \mu \mathrm{g} / \mathrm{mL}$ & $11.8 \mu \mathrm{g} / \mathrm{mL}$ & - & [202] \\
\hline NLys-NLys-W-Nsmb-IKRW-NH ${ }_{2}$ & $9.2 \mu \mathrm{g} / \mathrm{mL}$ & $5.7 \mu \mathrm{g} / \mathrm{mL}$ & - & [202] \\
\hline Nnal-Nmphe-Nnal-Nnle-KKKKK-NH ${ }_{2}$ & $1.6 \mu \mathrm{M}$ & $12.5 \mu \mathrm{M}$ & $3 \%$ & [204] \\
\hline KKKK-Nnal-Nmphe-Nnal-Nnle- $\mathrm{NH}_{2}$ & $1.6 \mu \mathrm{M}$ & $6.25 \mu \mathrm{M}$ & $6 \%$ & [204] \\
\hline
\end{tabular}

\section{3. $\beta$-Peptoids}

Conceptually, $\beta$-peptoids may be considered as the homologues of ordinary $\alpha$-peptoids in the same way as $\beta^{3}$-peptides corresponds to backbone methylene-elongated $\alpha$-peptides. However, despite its apparent simplicity the subclass of $N$-alkylated $\beta$-alanine oligomers (typical monomers are depicted in Figure 9) was for long only sporadically explored [206]. Whether $\beta$-peptoids might have an advantage as compared to $\alpha$-peptoids or other foldamers remains to be elucidated, but as recently reviewed by Olsen [207] the prospect of gaining more detailed knowledge on the factors that control their folding propensity may clearly extend the scope of these peptidomimetics further. 
From a synthesis point of view a major obstacle was the encountered difficulties in developing fast and efficient solid-phase routes to longer $\beta$-peptoid oligomers, since the obvious submonomer approach involving on-resin aza-Michael conjugate addition of a primary amine to a resin-bound acrylamide intermediate proved to be hampered by long reaction times $[208,209]$. For $\beta$-peptoid oligomers displaying $\alpha$-chiral side chains even the monomer-based strategy using Fmoc-protected building blocks proved challenging [210], while achiral oligomers readily could be obtained via microwave (MW)-assisted SPS under conditions similar to those applied in traditional SPPS [211]. Also, a block synthesis protocol has been reported [212], whereas cyclic $\beta$-peptoids have been assembled via a solution-phase method [213].

Although only two reports on antibacterial $\beta$-peptoids have appeared so far $[211,212]$ a comparative study comprising several subclasses of peptidomimetics showed that the $\beta$-peptoid backbone conferred similar antimicrobial activity to the resulting oligomer as other templates (e.g., $\alpha$-peptoid or $\beta^{3}$-peptide) when displaying an alternating sequence of cationic/hydrophobic side chains [211]).

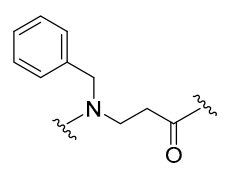

$\beta N P h e$

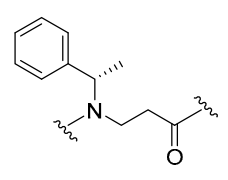

$\beta N$ spe

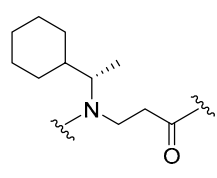

$\beta N$ sce

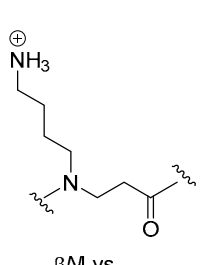

BMys

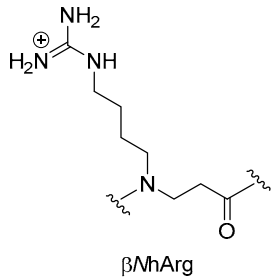

$\beta N \mathrm{NArg}$

Figure 9. Structure of commonly used $\beta$-peptoid building blocks. $\beta N P h e: ~ N-(1$-phenylethyl)- $\beta$-alanine; $\beta N$ spe: $\quad N-(S)-(1-$ phenylethyl)- $\beta$-alanine; $\quad \beta N$ sce: $\quad N-(S)-(1$-cyclohexylethyl)- $\beta$-alanine; $\beta N L y s:$ $N$-(4-aminobutyl)- $\beta$-alanine; $\beta N h A r g: N$-(3-guanidinobutyl)- $\beta$-alanine.

\subsubsection{Synthesis of $\beta$-Peptoid Oligomers}

The first report on solid-phase synthesis (SPS) of $\beta$-peptoid oligomers concerned assembly of a combinatorial library of trimers starting from an acryloylated Wang resin. Elongation was performed via a submonomer approach involving successive aza-Michael addition of an appropriate primary amine in DMSO (which proved superior to DMF, NMP or DCE) and acylation with acryloyl chloride in the presence of triethylamine (Scheme 2). Typically, each elongation cycle reached 2.5 day even for unhindered amines [208].

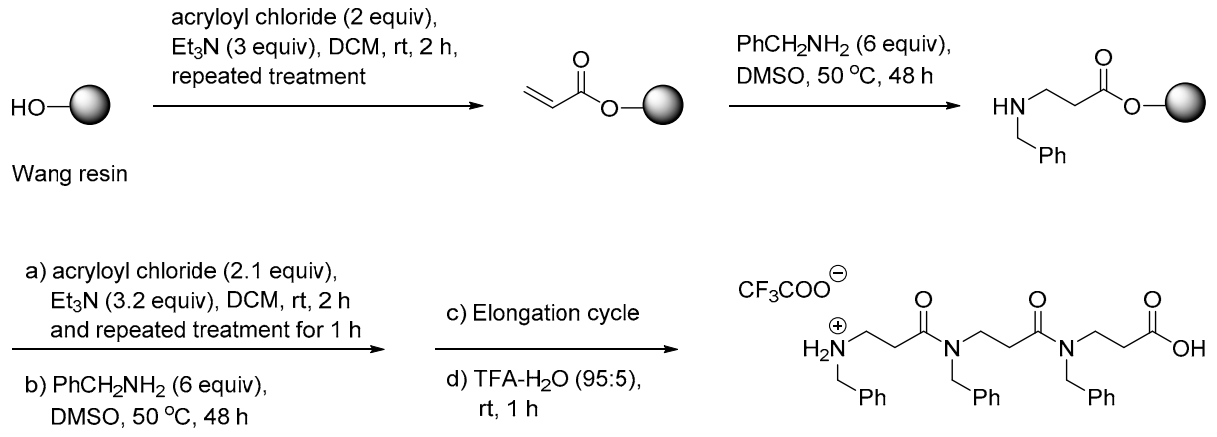

Scheme 2. SPS of achiral $\beta$-peptoids via the submonomer aza-Michael method [208].

Subsequently, SPS of longer $\beta$-peptoid oligomers (up to 10 residues; Scheme 3), displaying $\alpha$-chiral side chains, was achieved by using a Tentagel resin [209]. Although faster coupling cycles of approx. $10 \mathrm{~h}$ were applicable when $\mathrm{H}_{2} \mathrm{O}$-THF (8:2) was employed in the optimized aza-Michael addition, the protocol remained time-consuming as compared to preparation of peptides and $\alpha$-peptoids. 

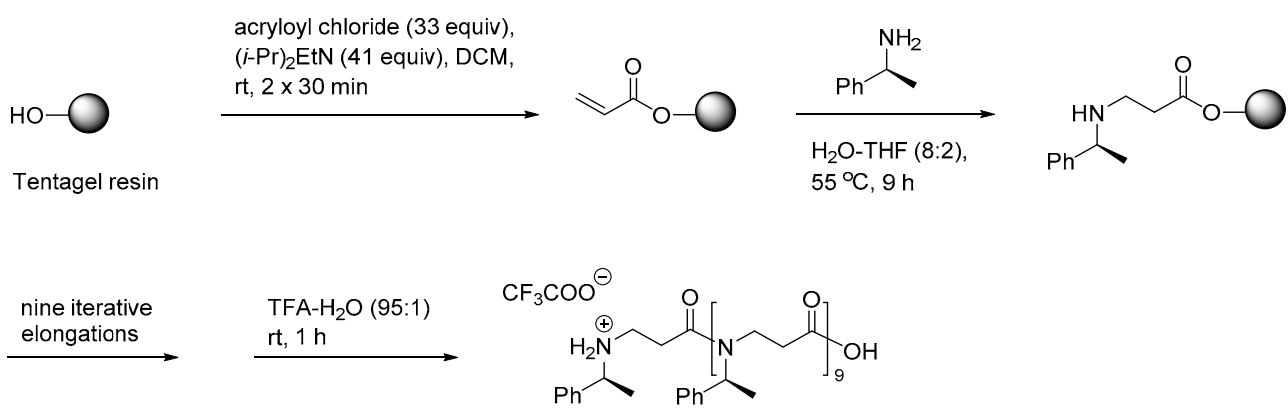

Scheme 3. SPS of $\alpha$-chiral $\beta$-peptoids via an optimized submonomer aza-Michael method [209].

To overcome the incomplete conversion during the aza-Michael addition step in SPS, an alternative method, involving a preformed Fmoc-protected substituted $\beta$-alanine monomer, was investigated [210]. In this case the aza-Michael addition to $t$-butyl acrylate was readily accomplished under MW heating to $160{ }^{\circ} \mathrm{C}$ in DMSO. Ester hydrolysis, Fmoc protection under standard conditions, followed by column chromatography afforded the required Fmoc- $\beta N$ spe-OH building block (Scheme $4 \mathrm{~A}$ ). Nevertheless, repeated couplings with PyBOP only yielded the full-length oligomer as a minor product, while in situ formation of the acyl fluoride with TFFH proved more efficient (Scheme 4B) [210].

Till now, the most convenient monomer-based protocol for synthesis of longer oligomers involves automated MW-assisted Fmoc-based SPS (Scheme 5) with preformed building blocks (e.g., alternating $\beta$-peptoid analogs of Lys and Phe) in combination with DIC/HOAt (standard coupling at $75^{\circ} \mathrm{C}$ ) [211]. This allowed assembly of a 16-mer in less than 1 day in a yield and purity comparable to that of the corresponding peptide. In this case Fmoc- $\beta N P h e-O H$ was obtained from the aza-Michael adduct by successive treatment with TFA-DCM (1:2) followed by N-protection with Fmoc-Cl [211].

A<smiles>C=CC(=O)OC(C)(C)C</smiles>

B

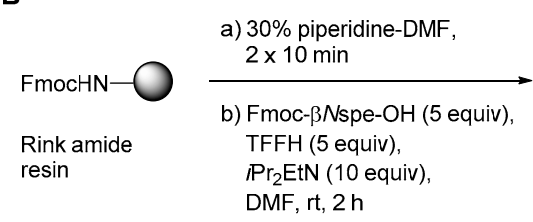

a) $1 \mathrm{M} \mathrm{NaOH}_{\mathrm{aq}}$ (2 equiv),

$\mathrm{MeOH}, 60^{\circ} \mathrm{C}, 2 \mathrm{~h}$

$\underset{\text { b) } \mathrm{Na}_{2} \mathrm{CO}_{3} \text { (2 equiv), } \mathrm{Fmoc}-\mathrm{Cl}}{\longrightarrow}$

dioxane- $\mathrm{H}_{2} \mathrm{O}(1: 1), 0^{\circ} \mathrm{C}$,

then $\mathrm{rt}, 2 \mathrm{~h}$
Fmoc- $\beta$ Nspe-OH

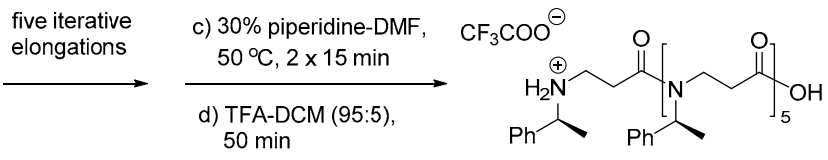

Scheme 4. Monomer-based SPS using prefomed $\alpha$-chiral Fmoc- $\beta N$ spe-OH building blocks [210]; (A) synthesis of monomers; (B) SPS protocol.

A<smiles>CCOC(=O)CCBr</smiles>

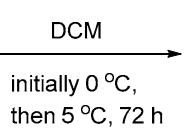<smiles>CCOC(=O)CCNCCCCNC(C)=O</smiles>

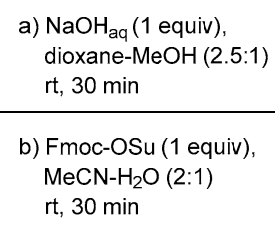

b) Fmoc-OSu (1 equiv) $\mathrm{MeCN}-\mathrm{H}_{2} \mathrm{O}(2: 1)$ rt, $30 \mathrm{~min}$

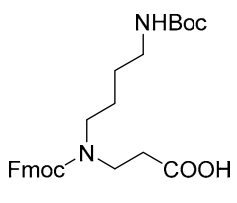

Fmoc- $\beta$ NLys-OH

Scheme 5. Cont. 
B

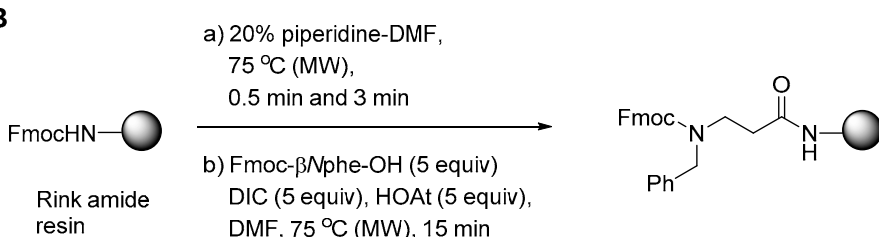

a) $20 \%$ piperidine-DMF,

$75^{\circ} \mathrm{C}(\mathrm{MW})$

$0.5 \mathrm{~min}$ and $3 \mathrm{~min}$

b) Fmoc- $\beta$ Mys (Boc)-OH (5 equiv) DIC (5 equiv), HOAt ( 5 equiv), $\mathrm{DMF}, 75^{\circ} \mathrm{C}(\mathrm{MW}), 15 \mathrm{~min}$

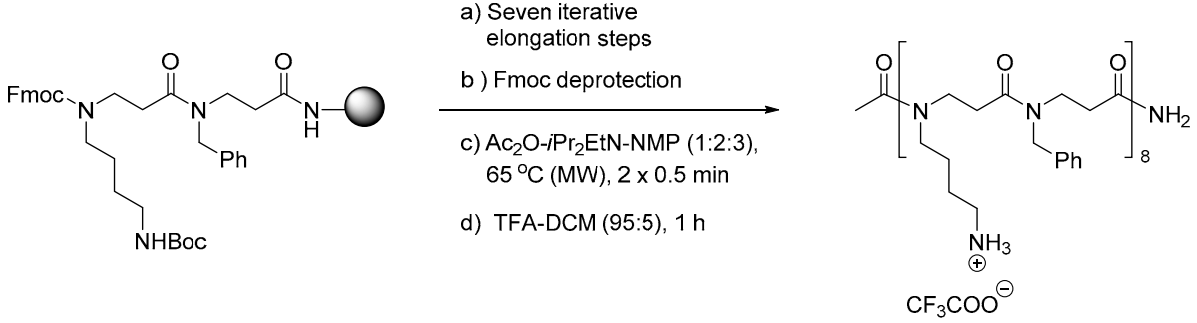

Scheme 5. MW-assisted SPS using prefomed Fmoc-protected building blocks [211]; (A) synthesis of Fmoc-protected $\beta N L y s$ monomer; (B) protocol for assembly of oligomers.

Yet another synthesis methodology has been reported by Shuey et al. [212]. Here dimeric and trimeric building blocks were prepared either by a solution-phase route (Scheme 6) or via the SPS method by Hamper et al. [208] by including on-resin Fmoc protection prior to release from resin. A library of peptidomimetics (9-18 residues) was obtained by assembly on a resin preloaded with Fmoc-Lys(Boc)-OH by using HATU/DIEA for amide ligations (Scheme 7).

Also, cyclic $\beta$-peptoids, displaying alkyne side chains, allowing for modification by click chemistry, have been prepared by repetitive solution-phase elongations (acylation with acryloyl chloride followed by aza-Michael addition at $50{ }^{\circ} \mathrm{C}$ in $\mathrm{MeOH}$ ) of the starting propargylamine aza-Michael adduct obtained with t-butyl acrylate (Scheme 8) [213]. Macrocyclisation of the linear intermediates was accomplished with HATU or diphenylphosphoryl azide (DPPA). However, cyclisation of the linear dimer and trimer $(n=2$ or 3$)$ gave rise to rings of doubled size due to an intermolecular elongation occurring prior to cyclisation.
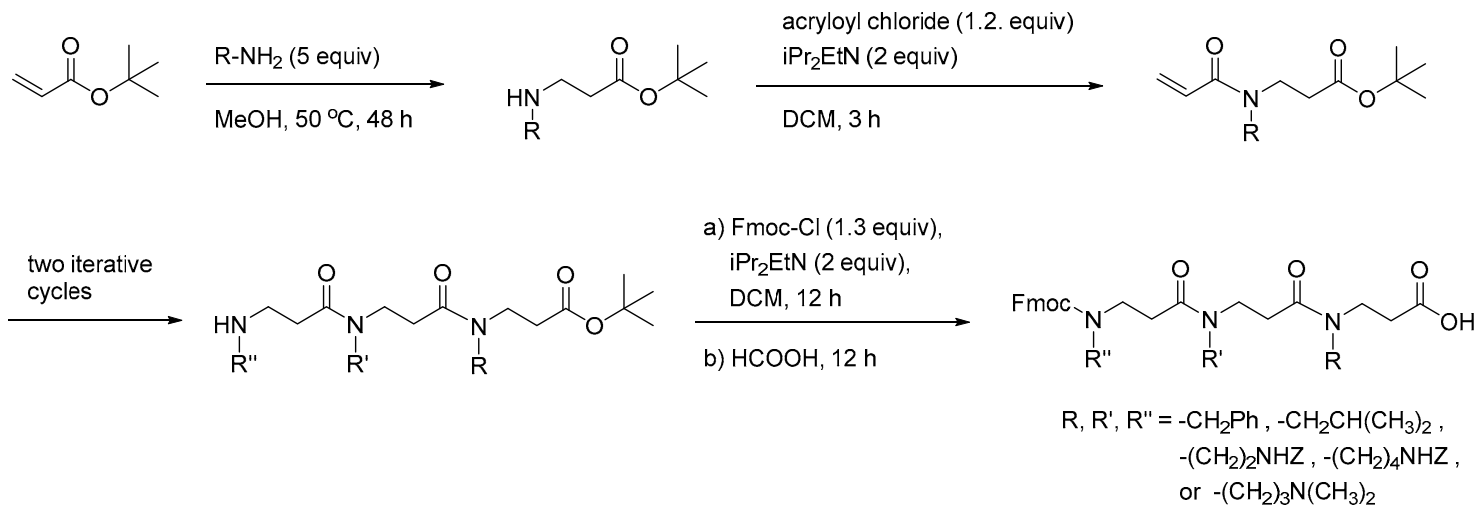

Scheme 6. Synthesis of trimeric achiral $\beta$-peptoid building blocks [212]. 

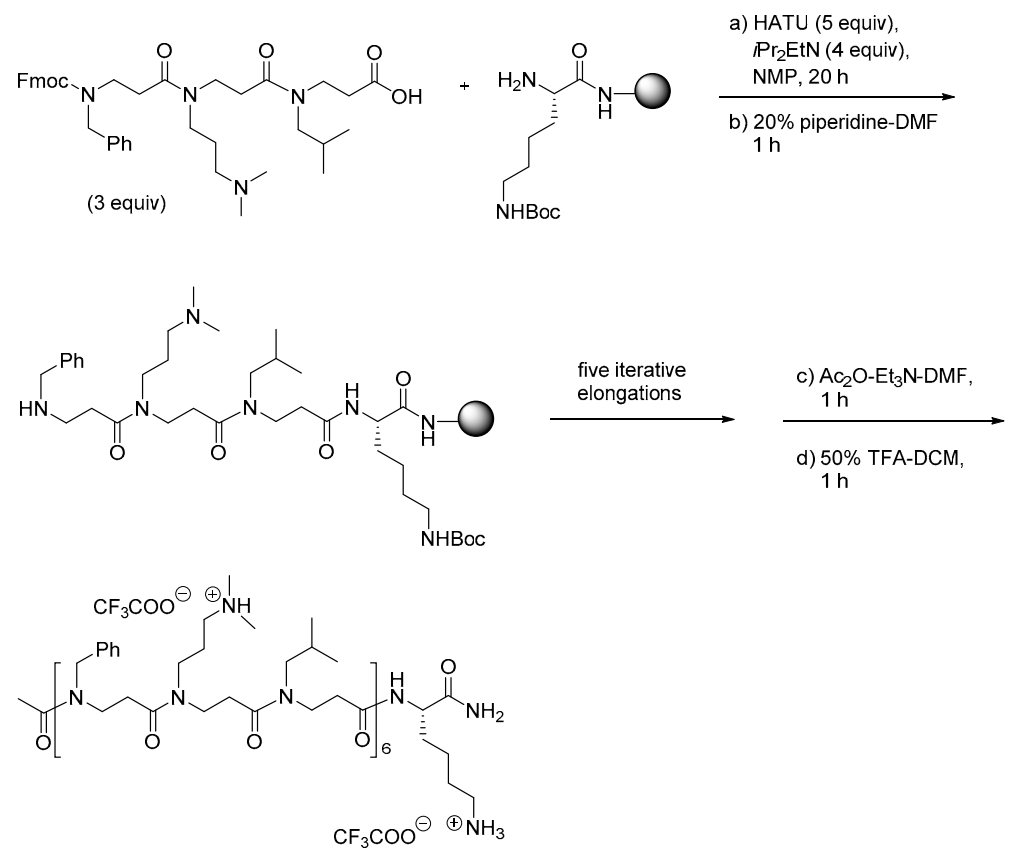

Scheme 7. Block SPS of H-[ $\left.\beta N P h e-\beta N O r n\left(\mathrm{Me}_{2}\right)-\beta-N L e u\right]_{6}-\mathrm{Lys}_{-} \mathrm{NH}_{2}$ [212].

\subsubsection{Antimicrobial Activity}

Of the 21 members in the array of $\beta$-peptoids (9-18 residues besides the C-terminal lysine), reported by Shuey et al., six oligomers showed moderate antibacterial activity corresponding to a MIC value of $128 \mu \mathrm{g} / \mathrm{mL}$ against E. coli (ATCC 25922) [212], which for the most active 19-mer oligomer (H-[ $\beta N$ Phe- $\left.\beta N O r n\left(\mathrm{Me}_{2}\right)-\beta N L e u\right]_{6}-\mathrm{Lys}_{-} \mathrm{NH}_{2}$ ) corresponds to $35 \mu \mathrm{M}$. In comparison, a 16-mer oligomer with an alternating cationic/hydrophobic sequence (i.e., Ac- $[\beta N L y s-\beta N P h e]_{8}-\mathrm{NH}_{2}$ ) exibited MIC values in the range 4-16 $\mu \mathrm{M}$ against wild-type E. coli (ATCC 25922) and three $\beta$-lactamase-producing (ESBL, AmpC and NDM-1) strains, whereas it was practically inactive toward K. pneumoniae (KPC-2 and NDM-1 strains) and MRSA (MIC values of $256 \mu \mathrm{M}$ ) [211]. Moreover this oligomer resisted enzymatic degradation with pronase and displayed weakly hemolytic properties $\left(\mathrm{HC}_{10}>128 \mu \mathrm{M}\right)$ and moderate cytotoxicity against HeLa cells ( $\mathrm{IC}_{50}$ of $\left.169 \mu \mathrm{M}\right)$ [211].
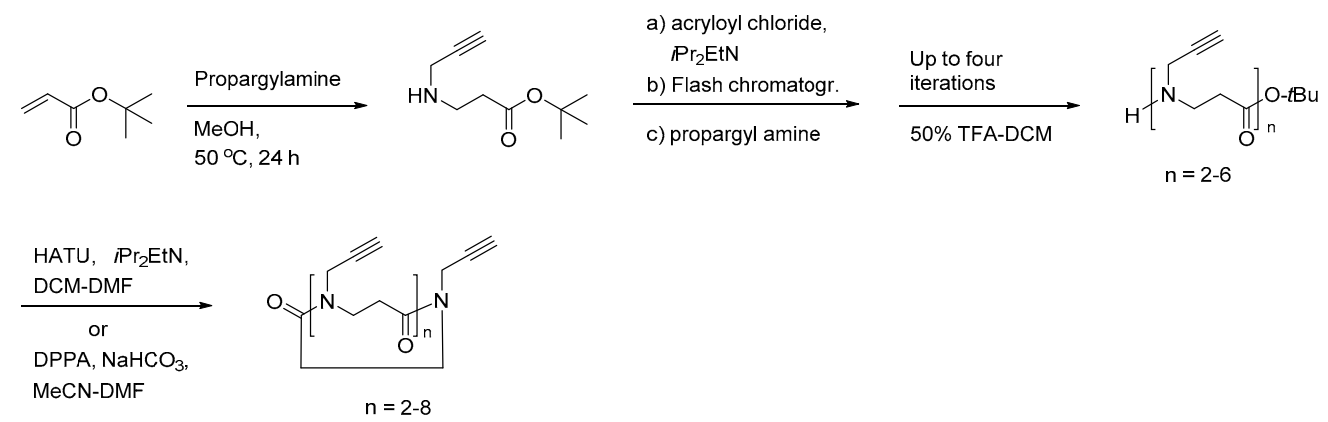

Scheme 8. Solution-phase synthesis of cyclic $\beta$-peptoids [213].

\section{4. $\alpha$-Peptide/ $\beta$-Peptoid Hybrids}

As discussed above (Section 2.3.1) SPS of $\alpha$-chiral $\beta$-peptoids proved surprisingly challenging due to sluggish amide formation involving resin-bound congested secondary amines [210], albeit it was later found that achiral oligomers were readily obtained by MW-assisted SPS [211]. In contrast, hybrids with a design of alternating $\alpha$-amino acid and $\beta$-peptoid residues were readily obtained via SPS by using dimeric building blocks synthesized by standard solution-phase methods [214,215]. 
In subsequent studies these $\alpha$-peptide/ $\beta$-peptoid hybrids were found to possess a number of favorable properties: (i) high potency toward MDR bacteria; (ii) proteolytic stability; (iii) low hemolysis and cytotoxicity, and (iv) increased activity in the presence of plasma as opposed to most antimicrobial peptides (AMPs) [113,120,216-220]. In addition, anti-biofilm and antiplasmodial activities have been reported [221,222]. Recently, lipidated analogs were found to exert anti-inflammatory and immunomodulating properties, e.g., neutralization of LPS- and LTA-induced proinflammatory responses by immune cells [223] as well as agonism and antagonism of neutrophilic formyl peptide receptors depending on the nature of the lipid headgroup [224,225].

\subsubsection{Synthesis}

In the initial synthetic work on $\alpha$-peptide/ $\beta$-peptoid hybrid oligomers with alternating sequences both submonomer and monomer approaches were considered to be inapplicable due to the incomplete conversion obtained in on-resin aza-Michael additions of sterically hindered $\alpha$-chiral amines as well as the sluggish amide formation involving the resulting even more congested $\beta$-peptoid amines as discussed above for SPS of homomeric $\beta$-peptoid oligomers involving preformed Fmoc-protected monomers [210]. Instead, versatile gram-scale protocols for obtaining dimeric building blocks were developed. Similar to the synthesis of $\beta$-peptoid monomers an aza-Michael addition of the appropriate primary amine to $t$-butyl acrylate produced an $N$-alkylated $\beta$-alanine ester that was subjected to coupling with a commercial Fmoc-protected lysine building block to give a dimeric intermediate (Scheme 9). Manipulation of the protection scheme gave access to building blocks displaying an $N^{\varepsilon}$-(2-trimethylsilylethyl)oxycarbonyl ( $N$-Teoc), or a bis(Boc)-guanidino side chain functionality [215].

The utility of these building blocks was explored via two routes (Scheme 10) of which the first comprised assembly of an $N^{\varepsilon}$-Teoc-protected resin-bound oligomer that subsequently was side-chain deprotected with TBAF allowing for on-resin re-functionalization, e.g., to give homoarginine-containing oligomers, which also could be obtained directly by employing the corresponding preformed dimeric building block, i.e., Fmoc-hArg(Boc 2$)-\beta N$ spe-OH [215].

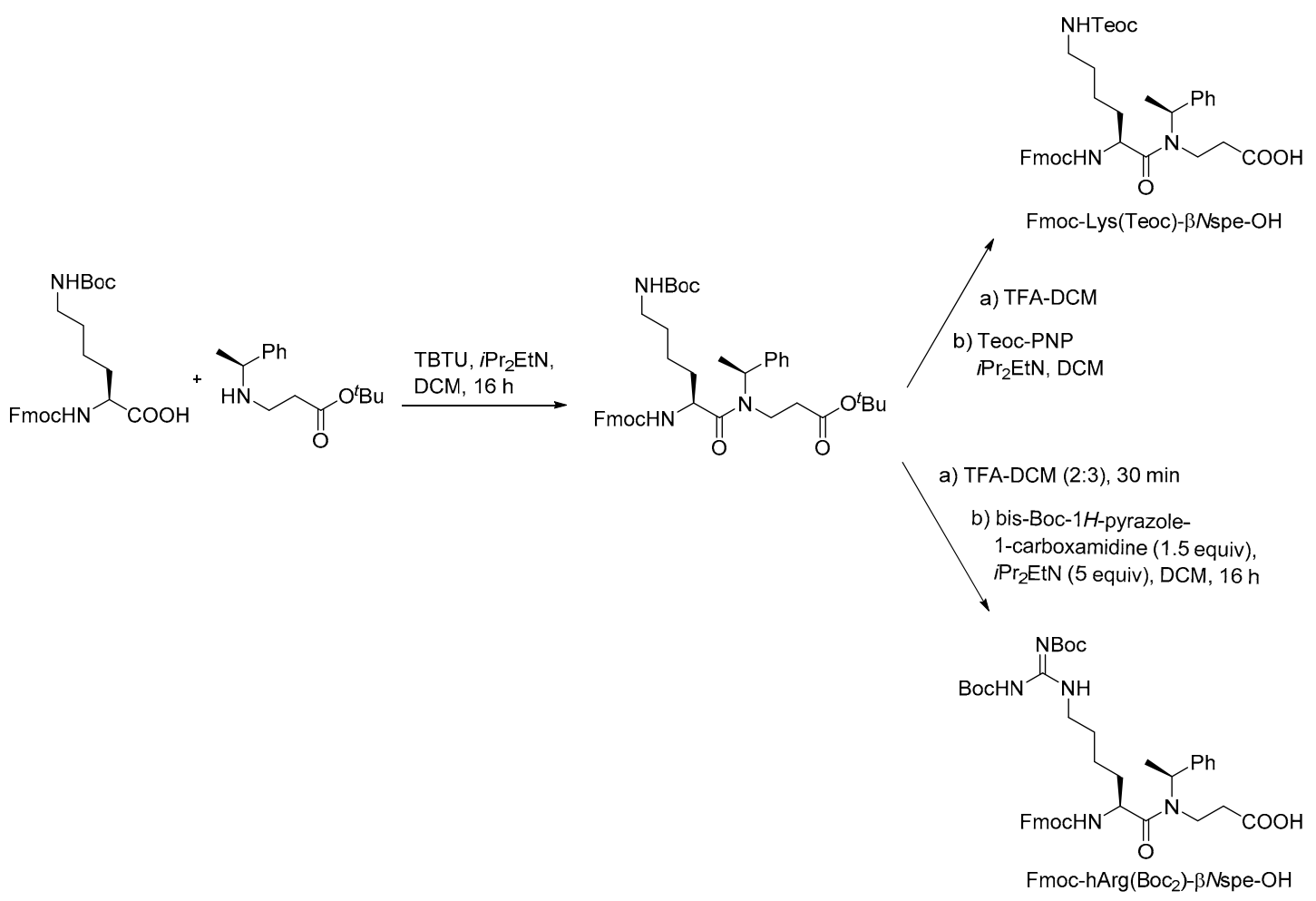

Scheme 9. Synthesis of Teoc-protected and guanidinylated dimeric building blocks [215]. 


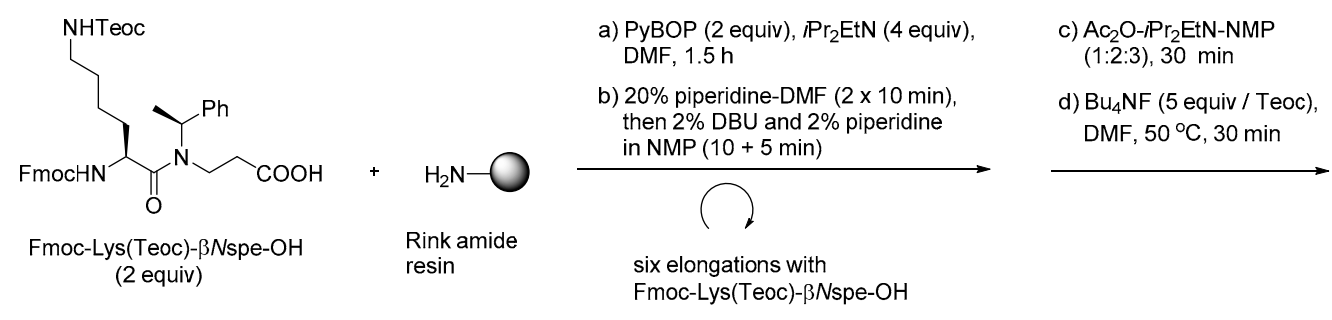

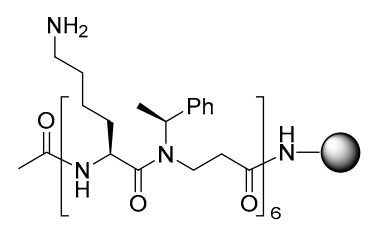

a) bis-Boc-1H-pyrazole-

1-carboxamidine (5 equiv / $-\mathrm{NH}_{2}$ ), $\operatorname{Pr}_{2} \mathrm{EtN}$ ( 5 equiv $/-\mathrm{NH}_{2}$ ), DMF, $2 \times 1 \mathrm{~h}$

b) TFA-DCM (95:5), $1 \mathrm{~h}$

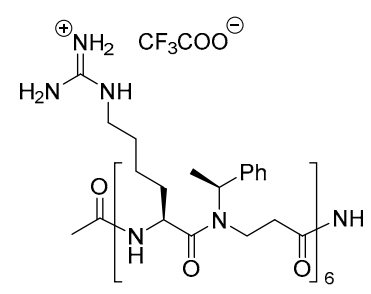

Ac-[hArg- $\beta N$ spe] ${ }_{6}-\mathrm{NH}_{2}$

a) six elongations with Fmoc-hArg $\left(\mathrm{Boc}_{2}\right)-\beta \mathrm{Nspe}-\mathrm{OH}$

b) Acetylation

c) Cleavage

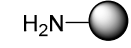

Rink amide

resin

Scheme 10. Approaches for assembly of cationic/hydrophobic $\alpha$-peptide/ $\beta$-peptoid oligomers [215].

To enable structure-activity studies of this novel class of peptidomimetics, an array of diverse dimeric building blocks comprising variations in hydrophobicity and charge was constructed (Figure 10) [214]. While the MW-assisted (DMSO, $150^{\circ} \mathrm{C}$ ) aza-Michael addition proved insensitive to sterical hindrance of the amine, the subsequent amide formation with an Fmoc-protected $\alpha$-amino acid required adjustment of the standard conditions (TBTU, room temperature, $16 \mathrm{~h}$ ) when one of the reactants was congested. Thus, for coupling of the Fmoc- ${ }^{t} \mathrm{BuGly}-\mathrm{OH} / \mathrm{H}-\beta \mathrm{Nspe}-\mathrm{OH}$ and Fmoc-Lys(Boc)-OH/H- $\beta$ Nsce-OH pairs use of TFFH in 1,2-dichlorothane (DCE) at elevated temperature (MW $60{ }^{\circ} \mathrm{C}, 0.5 \mathrm{~h}$ ) was found to give acceptable yields. To accomplish the coupling between the $\alpha$-chiral naphtylamine intermediate and Fmoc-Lys(Boc)-OH even harsher conditions were needed (TFFH, MW $80^{\circ} \mathrm{C}, 2 \mathrm{~h}$ ).

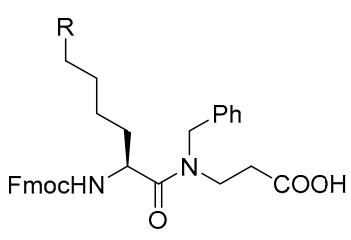

$\mathrm{R}=\mathrm{NHBOC}$

$\mathrm{R}=\mathrm{NH}(\mathrm{C}=\mathrm{NHBOC})-\mathrm{NHBoc}$

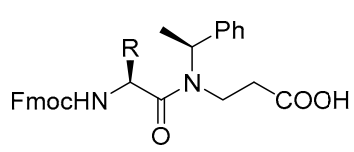

$R={ }^{i} \operatorname{Pr}$

$\mathrm{R}={ }^{t} \mathrm{Bu}$

$\mathrm{R}=-\left(\mathrm{CH}_{2}\right)_{2} \mathrm{COO}^{t} \mathrm{Bu}$<smiles>CC1CCCCC1NCCC(=O)O</smiles>

$\mathrm{R}=\mathrm{Me}$

$\mathrm{R}=-\left(\mathrm{CH}_{2}\right)_{4} \mathrm{NHBOC}$

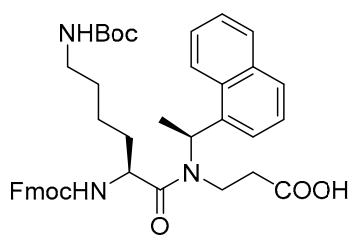

Figure 10. Dimeric building blocks obtained by solution-phase methods [214].

Dimeric $\quad \alpha$-peptide/ $\alpha$-peptoid building blocks Fmoc-Lys(Boc)-NPhe-OH and Fmoc-hArg(Boc $)-N$ Phe-OH were similarly prepared for use in manual SPS of oligomers (Scheme 11) [120]. 

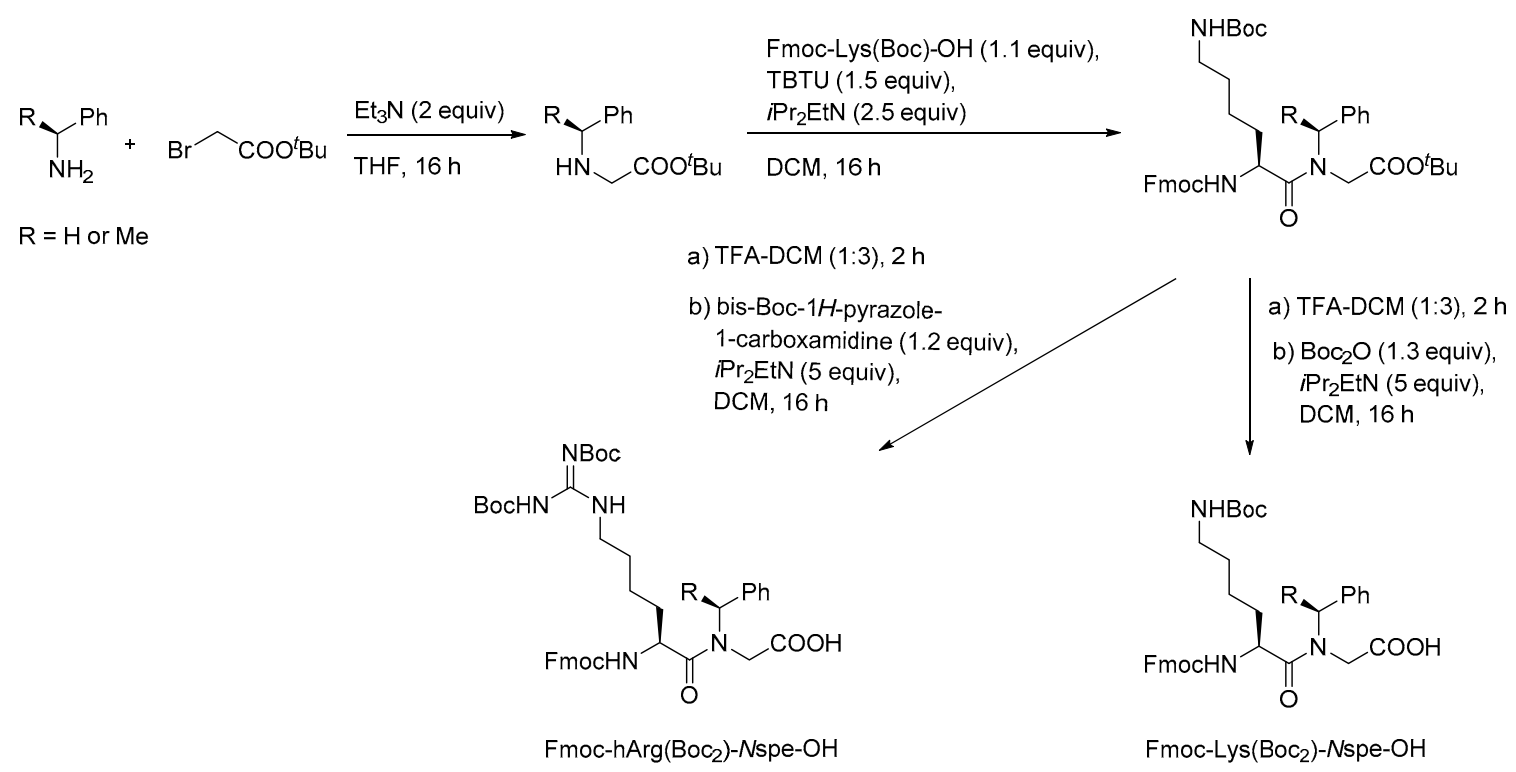

Scheme 11. Synthesis of $\alpha$-peptide/ $\alpha$-peptoid dimeric building blocks [120].

Monomer-based SPS of oligomers consisting of alternating $\alpha$-amino acids and achiral $\alpha$ - or $\beta$-peptoid residues (Figure 11) was feasible when preformed Fmoc-protected monomers were coupled under standard MW-heating conditions $\left(75^{\circ} \mathrm{C}\right)$ used for SPPS [211].

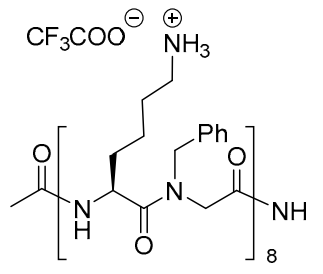

Ac-[Lys-NPhe $]_{8}-\mathrm{NH}_{2}$

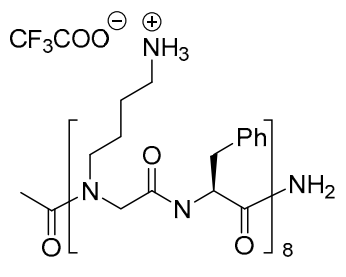

Ac- $[N \text { Lys-Phe }]_{8}-\mathrm{NH}_{2}$

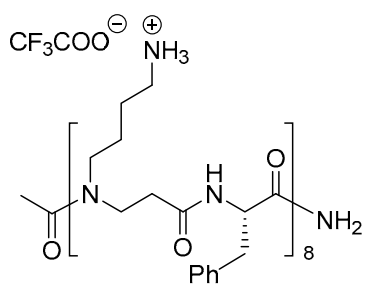

Ac-[ßNLys-Phe] ${ }_{8}-\mathrm{NH}_{2}$

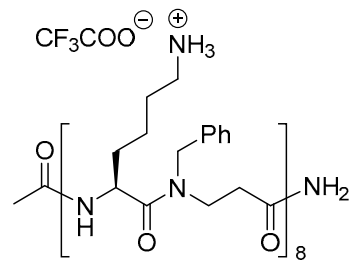

Ac-[Lys- $\beta N$ Phe $]_{8}-\mathrm{NH}_{2}$

Figure 11. Oligomers assembled by MW-assisted monomer-based SPS [211].

\subsubsection{Antimicrobial Activity of $\alpha$-Peptide/Peptoid Hybrids}

In a preliminary brief study by Olsen et al. $\alpha$-peptide/ $\beta$-peptoid hybrids (12-mers) with an alternating cationic/hydrophobic design, displaying Lys or hArg in combination with $\alpha$-chiral $\beta N$ spe or achiral $\beta N P h e$ residues, were tested for antibacterial activity [215]. The oligomer Ac-[hArg- $\beta N P h e]_{6}-\mathrm{NH}_{2}$ was most potent against both E. coli (ATCC 11229) and S. aureus (ATCC 6633) with MIC values of $2.9 \mu \mathrm{M}$ and $11.3 \mu \mathrm{M}$, respectively [215].

Next, a clear correlation between increasing oligomer length and antibacterial activity was established for Lys-based hybrids, i.e., Ac-[Lys- $\beta N s p e]_{n}-\mathrm{NH}_{2}(\mathrm{n}=5-8)$, against both Gram-positive (MRSA and VRE) and Gram-negative bacteria (E. coli and P. aeruginosa) [216]. The 16-mer in this series only displayed high activity against P. aeruginosa (MIC of $4.7 \mu \mathrm{M}$ ), thereby appearing to be a potential lead compound with a narrow antibacterial spectrum [216]. A requirement for at least 12 residues to confer activity was seen in two series of hArg-based oligomers, incorporating $\alpha$-chiral and achiral $\beta$-peptoid residues (i.e., Ac-[hArg- $\beta N$ spe $]_{n}-\mathrm{NH}_{2}$ and $A c-[h A r g-\beta-N P h e]_{n}-\mathrm{NH}_{2}$ ). When tested against MRSA (ATCC 33591) Ac-[hArg- $\beta N_{s}$ spe $]_{7}-\mathrm{NH}_{2}$ proved to be the most potent analog $(\mathrm{MIC}=2.7 \mu \mathrm{M})$, whereas most 12 - to 16 -mers displayed almost equal MICs $(2.5-5 \mu \mathrm{M})$ against E. coli (ATCC 25922). The general trend is that guanidino-containing compounds are more potent than the corresponding amino-functionalized oligomers (except against $P$. aeruginosa). Introduction of $\alpha$-chirality in the $\beta$-peptoid residues induces a 2 - to 4 -fold increase in activity 
toward MRSA, which in part may be ascribed to the concomitant incorporation of several methyl groups, thereby increasing hydrophobicity [216]. Noticeably, even for the 16-mers in each series the hemolytic activity remained low $\left(\mathrm{HC}_{10}>500 \mu \mathrm{g} / \mathrm{mL}\right)$. In addition, two 12-mers with increased hydrophobicity, obtained via incorporation of $\alpha$-chiral cyclohexyl-containing $\beta$-peptoid units (i.e., $\beta N s c e$ ), were examined: for Ac-[hArg- $\beta N$ sce $]_{6}-\mathrm{NH}_{2}$ high antimicrobial activity (e.g., MIC of $1.6 \mu \mathrm{M}$ against VRE) was accompanied by considerable hemolytic activity $\left(\mathrm{HC}_{10}=25 \mu \mathrm{g} / \mathrm{mL}\right)$, whereas the mixed analog Ac-[hArg- $\beta N$ sce-Lys- $\beta N$ spe $]_{3}-\mathrm{NH}_{2}$ had an activity profile similar to that of hArg-based oligomers while retaining low hemolytic activity.

Despite an observed low hemolytic activity independently of length and type of cationic $\alpha$-amino acid, prehemolytic alterations in the morphological appearance of erythrocytes were more pronounced for longer analogs containing hArg and/or $\alpha$-chiral $\beta$-peptoid residues [216,221]. Comparison of 16-mer oligomers indicated that Lys-based hybrids are 4-fold less cytotoxic than the corresponding hArg analogs when tested against HeLa cells [216].

In another study [217], also including some food-borne bacteria and clinical ESBL-producing E. coli strains, Ac-[hArg- $\beta$ Nspe $]_{6}-\mathrm{NH}_{2}$ and Ac-[hArg- $\beta N \mathrm{NPhe}_{6}-\mathrm{NH}_{2}$ exhibited MIC values of $1.5-6 \mu \mathrm{M}$ against E. coli (ATCC 25922 and ESBL-producers), Listeria monocytogenes, Vibrio spp., K. pneumoniae (ATCC 13883) and S. aureus (8325). By contrast, Ac-[Lys- $\beta \mathrm{Nspe}_{8}-\mathrm{NH}_{2}$ was less active against S. aureus and K. pneumoniae (MIC of 19 and $38 \mu \mathrm{M}$, respectively). Again, a strong correlation between length and increased potency was observed for a Lys/hArg mixed series: Ac-[Lys- $\beta N$ spe-hArg- $\beta N s p e]_{n}-\mathrm{NH}_{2}$ $(n=2-4)$ with the 8-mer being weekly active, while the 12-mer was potent (MIC of 3-6 $\mu \mathrm{M})$ toward most bacteria except S. aureus and K. pneumoniae (MIC $24 \mu \mathrm{M}$ ), whereas the 16-mer had MIC values of 1-9 $\mu \mathrm{M}$ against most bacteria in the test panel [217]. These findings confirm that approx. 12 residues constitute the minimum length required for substantial antibacterial activity of peptidomimetics belonging to this class. The only bacterium in the test panel that appears to be inherently resistant to these peptidomimetics is Serratia marcescens (also resistant to colistin) [217].

Moreover, an ATP leakage assay on S. aureus showed that the intracellular ATP content decreased rapidly to a constant low level in the presence of shorter analogs (8- and 12-mers), but was depleted immediately upon exposure to a 16-mer, which infers that the mode of action of these peptidomimetics involves different degrees of membrane permeabilization or disruption depending on the oligomer length [217]. In a model study of membrane interactions a high abundance of guanidino groups (e.g., in Ac-[hArg- $\beta N$ spe $]_{6}-\mathrm{NH}_{2}$ ) was found to promote enhanced perturbation (as compared to that of Ac-[Lys- $\left.\beta N_{s p e}\right]_{6}-\mathrm{NH}_{2}$ ) of monolayers of a typical outer-leaflet constituent (1,2-dipalmitoyl-sn-glycero-3-phosphatidylglycerol; DPPG) of Gram-positive cell membranes. Interestingly, there was no significant difference in the ability of the hArg- and Lys-based oligomer to interact with lipopolysaccharide Kdo2-lipid A monolayers mimicking the surface layer of Gram-negative cell envelopes [226]. A proposed interpretation is that both amino- and guanidino-containing compounds may have similar self-promoted mechanism of penetrating the LPS layer via displacement of bivalent metal cations with an ensuing destabilization of the integrity of the LPS layer. As a result of this the relative antibacterial activity of these two subtypes of peptidomimetics against Gram-negative bacteria appears to rely on their different ability to compromise the integrity of the inner membrane [226]. A direct comparison of Ac-[Lys- $\beta N$ spe $]_{6}-\mathrm{NH}_{2}$ and Ac-[hArg- $\beta \mathrm{Nspe}_{6}-\mathrm{NH}_{2}$ against a panel of pathogens showed that the hArg-based oligomer was 2- to 8-fold more active against Gram-negative species while it had 4- to 16-fold higher potency toward Gram-positive bacteria [226], which further corroborates previous findings that guanidino groups promote activity against Gram-positive bacteria [215-217].

Staphylococcus epidermidis is a common cause of nosocomial infections associated with surface colonization of indwelling devices such as catheters. Hence, an array of peptidomimetics, representing different lengths of subsets of oligomers displaying either Lys, hArg or Lys/hArg as the cationic residues, was tested against planktonic and biofilm cultures of methicillin-resistant S. epidermidis [222]. For Lys-containing subclasses Ac-[Lys- $\beta N s p e]_{n}-\mathrm{NH}_{2}$ 
( $\mathrm{n}=10-16)$ and Ac-[Lys- $\beta N$ spe-hArg- $\beta N$ spe $]_{n}-\mathrm{NH}_{2}(\mathrm{n}=1-4)$ the MIC values against planktonic bacteria decreased markedly with increasing oligomer length (MICs in the range 0.3-2.1 $\mu \mathrm{M}$ for 12-mers and longer analogs). On the other hand, all members of hArg-based subclasses, i.e., Ac-[hArg- $\beta N$ spe $]_{n}-\mathrm{NH}_{2}$ and Ac-[hArg- $\left.\beta N P h e\right]_{n}-\mathrm{NH}_{2}(\mathrm{n}=5-8)$, displayed high activity (MICs in the range $0.4-1.8 \mu \mathrm{M}$ ) with the dodecamers being the most potent. Time-kill experiments (at 2 or $4 \times$ MIC) revealed that fast-growing S. epidermidis was efficiently killed within $1-5 \mathrm{~h}$ by all tested subtypes, while bactericidal effect on slow-growing stationary-phase cells required 3-24 h depending on oligomer length and subtype. Importantly, at their MICs (measured in biofilm medium) representatives of all the above subtypes prevented formation of S. epidermidis biofilm, with Ac-[hArg- $\beta \mathrm{Nspe}_{6}-\mathrm{NH}_{2}$ being the most efficient, since treatment with $1.4 \mu \mathrm{M}$ led to $100 \%$ reduction of biomass. However, eradication of young (6-h-old) biofilm could only be achieved at concentrations 10 to 20 times the MIC, whilst complete killing of mature (24-h-old) biofilm required even higher concentrations [222]. In order to assess their potential clinical utility, the effect of 12- and 16-mers on cell viability was determined in HeLa cells, and the two dodecamers Ac-[Lys- $\beta \mathrm{Nspe}_{6}-\mathrm{NH}_{2}$ and Ac-[Lys- $\beta N$ spe-hArg- $\beta N$ spe $]_{3}-\mathrm{NH}_{2}$ were found to be least toxic $\left(\mathrm{IC}_{50}>1000 \mu \mathrm{M}\right.$ and $295 \mu \mathrm{M}$, respectively). Lack of $\alpha$-chirality in Ac-[hArg- $\beta N P h e]_{6}-\mathrm{NH}_{2}$ was beneficial, since it was 3 -fold less cytotoxic as compared to Ac-[hArg- $\left.\beta N_{\text {spe }}\right]_{6}-\mathrm{NH}_{2}\left(\mathrm{IC}_{50}\right.$ values of $96 \mu \mathrm{M}$ versus $\left.32 \mu \mathrm{M}\right)$ [222].

A follow-up study elaborated on the factors determining antibacterial activity versus cytotoxicity for $\alpha$-peptide/ $\alpha$-peptoid and $\alpha$-peptide/ $\beta$-peptoid oligomers displaying Lys and hArg residues as alternating cationic components [120]. An array of such achiral and $\alpha$-chiral hybrids with oligomer lengths of 10,12 and 14 residues was examined. All designs conferred high activity (MICs in the range 1-4 $\mu \mathrm{M}$ ) toward E. coli (ATCC 25922 and MDR strains) for oligomers with a minimum length of 12 residues. For A. baumannii a more clear length-activity correlation was observed with $\sim 4$-fold increase in potency by each elongation with a dimeric unit (with the 14-mer Ac-[Lys-Nspe-hArg-Nspe $]_{3}$-Lys-Nspe- $\mathrm{NH}_{2}$ being the most active: $\mathrm{MIC}=1 \mu \mathrm{M}$ ); a similar trend was seen for VRE (with Ac-[Lys-Nspe-hArg- $\mathrm{Nspe}_{3}-\mathrm{NH}_{2}$ displaying highest potency: MIC $=2 \mu \mathrm{M}$ ). By contrast, a generally reduced potency (MICs in the range 8-128 $\mu \mathrm{M}$ ) was observed against S. aureus [120]. Investigation of cytotoxic side effects of AMPs has often been confined to evaluation of hemolytic properties, however, this study infers that other relevant cell lines need to be considered as well, since even essentially non-hemolytic compounds were found to exert detrimental effects on e.g., HepG2, NIH 3T3 and human umbilical vein endothelial cells (HUVEC) at remarkably low concentrations $[120,211]$. In particular, HeLa cells were found to be extremely susceptible to longer oligomers: a 2.5- to 3.5-fold lowering of cell viability was seen for each added dimeric unit resulting in $\mathrm{IC}_{50}$ values below $100 \mu \mathrm{M}$ for all 14-mers, whereas 1.5- to 2-fold increments in cytotoxicity were seen for other cell lines with endothelial HUVEC being the most resistant benign cell type $\left(\mathrm{IC}_{50}\right.$ above $350 \mu \mathrm{M}$ for all 12-mers). Cytotoxicity of $\alpha$-peptide/ $\beta$-peptoid hybrids was only slightly increased as compared to that of the corresponding $\alpha$-peptoid-containing hybrids despite the presence of additional methylene units in the backbone, thus inferring that the number of side chains is more important than the distance between the $N$ - and $C$-termini. Moreover, introduction of $\alpha$-chiral side chains with concomitantly increased hydrophobicity resulted in more than 3-fold lowered viability (in terms of $\mathrm{IC}_{50}$ values) for all tested cell lines [120]. When targeting $E$. coli strains the best cell selectivity index ( $\mathrm{SI}=$ the mean $\mathrm{IC}_{50}$ divided by MIC) was found for the 12-mers Ac-[Lys-Nspe-hArg-Nspe $]_{3}-\mathrm{NH}_{2}$ and Ac-[Lys- $\beta N$ spe-hArg- $\beta N$ spe $]_{3}-\mathrm{NH}_{2}$ (SI > 450), while for $A$. baumannii the 14-mer analogs displayed best cell selectivity (SI $>65$ ). Thus, by careful optimization of oligomer length, presence/absence of peptoid chirality (and thus varying hydrophobicity and/or folding propensity), and balancing the ratio between Lys and hArg, potential lead compounds against MDR E. coli strains were identified [120].

Yet another optimization strategy, involving modification of the $\mathrm{N}$-terminus of these peptidomimetics, has been explored [218]. Introduction of $N$-terminal hydrophobic acyl moieties in Ac-[Lys- $\beta N$ spe-hArg- $\beta N$ spe $]_{3}-\mathrm{NH}_{2}$, displaying only a moderate activity against MDR Gram-positive bacteria (MIC $=16 \mu \mathrm{M}$ against MRSA and VRE [120]) led to remarkably increased activity against 
MRSA and VRE with typical MIC values of 1-2 $\mu \mathrm{M}$. Interestingly, the potency against $E$. coli (ATCC 25922 and MDR strains) was unaffected by modification with polycationic, PEG-like, or hydrophobic (aliphatic, aromatic and fluorous) moieties, whereas the activity toward A. baumannii was improved 4- to 8-fold (to MICs of 1-2 $\mu \mathrm{M}$ ) by appending polycationic or hydrophobic/fluorous moieties [218]. Increasing the cationicity via modification with spermine-acetyl was beneficial for the activity toward MRSA and VRE (4- and 16-fold improved MICs). Despite increased cytotoxicity against NIH 3T3 cells and HUVEC, the optimized peptide analogs exhibited promising cell selectivity (SI $~ 400-600$ ). However, it is striking that even though several analogs displayed similar cytotoxicity against HUVEC and NIH 3 T3 cells, they exhibited quite different hemolytic properties. For example, adamantylacetyl and decanoyl derivatives had 4- to 10 -fold lower $\mathrm{HC}_{50}$ as compared to the compounds modified with the overall most favorable hydrophobic activity-inducing (against Gram-positive bacteria) cyclohexylacetyl and pentafluorophenylacetyl groups. Interestingly, the hemolytic properties could be correlated to the hydrophobicity as measured by retention on reversed-phase analytical HPLC ( $\mathrm{C}_{18}$ column), where a certain acetonitrile concentration at peak elution could be defined as the upper threshold below which hemolysis was negligible. Hence, end group modification constitutes a powerful tool for improving potency of a moderately active compound, albeit it is necessary to include a thorough investigation of possible cytotoxic side effects [120,218].

The impact of the backbone design of peptidomimetics was explored by testing an array comprising 16-mer $\alpha$-peptides, $\beta^{3}$-peptides, $\alpha$ - and $\beta$-peptoids as well as hybrids with alternating $\alpha$-amino acids and unnatural residues. All compounds shared a common sequential display of cationic and hydrophobic side chains (Lys- and Phe-like) [211]. Test against four E. coli (ATCC 25922 and MDR) strains revealed that hybrids, consisting of alternating sequences of $\alpha$-amino acids and unnatural residues, exhibited superior antibacterial activity as compared to the $\alpha$-peptides (very hemolytic and cytotoxic), $\beta^{3}$-peptides and both types of peptoids. The two most active hybrids were Ac-[Lys-NPhe $]_{8}-\mathrm{NH}_{2}$ and Ac-[Lys- $\left.\beta N P h e\right]_{8}-\mathrm{NH}_{2}$ (MICs of $2-8 \mu \mathrm{M}$ ) that both were weakly hemolytic $\left(\mathrm{HC}_{10}>128 \mu \mathrm{M}\right)$, albeit the $\alpha$-peptoid-containing analog was less cytotoxic against HeLa cells than the slightly more hydrophobic $\beta$-peptoid-based analog ( $\mathrm{IC}_{50}$ of 100 and $26 \mu \mathrm{M}$, respectively) [211]. Such comparative investigations of different types of backbones may in fact constitute a powerful general optimization strategy although most previous work on antibacterial peptidomimetics concern specific subclasses.

A study focused on Ac-[Lys-NPhe $]_{8}-\mathrm{NH}_{2}$ showed that it exhibited activity against a range of Gram-negative pathogens (MICs in the range 0.2-10 $\mu \mathrm{M}$ ) [109]. Time-kill experiments at its MIC showed that killing was surprisingly slow $(>3 \mathrm{~h}$ ) including a lag period of approx. $1 \mathrm{~h}$. This infers that alternative mechanisms involving interference with intracellular processes are likely to contribute significantly to the killing at the MIC, while a mode of action involving outer membrane permeabilization and partial depolarization of the inner membrane appeared to be dominating at higher concentrations. Also, prevention of biofilm formation in several Gram-negative bacteria was seen even at subMIC levels. Moreover, after continuous exposure of E. coli to subinhibitory concentrations this peptidomimetic proved less prone to induce resistance development as compared to standard antibiotics (e.g., ciprofloxacin, gentamicin, cefotaxime and imipenem). Another intriguing feature of Ac-[Lys-NPhe $]_{8}-\mathrm{NH}_{2}$ is its anti-inflammatory effect, which proved similar to that of IDR-1018 [227] with respect to inhibition of the LPS-induced pro-inflammatory response of neutrophils (IL-6 and TNF- $\alpha$ secretion was abolished in the presence of $20 \mu \mathrm{g} / \mathrm{mL}$ of both compounds) [109]. Overall, the antibacterial effect of this peptidomimetic appears to involve multiple mechanisms with a simultaneous prevention of exacerbated immune response to pro-inflammatory components released from Gram-negative pathogens upon killing [109].

Most recently, 21 variants of $\mathrm{H}$-[Lys- $\beta N P h e]_{16}-\mathrm{NH}_{2}$ were investigated with emphasis on the influence of hydrophobicity, fluorination and distribution of cationic/hydrophobic residues on antibacterial activity against Gram-positive and Gram-negative bacteria versus hemolytic properties and cytotoxicity [219]. The array comprised subsets of analogs (12- and 16-mers) displaying: 
(i) variable side chain length of cationic residues, (ii) substitution in the aromatic $\beta$-peptoid units, and (iii) alternative distribution patterns of cationic/hydrophobic residues. An interesting correlation between oligomer length and activity toward the Gram-positive S. pseudintermedius (a major pathogen associated with infections in dogs) was observed, since most 12-mers were either equally or more potent (up to 4-fold lower MICs) than the corresponding 16-mers. Shortening of the cationic side chain (e.g., Lys $\rightarrow$ Dab) conferred slightly increased hydrophobicity that led to an unexpected decrease in activity against S. pseudintermedius, whereas the presumed opposite tendency was found for the other Gram-positive bacteria tested (i.e., S. aureus and VRE); this modification also induced hemolytic properties $\left(\mathrm{HC}_{10}=19 \mu \mathrm{M}\right)$ [219]. Introduction of hydrophobicity-increasing substituents (Me, one or three $\mathrm{F}$ atoms or a $\mathrm{CF}_{3}$ group) likewise conferred increased potency against Gram-positive bacteria, but the concomitant enhancement of hemolytic properties was considerably more pronounced except for the analogs displaying a single fluorine at the 4-position in the $\beta$-peptoid residues. In particular this 16-mer displayed promising activity towards both Gram-positive and Gram-negative species (MICs of 0.8-1.6 $\mu \mathrm{M}$ and 1.6-3.2 $\mu \mathrm{M}$, respectively). However, it affected the viability of NIH 3T3 cells $\left(\mathrm{IC}_{50}=132 \mu \mathrm{M}\right)$ more than the 4-Me substituted analog $\left(\mathrm{IC}_{50}=527 \mu \mathrm{M}\right)$, albeit the latter was much more hemolytic $\left(\mathrm{HC}_{10}=2.6 \mu \mathrm{M}\right)$, thus again highlighting the discrepancy between hemolysis and cytotoxicity toward other mammalian cells. In addition, comparison of the different arrangements of cationic and hydrophobic residues (alternating, pairwise and complete segregation at each terminus) revealed that analogs with an alternating display possess the overall most favorable activity profiles [219]. These findings confirm that for this class of peptidomimetics hydrophobicity must be kept below a certain threshold level to retain satisfactory cell selectivity. Indeed a low degree of fluorination appears to be beneficial as it promotes general antibacterial activity with only a minor effect on toxicity toward mammalian cells [219]. Table 6 shows the activity profiles for some of the most active $\alpha$-peptide/ $\beta$-peptoid hybrids.

Table 6. Antimicrobial and hemolytic activity of representative $\alpha$-peptide/ $\beta$-peptoid hybrids.

\begin{tabular}{|c|c|c|c|c|c|}
\hline \multirow{2}{*}{ Compound } & \multicolumn{5}{|c|}{ MIC (in $\mu \mathrm{M}$ ) Hemolysis (in $\mu \mathrm{M}$ ) } \\
\hline & S. aureus & E. coli & P. aeruginosa & $\mathrm{HC}_{10}$ & Refs. \\
\hline Ac- $[\text { Lys- } \beta N \text { spe }]_{8}-\mathrm{NH}_{2}$ & 37 & 9.1 & 4.7 & $>500$ & [216] \\
\hline Ac-[hArg- $\beta N P h e]_{6}-\mathrm{NH}_{2}$ & 5.9 & 1.5 & - & $>500$ & {$[216,217]$} \\
\hline Ac-[hArg- $\left.\beta N_{s p e}\right]_{6}-\mathrm{NH}_{2}$ & 2.8 & 2.8 & - & $>500$ & {$[216,217]$} \\
\hline Ac-[Lys- $\beta N$ Phe-hArg- $\beta N P h e]_{4}-\mathrm{NH}_{2}$ & 32 & 1 & - & - & [120] \\
\hline cHex-[hArg- $\beta N$ spe-Lys- $\beta N$ spe $]_{4}-\mathrm{NH}_{2}$ & 1 & 2 & - & $600^{a}$ & [218] \\
\hline Ac-[Lys- $\beta N(4-F-P h e)]_{8}-\mathrm{NH}_{2}$ & 0.8 & 3.2 & 1.6 & $>150$ & [219] \\
\hline
\end{tabular}

Intriguingly, the antibacterial activity of $\alpha$-peptide/ $\beta$-peptoid peptidomimetics (e.g., Ac-[hArg- $\beta N P h e]_{6}-\mathrm{NH}_{2}$ ) against $E$. coli was found to be potentiated by the presence of plasma with a typical lowering of the MICs by one order of magnitude, whereas testing in medium containing heat-inactivated plasma led to slightly lowered potency. A similar effect was observed for a membrane-active AMP, while the activity of two AMPs with intracellular targets was unaffected by plasma [220]. A similar enhancement effect of plasma (but not of serum) on the activity of these peptidomimetics was subsequently observed for a range of pathogenic Gram-positive and Gram-negative bacteria [113]. Typically, both MICs and MBCs were 2- to 16-fold lower when obtained at a plasma concentration that in itself did not exert membrane disruption as visualized by scanning electron microscopy [113]. Consequently, the traditional MIC determinations in growth medium (e.g., MHB) used for initial evaluation of the clinical relevance of a given membrane-active compound may in fact overestimate the concentrations required for in vivo proof-of-concept experiments. Although E. coli mutants with stable resistance could be selected for by adaptive evolution experiments [110], testing of these in the presence of plasma resulted in MICs of the peptidomimetics similar to those found against the original wild-type strain used in the adaption experiment [110]. Moreover, the acquisition of resistance towards these peptidomimetics seem to be 
specific as it did not confer cross-resistance to a number of AMPs including LL-37, which is part of the human innate immune defense [110]. Thus, in combination with the favorable synergistic interactions with plasma components these findings significantly increase the therapeutic potential of these peptidomimetics.

While Ac-[Lys-NPhe $]_{8}-\mathrm{NH}_{2}$ exerted anti-inflammatory effects at concentrations of 5-10 $\mu \mathrm{M}$ [109], lipidated analogs of Ac-[Lys- $\beta N$ spe $]_{8}-\mathrm{NH}_{2}$ blocked LPS-induced cytokine secretion from human leukocytes at nanomolar concentrations comparable to the effect of polymyxin B [223]. Additionally, these fatty acid-conjugated peptidomimetics were capable of neutralizing the response to LTA, which constitutes a major pro-inflammatory membrane component of Gram-positive bacteria. Overall the most promising compound was Pam-[Lys- $\beta N$ spe $]_{6}-\mathrm{NH}_{2}$ : for LPS and LTA neutralisation the IC 50 values measured for IL-6 secretion were $60 \mathrm{nM}$ and $0.85 \mu \mathrm{M}$, respectively; with a selectivity index of 400 based on its cytotoxicity toward leukocytes. This immunomodulatory activity is dependent on a high content of Lys residues and acylation with a long-chain fatty acid (e.g., palmitoylation) as well as on sufficient oligomer length (at least 12 residues). In contrast to many lipidated AMPs these peptidomimetics exhibited lower antibacterial activity (MICs of 8-16 $\mu \mathrm{M}$ ) as compared to the parent oligomer [223]. Moreover, Pam-[Lys- $\beta N$ spe] $]_{6}-\mathrm{NH}_{2}$ was recently identified as a promising selective inhibitor of human neutrophil activation via formyl peptide receptor 2 (FPR2) [225]. Thus, FPR2-induced NADPH-oxidase responses (e.g., superoxide release and degranulation) were antagonized by Pam-[Lys- $\beta N$ spe $]_{6}-\mathrm{NH}_{2}$ with a potency $\left(\mathrm{IC}_{50}=50 \mathrm{nM}\right)$ similar to that of the previously most efficient peptide, the gelsonin-derived PBP10 $\left(\mathrm{IC}_{50}=60 \mathrm{nM}\right)$ [225]. The related analog Lau-[Lys- $\beta N$ spe $]_{6}-\mathrm{NH}_{2}$ was found to be a potent antagonist of the mouse orthologue Fpr2, thereby establishing these compounds as the first class displaying selective cross-species activity, which enable exploration of the role of FRP2 in regulation of immunological processes via mouse models [228]. This novel class of selective FPR2 antagonists constitutes potential lead compounds for development of novel anti-inflammatory drugs. A SAR study of an array of lipidated analogs displaying a headgroup with two hydrophobic tails led to identification of Lau-[(S)-Aoc]-[Lys- $\beta N P h e]_{6}-\mathrm{NH}_{2}$ as a potent FPR2 agonist capable of activating both human and mouse neutrophil NADPH-oxidase (EC 50 of 167 nM and $82 \mathrm{nM}$, respectively) [224]. The structural requirements for potent agonistic interaction proved to be very specific: (i) analogs displaying slightly shorter or longer fatty acids, e.g., decanoyl or myristoyl instead of lauroyl, had significantly reduced potency, (ii) replacement of (S)-2-aminooctanoic acid (Aoc) with analogs having shorter/longer alkyl side chains were devoid of activity, and (iii) incorporation of $(R)$-Aoc also compromised activity [224]. This subclass of lipidated $\alpha$-peptide/ $\beta$-peptoid hybrids appears to constitute a valuable tool for future studies of FPR2 signalling in vivo as well as a source of potential leads for development of prophylactic anti-infectives that stimulate neutrophils towards enhanced phagocytosis of bacteria.

\section{5. $\beta^{3}$-Peptides}

$\beta^{3}$-Peptides constitute interesting antimicrobial candidates as they may possess stable secondary structures and are resistant to proteolytic degradation. In fact three distinct helical conformations have been identified for $\beta$-peptides, with the helix type depending on the substitution pattern on the $\beta^{3}$-amino acid residues [229-231]. The early work on antibacterial $\beta^{3}$-peptide oligomers comprise contributions by the groups of DeGrado in 1999 [232], Gellman in 2000 [233], and of Seebach in 2001 [230]. In general $\beta^{3}$-amino acids were assembled by standard Fmoc-based SPS; in Figure 12 some typical examples of residues are shown, while the synthesis of the building blocks will be briefly discussed below. 
<smiles>CCCCCCC(C)CC(C)NCC</smiles><smiles>CCCCC(=O)CC(NC(C)C)C(C)C</smiles><smiles>CCNC(CC(=O)CC)C(C)CC</smiles>

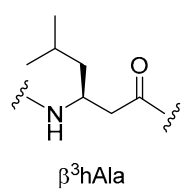<smiles>CC(C)CCC(=O)CC1Cc2ccccc2CN1</smiles><smiles>CC(=O)CC1Cc2ccc(O)cc2CN1</smiles>

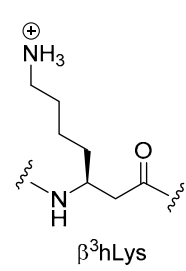

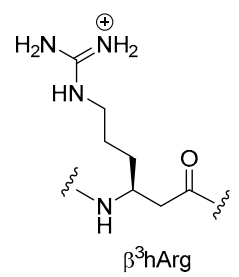<smiles>CCNC1CNCC1C(=O)CC</smiles><smiles>CCC(=O)C1CCCC1NC(C)C</smiles>

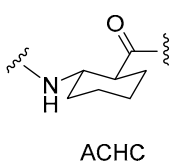

Figure 12. Typical $\beta^{3}$-amino acid residues in designed antibacterial and antifungal $\beta^{3}$-peptides.

\subsubsection{Synthesis of $\beta^{3}$-Amino Acid Building Blocks}

Although several suitably protected $\beta^{3}$-amino acid building blocks are commercially available they are usually exceedingly expensive due to their often quite elaborate total synthesis. However, simple acyclic compounds may be obtained via homologation of $\alpha$-amino acid derivatives, e.g., a convenient synthesis is based on Fmoc-protected pentafluorophenyl esters as depicted in Scheme 12 [234]. This procedure is chromatography-free and allows for the gram-scale preparation of building blocks corresponding to the acyclic residues depicted in Figure 12.

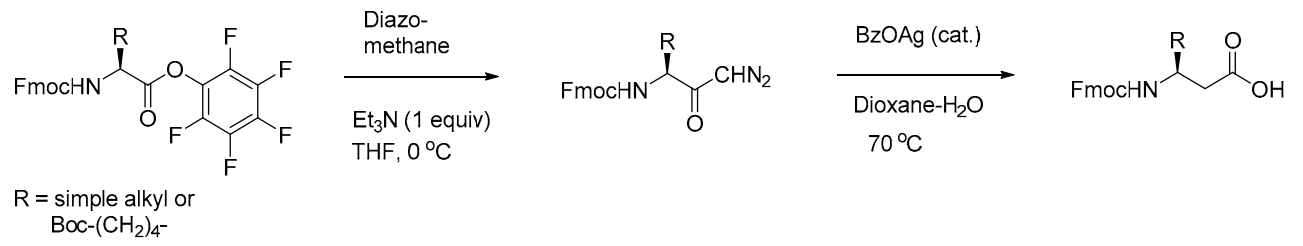

Scheme 12. Arndt-Eistert reaction of pentafluorophenyl esters with subsequent Wolff rearrangement of the $\alpha$-aminoacyldiazomethane intermediate to afford Fmoc-protected $\beta^{3}$-amino acid building blocks [234].

The building blocks corresponding to the cyclic residues APC and ACPC may readily be obtained in multigram scale from the corresponding commercially available $\beta$-keto ethyl esters by similar routes [235,236]. The synthetic sequence starts (shown for APC in Scheme 13) with a conversion into the corresponding enamine upon reaction with $(R)$ - $\alpha$-methylbenzylamine in the presence of acetic acid, followed by reduction in situ with sodium cyanoborohydride. The desired major isomer may be obtained as the corresponding hydrochloride in diastereomerically pure form via a two-step crystallization protocol from the mixture of four diastereomers produced. The subsequent alkaline ester hydrolysis, hydrogenolytic removal of the $(R)-\alpha$-methylbenzyl group, and Fmoc protection of the resulting amine can be performed in rapid succession to give the final product that can be purified by crystallization [236]. 

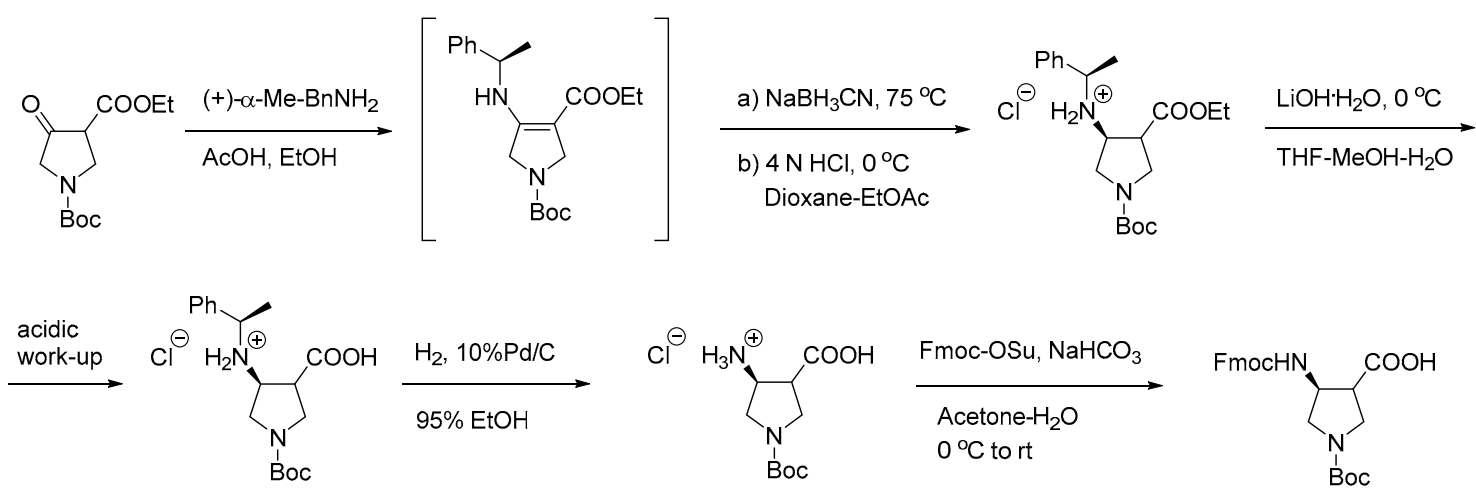

APC

Scheme 13. Synthesis of an Fmoc-protected cyclic $\beta^{3}$-amino acid building block [236].

\subsubsection{Antibacterial Activity of $\beta^{3}$-Peptides}

As only a very few works on the antibacterial activity of $\beta^{3}$-peptides have been reported during the last decade a brief account of the essential early findings is given together with the most recent contributions. The initial series of antimicrobial $\beta^{3}$-peptides reported by Hamuro et al. proved to be too hydrophobic to possess any cell selectivity for bacteria over erythrocytes [232]. Subsequently, it was shown that more polar analogs (e.g., $\mathrm{H}-\left[\beta^{3}-\mathrm{hAla}-\beta^{3} \mathrm{hLys}-\beta^{3}-\mathrm{hVal}\right]_{\mathrm{n}}-\mathrm{NH}_{2}, \mathrm{n}=4$ or 5 ) displayed lower antimicrobial activity (MICs of 26 and $20 \mu \mathrm{g} / \mathrm{mL}$, respectively), but with significantly less concomitant hemolytic properties $\left(\mathrm{HC}_{50}\right.$ values of 910 and $\left.320 \mu \mathrm{M}\right)$ [237]. In a related series of oligomers $\left(H-\left[\beta^{3} \mathrm{hAla}-\beta^{3} \mathrm{hLys}-\beta^{3} \mathrm{hPhe}\right]_{\mathrm{n}}-\mathrm{OH}, \mathrm{n}=3-6\right)$ only the 12 -mer showed moderate activity against $E$. coli and K. pneumoniae (MICs of 32-64 $\mu \mathrm{g} / \mathrm{mL}$ ) [230].

In the seminal work on amphipathic antibacterial $\beta^{3}$-peptides based on the constrained (3R,4S)-trans-4-aminopyrrolidine-3-carboxylic acid (APC) and $(R, R)$-trans-2-aminocyclopentane-carboxylic acid (ACPC), a 17-residue 12-helical oligomer (denoted $\beta$-17: Ac-[ACPC $]_{2}$-[APC-ACPC-APC-ACPC-ACPC $]_{3}-\mathrm{NH}_{2}$ ) was found to possess high antibacterial activity against E. coli ( $\mathrm{MIC}=6.3 \mu \mathrm{g} / \mathrm{mL})$, E. faecium ( $\mathrm{MIC}=12.5 \mu \mathrm{g} / \mathrm{mL}$ ) and S. aureus $(\mathrm{MIC}=3.2 \mu \mathrm{g} / \mathrm{mL})$ [238], while it was significantly less hemolytic $\left(\mathrm{HC}_{50} \sim 80 \mu \mathrm{g} / \mathrm{mL}\right)$ [238].

Although the non-hemolytic $\left(\beta^{3} \mathrm{hArg}\right)_{8}-\mathrm{NH}_{2}$ is devoid of antibacterial activity (against a panel of bacteria) it is able to penetrate the envelopes of E. coli and Bacillus megaterium [239], since confocal laser scanning microscopy (CLSM) of cells exposed to the 7-nitrobenzo-2-oxa-1,3-diazole (NBD)-labeled $\beta^{3}$-peptide showed a homogeneous intracellular distribution. Moreover, as NBD is a quenchable fluorescent probe it was possible to distinguish the internalized $\beta^{3}$-peptide from the surface-bound fraction by comparing the fluorescence intensity before and after addition of quenching agent (excess potassium iodide) [239].

Four lipo- $\beta^{3}$-peptides displaying palmitoyl (Pam) and lauroyl (Lau) moieties (i.e., $\quad$ Pam- $\beta^{3}$ hLys- $X-X-\beta^{3}$ hLys- $\mathrm{NH}_{2}, \quad X=\beta$-Ala, $\quad \beta^{3}$ hAla, $\quad \beta^{3}$ hLys; and Lau- $\beta^{3}$ hLys- $\beta^{3}$ hLeu- $\beta^{3}$ hLeu- $\beta^{3}$ hLys- $\mathrm{NH}_{2}$ ) were compared with the $\alpha$-peptide analogs, including partially D-amino acid substituted lipopeptides, with respect to their activities toward a panel of Gram-positive and Gram-negative bacteria [240]. Only minor differences were observed between the lipo- $\beta^{3}$-peptides and lipo- $\alpha$-peptides as well as analogs containing a single D- $\alpha$-amino acid [240]. Generally, Gram-positive bacteria proved more susceptible to these lipopeptides than Gram-negative bacteria, of which only E. coli strains proved moderately susceptible (MICs of $16-32 \mu \mathrm{g} / \mathrm{mL}$ ). The most active $\beta^{3}$-peptide was Pam- $\left[\beta^{3} \mathrm{hLys}\right]_{4}-\mathrm{NH}_{2}$ displaying MIC values in the range $4-32 \mu \mathrm{g} / \mathrm{mL}$ against the Gram-positive Enterococcus spp., S. aureus and S. epidermidis (including MRSA and MRSE), with the latter being most susceptible, however, no toxicity data were reported [240]. 


\subsubsection{Antifungal Activity of Helical $\beta^{3}$-Peptides}

In the last decade most research on antimicrobial $\beta^{3}$-peptides concern the design of short oligomers (9- and 10-mers) displaying trans-2-aminocyclohexanecarboxylic acid (ACHC) residues. Analysis by $\mathrm{CD}$ has shown that these oligomers typically adopt a 14-helical secondary structure (i.e., 14 atoms in the hydrogen-bonded ring). In the search for novel potential antifungal agents, these relatively short $\beta^{3}$-peptides (9-10 residues) have been extensively explored with particular focus on activity against Candida albicans and other pathogenic Candida species. Candida albicans is a commensal that may become an opportunistic pathogen causing life-threatening infections (e.g., mucosal candidiasis and invasive candidemia) especially in immunocompromised patients.

First, it was shown that designed 14-helical $\beta^{3}$-peptides exhibit considerable antifungal properties under CLSI-recommended conditions (i.e., physiological $\mathrm{pH}$ and ionic strength) where host-defense $\alpha$-peptides are inactive against fungal pathogens [241]. From an array of seven $\beta^{3}$-peptides, the decamer $\mathrm{H}-\beta^{3}$ hTyr-[ACHC- $\beta^{3}$ hVal- $\beta^{3}$ hLys $]_{3}-\mathrm{NH}_{2}$ was identified as the most favorable compound displaying a reasonably low MIC $(16 \mu \mathrm{g} / \mathrm{mL})$ combined with moderate hemolytic properties $(21 \%$ at the MIC) [241]. The 14-helix has ca. three residues per turn, and hence the repeating triad motif is expected to induce a globally amphipathic structure, in which the hydrophobic ACHC and $\beta^{3} \mathrm{hVal}$ residues are clustered on one side of the helix, while the cationic $\beta^{3}$ hLys residues are displayed on the opposite face. This class of antifungal agents may by virtue of its modular structure readily be designed towards improved activity. In a follow-up study, the antifungal activity of 14 -helical $\beta^{3}$-peptides was examined against both planktonic cells and biofilms [242]. Here, it was found that a non-amphipathic analog with a scrambled sequence was devoid of activity, while removal of the $N$-terminal $\beta^{3}$ hTyr residue afforded a significantly less hemolytic compound $\left(\mathrm{HC}_{10} \sim 100 \mu \mathrm{g} / \mathrm{mL}\right)$ with only slightly reduced antifungal activity (MIC 16-32 $\mu \mathrm{g} / \mathrm{mL}$ ). This truncated sequence was modified with a 7-methoxycoumarin fluorophore label via a short PEG linker without loss of activity, thereby enabling the use of confocal microscopy to study the interaction with $C$. albicans. It was found that the labelled $\beta^{3}$-peptide was distributed throughout the cytoplasm of primarily metabolically inactive cells inferring that its mode of action involves membrane disruption. Generally, significantly increased concentrations were required for killing of established biofilms (e.g., $512 \mu \mathrm{g} / \mathrm{mL}$ for coumarin-linker-[ACHC- $\left.\beta^{3} \mathrm{hVal}-\beta^{3} \mathrm{hLys}\right]_{3}-\mathrm{NH}_{2}$ ), however, at a concentration near its MIC this $\beta^{3}$-peptide completely prevented planktonic C. albicans cells from forming a biofilm, suggesting that $\beta^{3}$-peptides may be promising agents for preventing fungal colonization [242].

In order to further explore SARs of amphipathic 14-helical $\beta^{3}$-peptides an array of 25 compounds was designed to represent variations in hydrophobicity and helicity. This was ensured by including several simple hydrophobic $\beta^{3}$-amino acids (e.g., $\beta^{3} \mathrm{hAla}, \beta^{3} \mathrm{hVal}, \beta^{3} \mathrm{hIle}$, and $\beta^{3} \mathrm{hPhe}$ ) as well as the helix-stabilizing cyclic ACHC [243]. Hydrophobicity and helicity of the $\beta^{3}$-peptides were estimated by their retention in RP-HPLC and by their CD spectra, respectively. The presence of an ACHC residue in each triad of a putative 14-helix was found to be a prerequisite for a high degree of helicity, and at constant helicity increased hydrophobicity was associated with both increased antifungal and hemolytic activity. However, it was possible to identify a window of hydrophobicity in which the corresponding compounds exhibited both high antifungal activity and cell selectivity. Importantly, a detailed analysis of the data revealed a cooperative relationship between helicity and hydrophobicity that determines the antifungal and hemolytic activities of $\beta^{3}$-peptides [243]. The most active and selective $\beta^{3}$-peptides identified were $\mathrm{H}$-[ACHC- $\left.\beta^{3} \mathrm{hVal}-\beta^{3} \mathrm{hLys}\right]_{3}-\mathrm{NH}_{2}$ and the corresponding analog displaying $\beta^{3}$ hArg instead of $\beta^{3}$ hLys residues, which both exhibited an MIC of $8 \mu \mathrm{g} / \mathrm{mL}$ and less than $3 \%$ hemolysis at their MICs [243].

Next, an array of sixteen 14-helical $\beta^{3}$-peptides were found to be active against drug-resistant strains and clinical isolates of $C$. albicans as well as three other opportunistic Candida species, namely C. glabrata, C. parapsilopsis and C. tropicalis [244]. The three most active compounds (H- $\left[\mathrm{ACHC}-\beta^{3} \mathrm{hVal}-\beta^{3} \mathrm{hLys}\right]_{3}-\mathrm{NH}_{2}, \mathrm{H}-\left[\mathrm{ACHC}-\beta^{3} \mathrm{hVal}-\beta^{3} \mathrm{hArg}\right]_{3}-\mathrm{NH}_{2}$ and $\left.\mathrm{H}-\left[\mathrm{ACHC}-\beta^{3} \mathrm{hPhe}-\beta^{3} \mathrm{hLys}\right]_{3}-\mathrm{NH}_{2}\right)$ displayed MICs of $8-16 \mu \mathrm{g} / \mathrm{mL}$ against the MDR C. albicans 
strains and MICs of $2-32 \mu \mathrm{g} / \mathrm{mL}$ against the panel of Candida spp. with the most hydrophobic compound (i.e., H-[ACHC- $\beta^{3}$ hPhe- $\beta^{3}$ hLys $]_{3}-\mathrm{NH}_{2}$ ) being the most active (MICs of $2-8 \mu \mathrm{g} / \mathrm{mL}$ ). C. tropicalis and C. glabrata proved to be the most and least susceptible species, respectively [244]. Generally, an inverse relationship between hydrophobicity of a $\beta^{3}$-peptide and its MIC was seen for all Candida species, and a similar trend was seen for the hemolytic properties of the increasingly hydrophobic analogs H-[ACHC- $\left.\beta^{3} \mathrm{hVal}-\beta^{3} \mathrm{hLys}\right]_{3}-\mathrm{NH}_{2}, \mathrm{H}-\left[\mathrm{ACHC}-\beta^{3} \mathrm{hVal}-\beta^{3} \mathrm{hArg}\right]_{3}-\mathrm{NH}_{2}$ and $\mathrm{H}-\left[\mathrm{ACHC}-\beta^{3}\right.$ hPhe- $\beta^{3} \mathrm{hLys}_{3}-\mathrm{NH}_{2}$, displaying $\mathrm{HC}_{50}$ values of 161,77 and $15 \mu \mathrm{g} / \mathrm{mL}$, respectively. The MIC of H-[ACHC- $\beta^{3}$ hVal- $\beta^{3}$ hLys $]_{3}-\mathrm{NH}_{2}$ against 48 -h-old C. albicans biofilms was $128 \mu \mathrm{g} / \mathrm{mL}$, whereas prevention of biofilm formation could be achieved at the MIC against planktonic cells (i.e., at $16 \mu \mathrm{g} / \mathrm{mL}$ ); similar results were obtained for the most active $\beta^{3}$-peptides against $C$. glabrata, C. parapsilopsis and C. tropicalis biofilms [244].

Due to the relatively high toxicity of common antifungal drugs and the emerging resistance towards these, combination therapy appears as an appealing approach, which was explored by combining H-[ACHC- $\left.\beta^{3} \mathrm{hVal}-\beta^{3} \mathrm{hLys}\right]_{3}-\mathrm{NH}_{2}$ with fluconazole or ketoconazole [245]. Synergistically enhanced antifungal activity of these azoles was obtained with subMIC concentrations of $\beta^{3}$-peptide and azole, which proved efficient even against fluconazole-resistant $C$. albicans planktonic cells and azole-resistant biofilms; this dual treatment proved to be fungicidal after treatment for $48-72 \mathrm{~h}$. In vitro cytotoxicity of the $\beta$-peptide/azole combination was evaluated toward human HepG2 cells, for which viability was not significantly affected at the synergistic concentrations [245].

Recently, cytotoxicity of various antifungal $\beta$-peptides was investigated in vitro in the Caco- 2 and HepG2 mammalian cell lines [246]. In contrast to observations made for AMPs and antibacterial peptidomimetics, the most hydrophobic and relatively more hemolytic member tested (i.e., $\beta^{3}$ hTyr- $\left[\mathrm{ACHC}-\beta^{3} \mathrm{hPhe}-\beta^{3} \mathrm{hLys}\right]_{3}-\mathrm{NH}_{2}$ ) was the least cytotoxic toward Caco- 2 cells, while the most hydrophilic $\beta^{3}$-peptide (i.e., $\mathrm{H}$ - $\left.\left[\mathrm{ACHC}-\beta^{3} \mathrm{hVal}-\beta^{3} \mathrm{hLys}\right]_{3}-\mathrm{NH}_{2}\right)$ was least tolerated $\left(\mathrm{IC}_{50}\right.$ values of 53.2 and $27.3 \mu \mathrm{M}$, respectively). For HepG2 no clear trend was observed except that $\mathrm{H}$-[ACHC- $\left.\beta^{3} \mathrm{hVal}-\beta^{3} \mathrm{hLys}\right]_{3}-\mathrm{NH}_{2}$ despite its higher polarity affected viability most $\left(\mathrm{IC}_{50}\right.$ of $38.8 \mu \mathrm{M}$ ) [246]. Hence, the cell selectivity (ratio between $\mathrm{IC}_{50}$ and MIC) was in the range of 2-8 for the four tested compounds also comprising $\mathrm{H}-\left[\mathrm{ACHC}-\beta^{3} \mathrm{hVal}-\beta^{3} \mathrm{hArg}\right]_{3}-\mathrm{NH}_{2}$ and $\beta^{3} \mathrm{hTyr}-\left[\beta^{3} \mathrm{hVal}-\beta^{3} \mathrm{hVal}-\beta^{3} \mathrm{hArg}\right]_{3}-\mathrm{NH}_{2}$, which is considerably lower ( $\sim 10$ - to 100 -fold) than usually seen for optimized AMPs and antibacterial peptidomimetics.

Catheter-associated urinary tract infection (CAUTI) constitutes a common type of hospital-acquired infection that may be caused by $C$. albicans biofilm formation on the surfaces of urinary catheters. In view of the above-mentioned ability of antifungal $\beta^{3}$-peptides to kill C. albicans and prevent its biofilm formation under CLSI conditions [242,244], it was of interest to elucidate whether these properties were retained in the presence of urine, being a prerequisite for their potential clinical use in preventing fungal CAUTI. In a model study, a fluorescent $\beta^{3}$-peptide (i.e., coumarin-linker-[ACHC- $\left.\beta^{3} \mathrm{hVal}-\beta^{3} \mathrm{hLys}\right]_{3}-\mathrm{NH}_{2}$ [242]) was shown to remain as a stable 14-helix (inferred by $C D$ ) and to exhibit antifungal and anti-biofilm activity against $C$. albicans in a synthetic medium mimicking the composition of urine [247]. The $\beta^{3}$-peptide exhibited substantial antifungal activity in synthetic urine with a MIC of $16 \mu \mathrm{g} / \mathrm{mL}$ that was only 2-fold higher than its MIC under standard planktonic susceptibility testing conditions in RPMI medium. These promising findings prompted an investigation of whether this $\beta^{3}$-peptide could be loaded into polymeric thin film coatings on the intraluminal walls of urinary catheters, thereby creating a surface resistant to C. albicans colonization. In fact it proved possible to obtain such polymer-modified polyethylene, polyurethane, and silicone catheters that were capable of continuously releasing $\beta^{3}$-peptide into the intraluminal space [247]. Catheters coated with $\beta^{3}$-peptide-loaded polymer multilayers could eradicate planktonic fungal cells for up to 21 days of intermittent challenges with $C$. albicans, and prevent biofilm formation for at least $48 \mathrm{~h}$. This approach holds promise for development of new catheter materials that may reduce the incidence of fungal CAUTIs. In fact, coatings constructed from hyaluronic acid (HA) and chitosan $(\mathrm{CH})$ as well as coatings made-up of poly-L-lysine (PLL) and poly-L-glutamic acid (PGA) both 
served as reservoirs for the loading and sustained release of the above $\beta^{3}$-peptide [248]. Moreover, $\mathrm{CH} / \mathrm{HA}$ films exhibited inherent antifungal and antibiofilm activity in vitro and in vivo, which may be attributed to $\mathrm{CH}$ being a weak polycation. Nevertheless, the antifungal properties of both types of coatings were improved substantially when the $\beta^{3}$-peptide was incorporated. Catheter segments coated with $\beta^{3}$-peptide-loaded CH/HA or PLL/PGA films displayed efficient antifungal effects on planktonic $C$. albicans and substantially reduced formation of $C$. albicans biofilms both in vitro and in vivo using a rat model of central venous catheter infection [248].

\section{6. $\alpha$-Peptide/ $\beta^{3}$-Peptide Hybrids}

Inspired by previous work concerning design of antibacterial helical $\beta^{3}$-peptides [238], the group of Gellman explored $\alpha$-peptide $/ \beta^{3}$-peptide hybrids, consisting of L-Lys and L-Leu as well as the constrained (via five-membered rings) $\beta^{3}$-amino acids ACPC and APC in a 1:1 ratio, and with an alternating design (also referred to as $\alpha / \beta$-peptides). Such peptidomimetics typically adopt either a so-called 11-helix (i.e., 11 atoms in the hydrogen-bonded ring; ca. 3 residues per turn) or a 14/15-helix (ca. 4.5 residues per turn) [249]. Two 15-residue sequence isomers were designed to display an amphipathic 11-helix (i.e., H-APC-Leu-ACPC-Lys-ACPC-Leu-APC-Leu-ACPC-Lys-ACPC-Leu-APC-Leu-ACPC-NH ${ }_{2}$ ) or an amphipathic 14/15-helix (i.e., H-APC-Leu-ACPC-Leu-APC-Leu-ACPC-Lys-ACPC-Leu -ACPC-Lys-ACPC-Leu-APC-NH $\mathrm{N}_{2}$ ), respectively. For comparison a scrambled sequence (i.e., H-ACPC-Leu-APC-Lys-APC-Leu-ACPC-Lys-APC-Leu-ACPC-Leu-ACPC-Leu-ACPC- $\mathrm{NH}_{2}$ ), devoid of amphipathicity in either of these conformations, was included. Intriguingly, the isomer designed to adopt an amphipathic 14/15-helical conformation proved to be least active among the three $\alpha / \beta$-peptide isomers. Noticeably, the scrambled analog, designed not to possess amphipathicity in either helical conformation, was found to be the most potent isomer against E. coli, while the putative 11-helical isomer exhibited superior activity against Gram-positive E. faecium and S. aureus strains. This is contradictory to the trend seen for $\beta^{3}$-peptides, for which an amphipathic helical structure was essential for high antibacterial activity [238]. However, the most striking discovery was that the scrambled isomer was non-hemolytic at 15- to 30-fold higher concentrations than the two isomers designed to adopt helical conformations [249]. In a subsequent study, an alternative scrambled sequence (H-APC-Leu-APC-Leu-ACPC-Lys-ACPC-Leu-ACPC-Leu-APC-Leu-ACPC-Lys-ACPC-NH ${ }_{2}$ ) with a more even distribution of cationic residues along the sequence was investigated [241], while the original scrambled sequence displayed "longitudinal" amphipathicity with cationic residues clustered towards the $\mathrm{N}$-terminus [249]. However, similar activity profiles were seen for these two hybrids (MICs typically in the range 6.3-12.5 $\mathrm{\mu g} / \mathrm{mL}$ ). Another $\alpha / \beta$-peptide (i.e., H-APC-Leu-ACPC-Leu-APC-Leu-ACPC-Leu-APC-Leu-ACPC-Lys-ACPC-Leu-APC- $\mathrm{NH}_{2}$ ), designed to achieve more pronounced amphipathicity in a 14/15-helical conformation, displayed more potent activity against pathogenic bacteria (MICs of $12.5-25 \mu \mathrm{g} / \mathrm{mL}$ ), but remained hemolytic at the MIC [250]. Examination of a more polar set of isomeric $\alpha / \beta$-peptides displaying triple Leu $\rightarrow$ Ala substitutions (as compared to the original sequences) revealed that such changes gave rise to different effects on the relative antibacterial potency. For the pair designed to be amphipathic in the 11-helical conformation the Leu $\rightarrow$ Ala substitutions led to slightly lower activity against Gram-positive strains, while the effect for the putative amphipathic 14/15-helical pair was opposite, with the polar analog having generally improved activity (MICs of 3.1-12.5 $\mu \mathrm{g} / \mathrm{mL}$ ). Noticeably, the polar analog with an 11-helical amphipathic design was devoid of hemolytic activity even at $400 \mu \mathrm{g} / \mathrm{mL}$, while the polar 14/15-helical compound had an $\mathrm{HC}_{10}$ of $100 \mu \mathrm{g} / \mathrm{mL}$. By contrast, the Leu $\rightarrow$ Ala mutations in the scrambled isomer conferred a dramatic loss of activity [250]. Hence, design strategies toward antimicrobial oligomers with favorable cell selectivity should be extended to include peptidomimetics not displaying amphipathicity, albeit the outcome, in terms of whether a desirable overall activity profile may be achieved, appears to depend on the hydrophobicity of the compounds. Table 7 shows the activity profiles for some of the most active $\alpha$-peptide $/ \beta^{3}$-peptide hybrids. 
Table 7. Antimicrobial and hemolytic activity of representative $\alpha$-peptide $/ \beta^{3}$-peptide hybrids.

\begin{tabular}{lcccc}
\hline \multirow{2}{*}{ Compound } & \multicolumn{4}{c}{ MIC (in $\mu \mathrm{g} / \mathrm{mL}$ ) Hemolysis (in $\mu \mathrm{g} / \mathrm{mL})$} \\
\cline { 2 - 5 } & S. aureus & E. coli & HC $_{\mathbf{1 0}}$ & Ref. \\
\hline $\begin{array}{l}\text { H-ACPC-Leu-APC-Lys-APC-Leu-ACPC-Lys- } \\
\text { APC-Leu-ACPC-Leu-ACPC-Leu-ACPC-NH }\end{array}$ & 12.5 & 6.3 & 100 & {$[250]$} \\
\hline $\begin{array}{l}\text { H-APC-Leu-ACPC-Lys-ACPC-Ala-APC-Ala- } \\
\text { ACPC-Lys-ACPC-Ala-APC-Leu-ACPC-NH }\end{array}$ & 12.5 & 6.3 & $>400$ & {$[250]$} \\
\hline
\end{tabular}

\subsection{AApeptides}

AApeptides were first described by Cai et al. in 2011 [251]. They are oligomers of $N$-acetylated $\mathrm{N}$-aminoethylamino acid units, which are derived from the chiral peptide nucleic acid (PNA) backbone. AApeptides are divided into two main subclasses, namely $\alpha$-AApeptides [252] and $\gamma$-AApeptides [253], depending on the position of the side chain (Figure 1). Other subclasses include lipidated linear $\alpha$-AApeptides [254], lipidated cyclic $\alpha$-AApeptides [255], lipidated linear $\gamma$-AApeptides [256], cyclic $\gamma$-AApeptides [257], lipidated cyclic $\gamma$-AApeptides [258], sulfono- $\gamma$-AApeptides [259,260], and combinations of these [260]. AA-peptides are enzymatically stable, display excellent antimicrobial activity and show promise in many other biological applications such as cancer, Alzheimer's disease and biomaterial science [261]. AApeptides have recently been reviewed [261-263].

\subsubsection{Synthesis}

A general strategy for the synthesis of AApeptides is as follows: (i) Synthesis of AApeptide building blocks; (ii) Assembly on solid-phase; (iii) Optional lipidation and/or cyclisation on solid phase; (iv) Cleavage from resin, HPLC purification and lyophilisation [264].

\subsubsection{Synthesis of $\alpha$-AApeptides}

$\alpha$-AApeptides are synthesized by SPS using Fmoc-protected $\alpha$-AApeptide building blocks (Scheme 14). These building blocks are prepared by reductive amination involving the benzyl ester of the amino acid, Fmoc-glycine aldehyde and sodium cyanoborohydride. Following acylation of the intermediate with a carboxylic acid (e.g., 3-phenylpropionic acid), the benzyl protecting group is removed by hydrogenation to give the desired building block [264]. The $\alpha$-AApeptide sequence is then assembled by using standard Fmoc-based SPS with DIC/HOBt as coupling reagents.

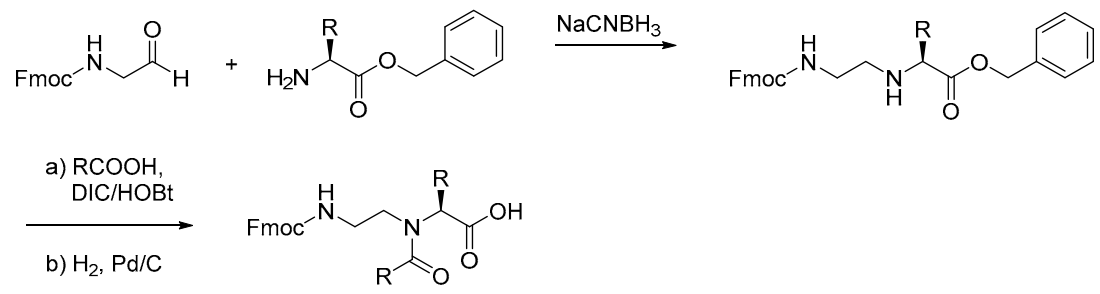

Scheme 14. General synthesis of $\alpha$-AApeptide building blocks [264].

\subsubsection{Synthesis of $\gamma$-AApeptides}

$\gamma$-AApeptides are synthesized by SPS using $N$-Alloc $\gamma$-AApeptide preformed building blocks [265], which may be prepared by two different routes; route $A$ is used when the side chain (R) is unprotected, while route B is employed when the side chain requires protection by an acid-labile group.

In route A (Scheme 15), the benzyl ester of glycine, an Fmoc-protected amino aldehyde and sodium cyanoborohydride are condensed, followed by hydrogenolysis and treatment with Alloc- $\mathrm{Cl}$ to give the protected $\gamma$-AApeptide building block. The first step of route B involves a reductive amination of glycine $t$-butyl ester with an Fmoc-protected amino aldehyde and sodium cyanoborohydride. Following reaction with Alloc-Cl, the $t$-butyl group is cleaved by $50 \%$ TFA in DCM. Alternatively, 
the Alloc group may be cleaved and acylated to generate a number of different backbone scaffolds, which can be employed in SPS [265]. The $\gamma$-AApeptide sequence is then assembled by using Fmoc-based SPS as shown in Scheme 16.

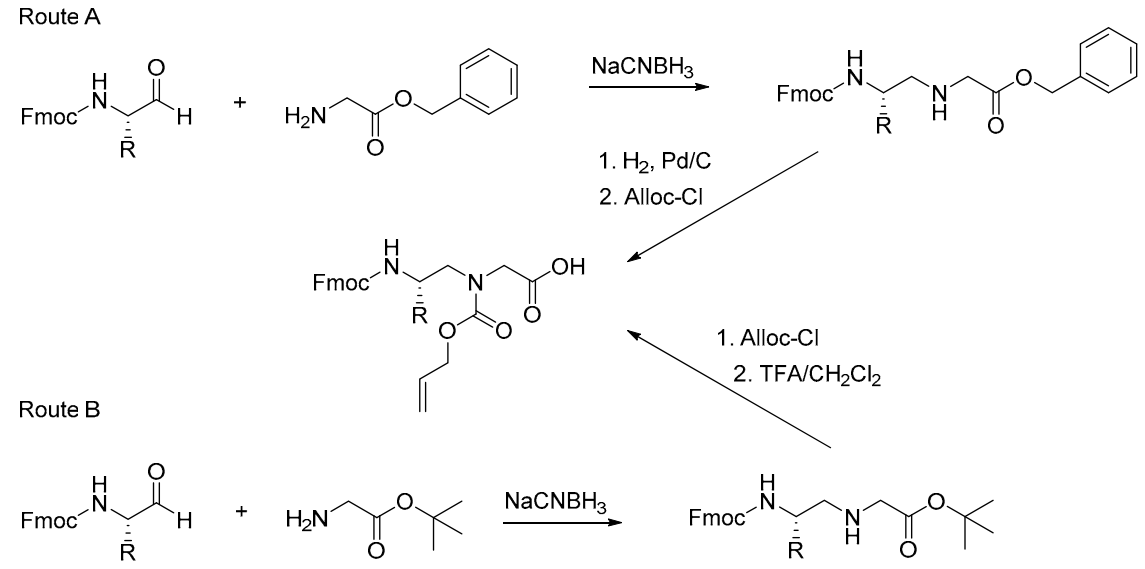

Scheme 15. Synthesis of $\gamma$-AApeptide building blocks by two different routes.

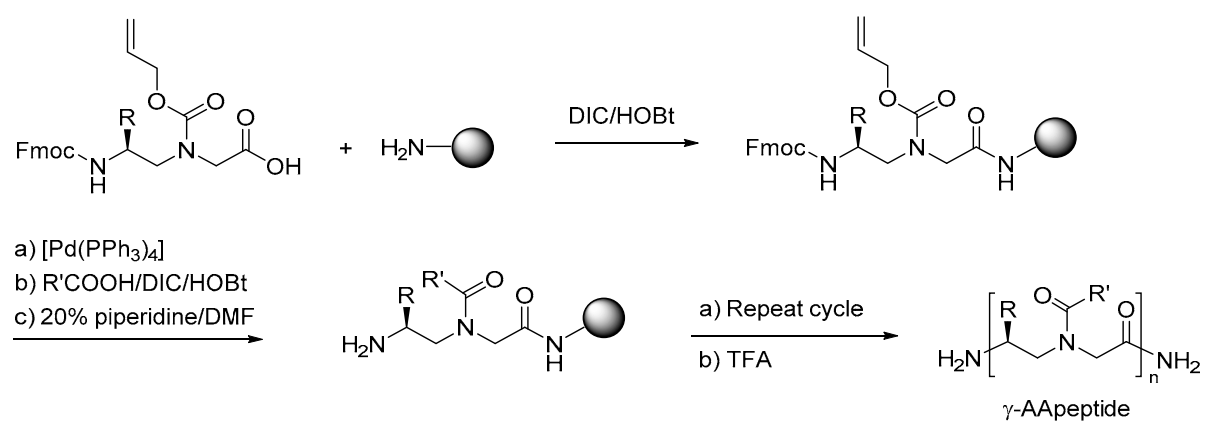

Scheme 16. $\gamma$-AApeptide oligomer assembly via Fmoc-based SPS; adapted from Teng et al. [261].

It is worth noting that both $\alpha$-AApeptides and $\gamma$-AApeptides may also be synthesized by submonomer approaches that circumvent the need for preparation of building blocks [266]. However, these approaches require many additional steps and results in significantly lower yields when synthesizing longer sequences [263].

\subsubsection{Antimicrobial Activity}

$\alpha$-AApeptides and $\gamma$-AApeptides

Padhee and co-workers first reported on the antimicrobial activity of $\alpha$-AApeptides [252]. The authors studied $\alpha$-AApeptides consisting of one to six cationic/hydrophobic building blocks (i.e., $N^{\alpha}$-(2-aminoethyl)- $N^{\alpha}$-(3-phenylpropanoyl)lysine), against different Gram-positive and Gram-negative bacteria. They found that the compound containing six of these $\alpha$-AApeptide residues exhibited the best activity against S. epidermidis (MIC of $4.6 \mu \mathrm{g} / \mathrm{mL}$ ) and B. subtilis (MIC of $1 \mu \mathrm{g} / \mathrm{mL}$ ). Furthermore, $\mathrm{HC}_{50}$ was found to be larger than $250 \mu \mathrm{g} / \mathrm{mL}$.

The antimicrobial activity of $\gamma$-AApeptides was first reported by Niu et al. [253]. They studied $\gamma$-AApeptides of different lengths $(n=3,5,7)$, and found that seven $\gamma$-AA residues are necessary for potent activity. The most potent compound proved to be $\gamma 5$ (Figure 13), which displayed MICs of $2-6.3 \mu \mathrm{g} / \mathrm{mL}$ against different MDR Gram-positive and Gram-negative bacteria, while $\mathrm{HC}_{50}$ was $300 \mu \mathrm{g} / \mathrm{mL}$.

Besides antibacterial activity, a number of other studies have revealed a potential for mimicking other biologically active peptides. Thus, a ten-residue $\gamma$-AApeptide mimic of Tat peptide 
(GRKKRRQRRRPQ) was able to bind to HIV TAR RNA and BIV TAR RNA with comparable selectivity and specificity to that of the Tat peptide [267]. Furthermore, $\gamma$-AApeptide mimics of RGD peptides (including ${ }^{64} \mathrm{Cu}$-labelled compounds) [268], and of fMLF [269] (a selective formyl peptide receptor agonist) have been reported. In addition, $\gamma$-AApeptides have been shown to disrupt A $\beta$ aggregation in Alzheimer's disease [270], and to have potential applications in biomaterial science [271].

\section{Lipidated Linear AApeptides and Lipocyclic AApeptides}

Lipidation is a well-known approach for increasing the interaction between an antimicrobial peptide and the bacterial envelope. A series of lipidated $\alpha$-AApeptides, carrying two-six residues and a fatty acid attached to the $C$-terminus were reported by Hu et al. [254]. The most active compound, consisting of five $\mathrm{N}$-(4-aminobutanoyl)- $\mathrm{N}$-(2-aminoethyl)-L-phenylalanyl trimeric units and carrying a $C_{16}$ lipid tail, showed MICs of 4-12 $\mu \mathrm{g} / \mathrm{mL}$ against different Gram-positive and Gram-negative bacteria, while $\mathrm{HC}_{50}$ was $250 \mu \mathrm{g} / \mathrm{mL}$.

Daptomycin and colistin are two naturally occurring cyclic lipopeptide antibiotics, used for treatment of Gram-positive and Gram-negative infections, respectively. In recent years, considerable efforts have aimed at designing less toxic antimicrobial mimics of these compounds. The antimicrobial and hemolytic activity of six cyclic lipo- $\alpha$-AApeptides, containing 3-5 residues and a $\mathrm{C}_{6}, \mathrm{C}_{12}$ or $\mathrm{C}_{16}$ lipid tail, were investigated by Padhee et al. [255]. The most potent compound showed MICs of $1-10 \mu \mathrm{g} / \mathrm{mL}$ against Gram-positive and Gram-negative bacteria and an $\mathrm{HC}_{50}$ of $150 \mu \mathrm{g} / \mathrm{mL}$. The authors also conducted mechanistic studies, and this compound was able to permeate MRSA membranes (as indicated by staining with 4',6-diamidino-2-phenylindole dihydrochloride and propidium iodide), indicating loss of membrane potential or lysis. Furthermore, the authors showed that the lead compound can mimic host-defense peptides by antagonizing Toll-like receptor 4 (TLR4)-induced responses via suppressing secretion of proinflammatory cytokines.

In a follow-up study [258], the authors showed that lipidated cyclic $\gamma$-AApeptides display potent antibacterial activity against clinically relevant bacteria. The best compound, YL-36 (Figure 13), showed MICs of 1-3 $\mu \mathrm{g} / \mathrm{mL}$ against different Gram-positive and Gram-negative bacteria, while $\mathrm{HC}_{50}$ was $100 \mu \mathrm{g} / \mathrm{mL}$. Increasing the ring size did not improve the antimicrobial activity. The above lipidated cyclic $\gamma$-AApeptides have also been tested against planktonic cells and biofilms of S. epidermidis and $P$. aeruginosa. In comparison with ciprofloxacin they performed equally well in preventing formation of biofilm of Gram-positive and Gram-negative bacteria [272]. The authors also studied how lipidated cyclic $\gamma$-AApeptides disrupt bacterial membranes by electron paramagnetic resonance, which suggested that they act through a carpet mechanism [273].

Sulfono- $\gamma$-AApeptides are peptidomimetics that are oligomers of $\mathrm{N}$-sulfono-acylated $\mathrm{N}$-aminoethyl amino acids [259]. Li et al. synthesized 15 analogs displaying different length and distribution of hydrophobic/cationic residues. Longer oligomers, containing additional cationic and hydrophobic groups, were more potent than shorter ones. The most active compound was an eight-mer, which showed MIC values of 2-4 $\mathrm{g} / \mathrm{mL}$ against Gram-positive and Gram-negative bacteria as well as an $\mathrm{HC}_{50}$ of $100 \mu \mathrm{g} / \mathrm{mL}$. This compound killed MRSA and E. coli within 30 and $60 \mathrm{~min}$, respectively, when applied at $12 \times$ MIC. X-ray crystallography and 2D NMR analysis suggested that eight-mers of sulfono- $\gamma$-AApeptides adopt a well-defined helical structure in solution.

Recently, She et al. reported a related subclass of peptidomimetics (1:1 sulfono- $\gamma$-AA heterogeneous peptides) with antibacterial activity [260]. The best compound showed an MIC of $3 \mu \mathrm{g} / \mathrm{mL}$ against MRSA and $4 \mu \mathrm{g} / \mathrm{mL}$ against E. coli and K. pneumonia. Furthermore, the authors found a $\mathrm{HC}_{50}$ above $250 \mu \mathrm{g} / \mathrm{mL}$. Small-angle scattering experiments suggested that this compound adopts a helical structure. Time-kill experiments showed that the lead compound kills MRSA in $2 \mathrm{~h}$ at $16 \times$ MIC. Table 8 shows the activity profiles for selected AApeptides. 


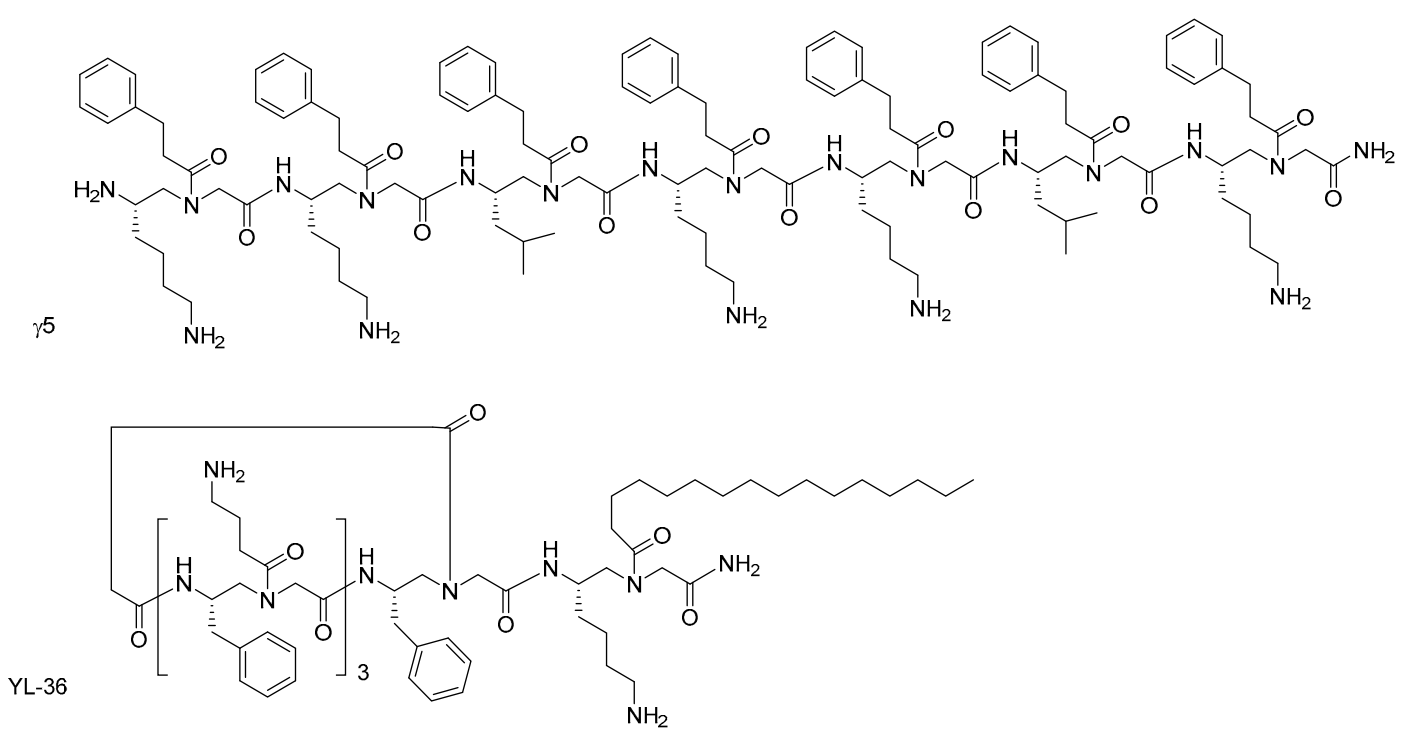

Figure 13. Most active compounds found in the studies by Niu [253] and Li [258].

Table 8. Antimicrobial and hemolytic activity of selected AApeptides (in $\mu \mathrm{g} / \mathrm{mL}$ ).

\begin{tabular}{|c|c|c|c|c|c|c|}
\hline \multirow[b]{2}{*}{ Compound type } & \multicolumn{6}{|c|}{ MIC Hemolysis } \\
\hline & ID & MRSA & P. aeruginosa & K. pneumonia & $\mathrm{HC}_{50}$ & Ref. \\
\hline$\alpha$-AApeptide & $\alpha 4$ & 4 & 8 & 8 & $>250$ & [274] \\
\hline$\gamma$-AApeptide & $\gamma-5$ & 5 & ND & 5 & 300 & [253] \\
\hline Cyclic $\gamma$-AApeptide & HW-B-13 & 1 & 8 & 8 & 100 & [257] \\
\hline Lipo- $\gamma-\mathrm{AA}$ & 13 & 3 & 3 & 3 & $>500$ & [256] \\
\hline Cyclic lipo- $\gamma$-AA & YL-36 & 2 & 5 & 3 & 100 & [258] \\
\hline Sulfono- $\gamma$-AApeptide & 7 & 2 & 4 & ND & 100 & [259] \\
\hline $1: 1 \alpha /$ sulfono- $\gamma$-AApeptide & 6 & 3 & 4 & 4 & $>250$ & [260] \\
\hline
\end{tabular}

\subsection{Oligo-Acyl-Lysyl Peptidomimetics (OAKs)}

Mor et al. introduced peptidomimetic sequences consisting of alternating acyl chains and cationic amino acids, termed oligo AQs (OAQs), where A represents a fatty acid of variable length while $\mathrm{Q}$ is a cationic amino acid. However, since the cationic amino acid often is lysine, they are now known as OAKs [275]. For reviews see Rotem and Mor [276] and Mor [277]. This class of peptidomimetics is composed of a small number of building blocks referred to as $\alpha_{\mathrm{i}}$ (acyl-lysyl) or $\beta_{\mathrm{i}}$ (lysyl-acyl-lysyl) subunits where i specifies the number of carbons in the acyl moiety. OAKs may display broad-spectrum antimicrobial activity against MDR bacteria $[278,279]$, selectivity against Gram-negative bacteria [280] as well as S. aureus [281]. Furthermore, OAKs displaying potent activity against Helicobacter pylori [282,283] and malaria parasites [284,285] have been reported.

\subsubsection{Synthesis}

OAKs are synthesized by standard Fmoc-based SPPS [286], e.g., by using $\mathrm{DIC} / \mathrm{HOBt}$ or $\mathrm{HBTU} / \mathrm{HOBt}$ as coupling reagents. Starting from an H-Lys(Boc)-4-methylbenzhydrylamine resin, the appropriate Fmoc-protected $\omega$-amino fatty acid, e.g., $N$-(9-fluorenylmethyloxycarbonyl)-10-amino-decanoic acid, is coupled to the $N^{\alpha}$-group of the resin-bound C-terminal Lys residue. The Fmoc group is then removed with $20 \%$ piperidine in DMF, yielding a basic $\alpha_{10}$ subunit. If a basic $\beta_{10}$ subunit is required another Fmoc-Lys(Boc)-OH is coupled and deprotected. The described process is repeated until the desired sequence is obtained. The product is then cleaved with $95 \%$ aqueous TFA using standard SPPS procedures, purified by preparative HPLC and lyophilized. In Figure 14 representatives of different subtypes of OAKs are depicted. 

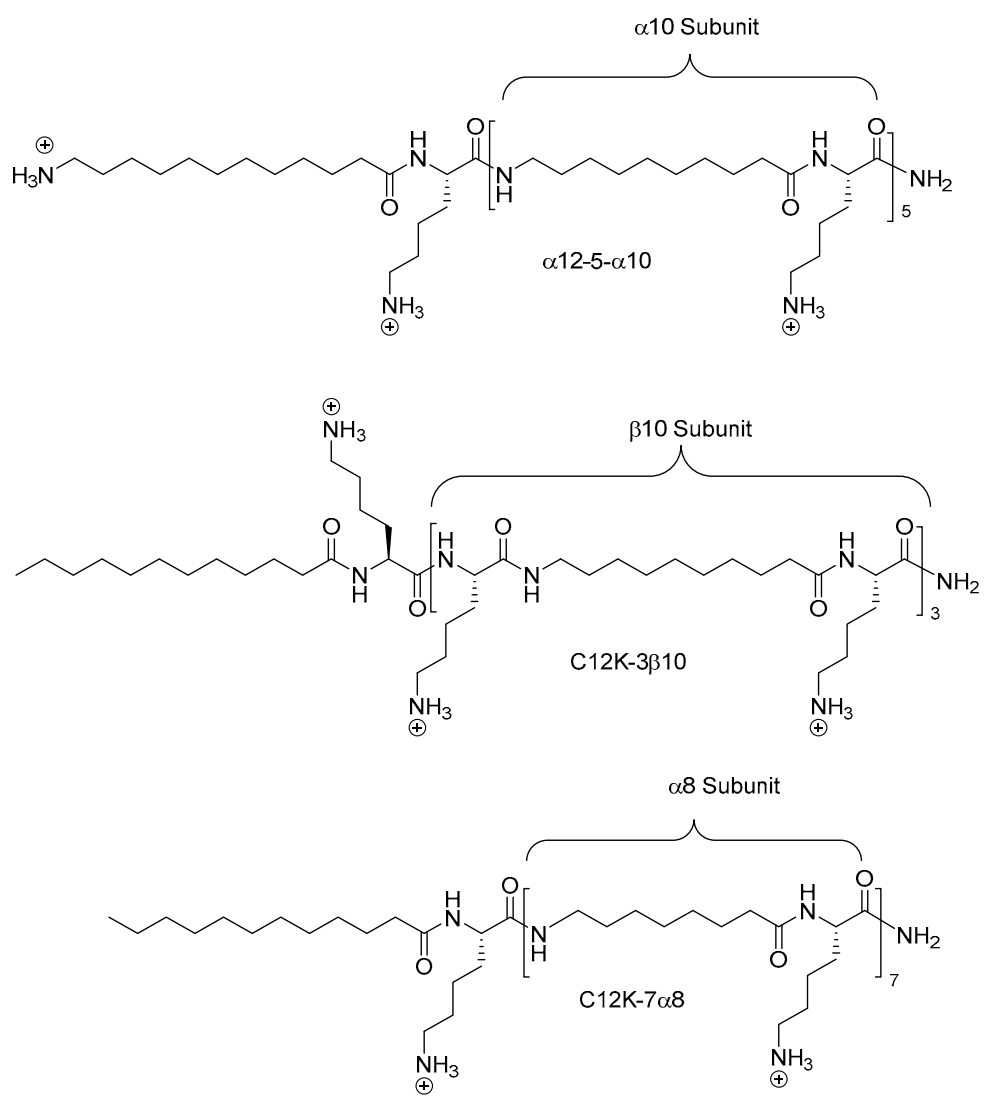

Figure 14. Representative OAK structures.

\subsubsection{Antimicrobial Activity}

Radzishevsky et al. described 16 OAKs [275] comprising the seven butyroyl-based $\mathrm{C}_{4} \mathrm{~K}(1-7) \alpha_{4}$, the seven octanoyl-based $C_{8} K(1-7) \alpha_{8}$ OAKs as wells as two substituted OAKs $\left(C_{12} K-7 \alpha_{4}\right.$ and $\left.C_{12} K-7 \alpha_{8}\right)$. The best compound was $\mathrm{C}_{12} \mathrm{~K}-7 \alpha_{8}$, which showed potent activity against most Gram-negative bacteria tested (MICs of 1.6-12.5 $\mu \mathrm{M}$ ), including Pseudomonas, Acinetobacter and Klebsiella spp. At $6 \times$ MIC, this compound was able to reduce E. coli bacterial populations from $10^{6}$ to $<50 \mathrm{CFU} / \mathrm{mL}$ within $1 \mathrm{~h}$, which is faster than both imipenem and ciprofloxacin. Furthermore, $\mathrm{C}_{12} \mathrm{~K}-7 \alpha_{8}$ displayed virtually no hemolytic activity.

The experimental conditions that enhance the potency of $\mathrm{C}_{12} \mathrm{~K}-7 \alpha_{8}$ against E. coli, Listeria monocytogenes and S. aureus were reported by Goldfeder et al. [287]. They found that the potency was proportionally affected by $\mathrm{pH}$ changes and subsided essentially throughout a wide range of salt concentrations and temperature values, whereas anti-staphyloccocal activity was relatively more vulnerable. The optimal incubation conditions resulted in a 16- to 32-fold reduction of the MIC value.

Livne et al. [279] determined the MIC of $\mathrm{C}_{12} \mathrm{~K}-7 \alpha_{8}$ in combination with different antibiotics against MDR strains of E. coli, and found that subMIC levels of $C_{12} \mathrm{~K}-7 \alpha_{8}$ acted synergistically with several antibiotics. Single-dose administration of erythromycin co-encapsulated in $\mathrm{C}_{12} \mathrm{~K}-7 \alpha_{8}$-based cochleates was effective in systemic treatment of neutropenic mice infected with lethal inoculums of MDR E. coli. In a follow-up study, Sarig et al. [288] compared the encapsulation efficiency in different lipid mixtures with $\mathrm{C}_{12} \mathrm{~K}-7 \alpha_{8}$ in the presence and absence of erythromycin. They showed that the in vivo activity of $\mathrm{C}_{12} \mathrm{~K}-7 \alpha_{8}$ and erythromycin against MDR bacteria can be enhanced significantly by incorporating the drugs into cochleates as compared to their activity in the absence of lipid.

Epand et al. [289] used light microscopy to screen for cochleate formation in several OAK-lipid systems including $\mathrm{C}_{12} \mathrm{~K}-7 \alpha_{8}$, while freeze-fracture electron microscopy was employed to assess their 
morphological features and size. They found that in OAK-based lipid systems, cochleate formation is enhanced by dehydration of the membrane interface and a high melting temperature.

A structure-activity study of 103 OAKs, designed to assess the importance of charge and hydrophobicity was reported by Radzishevsky [290]. They systematically modified both the acyl length (butanoyl, octanoyl, or dodecanoyl) and the number of $\alpha$-subunits (1-9). The most active compound, $\mathrm{C}_{12}-2 \beta_{12}$, displayed an MIC of $3.1 \mu \mathrm{M}$ and $1.6 \mu \mathrm{M}$ against $E$. coli and $S$. aureus, respectively, while $\mathrm{HC}_{50}$ was $17 \mu \mathrm{M}$. The authors found that the butyryl- and octanoyl-based series were non-hemolytic and displayed activity when the charge was equal to or above +5 and the hydrophobicity corresponded to at least $45 \%$ acetonitrile in the eluent at peak elution on a $\mathrm{C}_{18}$ HPLC column. For the dodecanoyl-based OAKs, antibacterial activity was achieved already with the small compound $\mathrm{C}_{12} \mathrm{~K}-\alpha_{12}$ (charge +2 and hydrophobicity $\sim 56 \% \mathrm{MeCN}$ ) that had modest hemolytic activity. All longer derivatives showed a strong hemolytic activity and were inactive (MIC above $50 \mu \mathrm{M}$ ). The authors also noted that for a potent antibacterial activity $(<3.1 \mu \mathrm{M})$ against $E$. coli a sufficient hydrophobicity $(\sim 50 \% \mathrm{MeCN})$ and charge of $6.5 \pm 2$ are required. For $S$. aureus these numbers are the $48 \%$ and $4 \pm 1$, respectively.

Livne et al. [278] reported a structure-activity study of three series of OAKs, all having a lauroyl-lysyl at the N-terminus and 1-5 $\alpha$ - or $\beta$-subunits. Generally, the more hydrophobic $\alpha_{10}$-OAKs showed increased hemolytic properties and a tendency to aggregate with increasing length. The less hydrophobic $\beta_{10}$ series showed significantly less hemolytic activity and aggregation. The most active compound, $\mathrm{C}_{12} \mathrm{~K}-3 \beta_{10}$, displayed MICs of 3.1-6.2 $\mu \mathrm{M}$ against E. coli and P. aeruginosa and 1.6-12.5 $\mu \mathrm{M}$ against $A$. baumannii and Staphylococcus spp. Furthermore, $\mathrm{HC}_{50}$ was $>100 \mu \mathrm{M}$. The mode of action of $\mathrm{C}_{12} \mathrm{~K}-3 \beta_{10}$ was investigated, and this showed that its effects on $E$. coli and $S$. aureus are bactericidal and bacteriostatic, respectively.

The cell-wall interactions and the selective bacteriostatic activity of $C_{12(\omega-7)} \mathrm{K}-\beta_{12}$, which is 10 -fold more potent against Gram-positive bacteria, have been studied by isothermal titration calorimetry and permeabilization assays [291]. The authors found that in Gram-positive bacteria, $C_{12(\omega-7)} \mathrm{K}-\beta_{12}$ accumulates in the small periplasm followed by electrostatic interactions. However, $C_{12(\omega-7)} \mathrm{K}-\beta_{12}$ does not cross the outer membrane of Gram-negative bacteria, but acts by depositing on the LPS layer. A study by Kaneti et al. [281] describes the anti-staphylococcal synergistic activity observed between subinhibitory concentrations of $C_{12(\omega-7)} \mathrm{K}-\beta_{12}$ and several antibiotics (e.g., ciprofloxacin, gentamicin and $\beta$-lactams) targeting distinct cytoplasmic and extracellular molecular entities. These OAKs were able to improve the potency of oxacillin and piperacillin from MICs of $256 \mu \mathrm{g} / \mathrm{mL}$ to $0.256 \mu \mathrm{g} / \mathrm{mL}$, and it was suggested that transient membrane depolarization was the reason. In another study, similar results were obtained with $E$. coli, where $C_{12(\omega-7)} \mathrm{K}-\beta_{12}$ at subinhibitory concentrations enhanced the activity of erythromycin three orders of magnitude [292].

The antibacterial mechanism of action of a single OAK may vary among intra- and interspecies strains. Sarig et al. [293] investigated the mechanism of action of $C_{16(\omega-7)}-K_{K} C_{12}-K_{a m i d e}$, against a multispecies and multi-strain panel of bacteria. Mechanistic comparison between equally sensitive and related strains showed that death of one strain resulted from $C_{16(\omega-7)}-K_{K} C_{12}-K_{a m i d e}$ being able to disrupt the cell membrane permeability barrier, whereas the death of a related strain resulted from the direct interference of $\mathrm{C}_{16(\omega-7)}-\mathrm{KKC}_{12}-\mathrm{K}_{\text {amide }}$ with DNA functions, without detectable membrane damage.

Acyl-lysyl oligomers have shown activity against the gastric pathogen Helicobacter pylori. Makobongo et al. [282] screened fived OAKs for activity against $H$. pylori strain G27. The most active compound was $C_{12} \mathrm{~K}-2 \beta_{12}$, which displayed MIC and $\mathrm{MBC}$ (minimum bactericidal concentration) in the ranges of $6.5-26 \mu \mathrm{M}$ and $14.5-90 \mu \mathrm{M}$, respectively, across the six strains tested. At $2 \times \mathrm{MBC}$, $\mathrm{C}_{12} \mathrm{~K}-2 \beta_{12}$ completely killed $H$. pylori after $6-8 \mathrm{~h}$ of incubation in liquid cultures. Furthermore, the compound displayed only modest hemolytic activity (4-8\%) at $80 \mu \mathrm{M}$. In a follow-up study [283], the authors showed that $\mathrm{C}_{12} \mathrm{~K}-2 \beta_{12}$ rapidly permeabilizes the bacterial membrane and crosses the bacterial membranes into the cytoplasm and binds tightly to bacterial DNA, RNA, and proteins. 
Zaknoon et al. [284] reported the screening of more than 50 OAKs against the virulent malaria parasite Plasmodium falciparum. The most active compound was $\mathrm{C}_{12} \mathrm{~K}-2 \alpha_{8}$, which showed an $\mathrm{IC}_{50}$, of $0.3 \mu \mathrm{M}$ and no hemolytic activity at $150 \mu \mathrm{M}$. Furthermore, $\mathrm{C}_{12} \mathrm{~K}-2 \alpha_{8}$ significantly affected parasite growth in Plasmodium vinckei-infected mice. Table 9 shows the activity profiles for selected OAKs.

Table 9. Antimicrobial and hemolytic activity of selected OAKs (in $\mu \mathrm{M})$.

\begin{tabular}{cccccc}
\hline \multicolumn{5}{c}{ MIC Hemolysis } \\
\hline Compound & S. aureus & E. coli & P. aeruginosa & HC $_{50}$ & Ref. \\
\hline $\mathrm{C}_{12} \mathrm{~K}-7 \alpha_{8}$ & 50 & 1.6 & 6.2 & $>100$ & {$[275]$} \\
$\mathrm{C}_{12}-2 \beta_{12}$ & 1.6 & 3.1 & $\mathrm{ND}$ & 17 & {$[290]$} \\
$\mathrm{C}_{12} \mathrm{~K}-3 \beta_{10}$ & $1.6-12.5^{\text {a }}$ & $3.1-6.2^{\mathrm{b}}$ & $3.1-6.2^{\mathrm{c}}$ & $>100$ & {$[278]$} \\
\hline \multicolumn{7}{c}{${ }^{\mathrm{a}}$ Staphylococcus spp. $(\mathrm{n}=9),{ }^{\mathrm{b}}(\mathrm{n}=13),{ }^{\mathrm{c}}(\mathrm{n}=11)}$.
\end{tabular}

\section{Conclusions and Outlook}

In the present review, recent advances in development of antimicrobial peptidomimetics as potential drugs have been discussed with respect to accessibility via chemical synthesis and optimization strategies for obtaining compounds with an appropriate pharmacological profile. The key hurdles with peptidomimetics as therapeutics are: (i) availability; (ii) toxicity; (iii) bioavailability; and (iv) drug approval regulations (which applies to all antibiotics).

In order for synthetic peptidomimetics to be considered as actual drug entities they should be readily prepared in large scale, e.g., via assembly on solid phase by simple methods involving as few steps as possible. Hence, commercial availability and/or easy preparation of the starting materials constitute important factors when considering the practical utility of a class of peptidomimetics as a source of actual drugs; e.g., OAKs, peptoids and their peptide hybrids may be prepared efficiently from cheap starting materials, while assembly of $\beta^{3}$-peptides and AApeptides require more elaborate syntheses of building blocks. Also, simple designs consisting of a very few different residues may facilitate up-scaling by allowing for combination of solution-phase and solid-phase methods, e.g., via block syntheses.

Although many peptidomimetics exhibit excellent antimicrobial potency in vitro (i.e., MICs below $2 \mu \mathrm{M})$ with rapid killing of bacteria they may exert unexpected side effects when tested via in vivo animal models. Thus, peptides and peptidomimetics designed for optimal antimicrobial activity often possess undesired safety profiles since the properties promoting efficient bactericidal effect also to some extent confer increased toxicity toward mammalian cells including immediate immunogenic responses. These characteristics may explain why no peptidomimetics have reached the market yet.

Typically, chemical modification toward lower toxicity involves adjustment of hydrophobicity to below the critical threshold, and the conformation toward the most favorable secondary structure (appears to depend on the subclass). However, another key challenge is to deliver the antimicrobial drug to its target with high efficacy and few side effects, which may be addressed by development of appropriate formulations. This may involve e.g., conjugation to charge-reducing prodrug moieties [294] and/or shielding of the optimized molecule by PEGylation [295] or encapsulation in biocompatible polymer-based nanoparticles [296-299], which all may contribute to improvement of the efficacy-safety profile due to a lower required dose because of improved distribution into infected tissue.

Another promising prospective application for peptidomimetics is as potentiators of other antibiotics e.g., via membrane permeabilization conferring enhanced uptake of antibiotics thereby circumventing antimicrobial resistance arising from upregulated bacterial efflux or membrane modifications. Also, they may be employed for bacterial delivery of other antibiotics, e.g., antisense PNA oligomers. Peptidomimetics of AMPs display a number of other interesting activities such as anticancer activity [300], antibiofilm activity [184] and anti-inflammatory effects [223].

In order for antibiotic development to be attractive for the pharmaceutical industry the following are needed: (i) shorter time to market, and (ii) prolonged market exclusivity [20]. To this end, 
new regulatory incentives may stimulate the development of novel antibiotics. For example, the GAIN ACT (Generating Antibiotic Incentives Now), by which new antibiotics may be designated as QIDPs (Qualified Infectious Disease Products) if they target one or more of 20 critical pathogens. When these criteria are met such antibiotics may receive prolonged market exclusivity for up to 12 years. Another incentive is the Century Cures Act of 2015, allowing approval of new antibiotics based on studies in limited patient populations rather than full clinical trials [20].

In conclusion, recent progress in optimization of antimicrobial peptidomimetics combined with an increased focus on appropriate formulation for improved delivery may unleash the potential of antimicrobial peptidomimetics as future antibiotics.

Author Contributions: All co-authors contributed equally to writing this manuscript and preparing figures and tables.

Conflicts of Interest: The authors declare no conflict of interest.

\section{References}

1. O'Neill, J. Tackling Drug-Resistant Infections Globally: Final Report and Recommendations. 2016. Available online: https:/ /amr-review.org/sites/default/ files/160518_Final\%20paper_with\%20cover.pdf (accessed on 18 August 2017).

2. Pendleton, J.N.; Gorman, S.P.; Gilmore, B.F. Clinical relevance of the eskape pathogens. Expert Rev. Anti-Infect. Ther. 2013, 11, 297-308. [CrossRef] [PubMed]

3. Liu, Y.-Y.; Wang, Y.; Walsh, T.R.; Yi, L.-X.; Zhang, R.; Spencer, J.; Doi, Y.; Tian, G.; Dong, B.; Huang, X.; et al. Emergence of plasmid-mediated colistin resistance mechanism mcr-1 in animals and human beings in China: A microbiological and molecular biological study. Lancet Infect. Dis 2016, 16, 161-168. [CrossRef]

4. Xavier, B.B.; Lammens, C.; Ruhal, R.; Kumar-Singh, S.; Butaye, P.; Goossens, H.; Malhotra-Kumar, S. Identification of a novel plasmid-mediated colistin-resistance gene, mcr-2, in Escherichia coli, Belgium, June 2016. Eurosurveillance 2016, 21, 8-13. [CrossRef] [PubMed]

5. Meletis, G. Carbapenem resistance: Overview of the problem and future perspectives. Ther. Adv. Infect. Dis. 2016, 3, 15-21. [CrossRef] [PubMed]

6. Righi, E.; Peri, A.M.; Harris, P.N.A.; Wailan, A.M.; Liborio, M.; Lane, S.W.; Paterson, D.L. Global prevalence of carbapenem resistance in neutropenic patients and association with mortality and carbapenem use: Systematic review and meta-analysis. J. Antimicrob. Chemother. 2017, 72, 668-677. [CrossRef] [PubMed]

7. Foster, T.J. Antibiotic resistance in Staphylococcus aureus. Current status and future prospects. FEMS Microbiol. Rev. 2017, 41, 430-449. [CrossRef] [PubMed]

8. Endres, B.T.; Basseres, E.; Alam, M.J.; Garey, K.W. Cadazolid for the treatment of Clostridium difficile. Expert Opin. Investig. Drugs 2017, 26, 509-514. [CrossRef] [PubMed]

9. Flokas, M.E.; Karageorgos, S.A.; Detsis, M.; Alevizakos, M.; Mylonakis, E. Vancomycin-resistant Enterococci colonisation, risk factors and risk for infection among hospitalised paediatric patients: A systematic review and meta-analysis. Int. J. Antimicrob. Agents 2017, 49, 565-572. [CrossRef] [PubMed]

10. Kennedy, D. Time to deal with antibiotics. Science 2013, 342, 777. [CrossRef] [PubMed]

11. Watkins, R.R.; Smith, T.C.; Bonomo, R.A. On the path to untreatable infections: Colistin use in agriculture and the end of "last resort' antibiotics. Expert Rev. Anti-Infect. Ther. 2016, 14, 785-788. [CrossRef] [PubMed]

12. Larsen, J.; Clasen, J.; Hansen, J.E.; Paulander, W.; Petersen, A.; Larsen, A.R.; Frees, D. Copresence of tet(k) and tet $(\mathrm{m})$ in livestock-associated methicillin-resistant Staphylococcus aureus clonal complex 398 is associated with increased fitness during exposure to sublethal concentrations of tetracycline. Antimicrob. Agents Chemother. 2016, 60, 4401-4403. [CrossRef] [PubMed]

13. Collignon, $\mathrm{P}$. The importance of a one health approach to preventing the development and spread of antibiotic resistance. In One Health: The Human-Animal-Environment Interfaces in Emerging Infectious Diseases; Mackenzie, J.S., Jeggo, M., Daszak, P., Richt, J.A., Eds.; Springer: Berlin/Heidelberg, Germany, 2013; Volume 366, pp. 19-36.

14. Van Duijkeren, E.; Catry, B.; Greko, C.; Moreno, M.A.; Pomba, M.C.; Pyörälä, S.; Ružauskas, M.; Sanders, P.; Threlfall, E.J.; Torren-Edo, J.; et al. Review on methicillin-resistant Staphylococcus pseudintermedius. J. Antimicrob. Chemother. 2011, 66, 2705-2714. [CrossRef] [PubMed] 
15. Stegmann, R.; Burnens, A.; Maranta, C.A.; Perreten, V. Human infection associated with methicillin-resistant Staphylococcus pseudintermedius st71. J. Antimicrob. Chemother. 2010, 65, 2047-2048. [CrossRef] [PubMed]

16. Starlander, G.; Borjesson, S.; Gronlund-Andersson, U.; Tellgren-Roth, C.; Melhusa, A. Cluster of infections caused by methicillin-resistant Staphylococcus pseudintermedius in humans in a tertiary hospital. J. Clin. Microbiol. 2014, 52, 3118-3120. [CrossRef] [PubMed]

17. Czaplewski, L.; Bax, R.; Clokie, M.; Dawson, M.; Fairhead, H.; Fischetti, V.A.; Foster, S.; Gilmore, B.F.; Hancock, R.E.W.; Harper, D.; et al. Alternatives to antibiotics-A pipeline portfolio review. Lancet Infect. Dis. 2016, 16, 239-251. [CrossRef]

18. Dodds, D.R. Antibiotic resistance: A current epilogue. Biochem. Pharmacol. 2017, 134, 139-146. [CrossRef] [PubMed]

19. WHO. Global Action Plan for Antimicrobial Resistance; WHO: Geneva, Switzerland, 2015.

20. Sinha, M.S.; Kesselheim, A.S. Regulatory incentives for antibiotic drug development: A review of recent proposals. Bioorg. Med. Chem. 2016, 24, 6446-6451. [CrossRef] [PubMed]

21. Arzanlou, M.; Chai, W.C.; Venter, H. Intrinsic, adaptive and acquired antimicrobial resistance in Gram-negative bacteria. Essays Biochem. 2017, 61, 49-59. [CrossRef] [PubMed]

22. Keeling, P.J.; Palmer, J.D. Horizontal gene transfer in eukaryotic evolution. Nat. Rev. Genet. 2008, 9, 605-618. [CrossRef] [PubMed]

23. Tangden, T.; Adler, M.; Cars, O.; Sandegren, L.; Lowdin, E. Frequent emergence of porin-deficient subpopulations with reduced carbapenem susceptibility in ESBL-producing Escherichia coli during exposure to ertapenem in an in vitro pharmacokinetic model. J. Antimicrob. Chemother. 2013, 68, 1319-1326. [CrossRef] [PubMed]

24. Katayama, Y.; Ito, T.; Hiramatsu, K. A new class of genetic element, Staphylococcus cassette chromosome mec, encodes methicillin resistance in Staphylococcus aureus. Antimicrob. Agents Chemother. 2000, 44, 1549-1555. [CrossRef] [PubMed]

25. Mishra, N.N.; Yang, S.J.; Chen, L.; Muller, C.; Saleh-Mghir, A.; Kuhn, S.; Peschel, A.; Yeaman, M.R.; Nast, C.C.; Kreiswirth, B.N.; et al. Emergence of daptomycin resistance in daptomycin-naive rabbits with methicillin-resistant Staphylococcus aureus prosthetic joint infection is associated with resistance to host defense cationic peptides and mprf polymorphisms. PLoS ONE 2013, 8, e71151. [CrossRef] [PubMed]

26. Johnson, A.P.; Woodford, N. Global spread of antibiotic resistance: The example of new delhi metallo-beta-lactamase (NDM)-mediated carbapenem resistance. J. Med. Microbiol. 2013, 62, 499-513. [CrossRef] [PubMed]

27. Aminov, R.I. A brief history of the antibiotic era: Lessons learned and challenges for the future. Front. Microbiol. 2010, 1, 134. [CrossRef] [PubMed]

28. Butler, M.S.; Blaskovich, M.A.T.; Cooper, M.A. Antibiotics in the clinical pipeline at the end of 2015. J. Antibiot. 2017, 70, 3-24. [CrossRef] [PubMed]

29. Tsiodras, S.; Gold, H.S.; Sakoulas, G.; Eliopoulos, G.M.; Wennersten, C.; Venkataraman, L.; Moellering, R.C.; Ferraro, M.J. Linezolid resistance in a clinical isolate of Staphylococcus aureus. Lancet 2001, 358, 207-208. [CrossRef]

30. Bush, K. Investigational agents for the treatment of Gram-negative bacterial infections: A reality check. ACS Infect. Dis. 2015, 1, 509-511. [CrossRef] [PubMed]

31. Haney, E.F.; Mansour, S.C.; Hancock, R.E.W. Antimicrobial peptides: An introduction. In Antimicrobial Peptides: Methods and Protocols; Hansen, P.R., Ed.; Springer: New York, NY, USA, 2017; pp. 3-22.

32. Fan, L.L.; Sun, J.; Zhou, M.F.; Zhou, J.; Lao, X.Z.; Zheng, H.; Xu, H.M. Dramp: A comprehensive data repository of antimicrobial peptides. Sci. Rep. 2016, 6, 24482. [CrossRef] [PubMed]

33. Zasloff, M. Antimicrobial peptides of multicellular organisms. Nature 2002, 415, 389-395. [CrossRef] [PubMed]

34. Mojsoska, B.; Jenssen, H. Peptides and peptidomimetics for antimicrobial drug design. Pharmaceuticals 2015, 8, 366-415. [CrossRef] [PubMed]

35. Harris, F.; Dennison, S.R.; Phoenix, D.A. Anionic antimicrobial peptides from eukaryotic organisms. Curr. Protein Pept. Sci. 2009, 10, 585-606. [CrossRef] [PubMed]

36. Yeaman, M.R.; Yount, N.Y. Mechanisms of antimicrobial peptide action and resistance. Pharmacol. Rev. 2003, 55, 27-55. [CrossRef] [PubMed] 
37. Torcato, I.M.; Huang, Y.-H.; Franquelim, H.G.; Gaspar, D.; Craik, D.J.; Castanho, M.A.R.B.; Troeira Henriques, S. Design and characterization of novel antimicrobial peptides, r-bp100 and rw-bp100, with activity against Gram-negative and Gram-positive bacteria. Biochim. Biophys. Acta Biomembr. 2013, 1828, 944-955. [CrossRef] [PubMed]

38. Shai, Y.; Oren, Z. From "carpet" mechanism to de-novo designed diastereomeric cell-selective antimicrobial peptides. Peptides 2001, 22, 1629-1641. [CrossRef]

39. Wu, M.; Maier, E.; Benz, R.; Hancock, R.E.W. Mechanism of interaction of different classes of cationic antimicrobial peptides with planar bilayers and with the cytoplasmic membrane of Escherichia coli. Biochemistry 1999, 38, 7235-7242. [CrossRef] [PubMed]

40. Miteva, M.; Andersson, M.; Karshikoff, A.; Otting, G. Molecular electroporation: A unifying concept for the description of membrane pore formation by antibacterial peptides, exemplified with nk-lysin. FEBS Lett. 1999, 462, 155-158. [CrossRef]

41. Van't Hof, W.; Veerman, E.C.I.; Helmerhorst, E.J.; Amerongen, A.V.N. Antimicrobial peptides: Properties and applicability. Biol. Chem. 2001, 382, 597-619. [CrossRef]

42. Pokorny, A.; Birkbeck, T.H.; Almeida, P.F.F. Mechanism and kinetics of delta-lysin interaction with phospholipid vesicles. Biochemistry 2002, 41, 11044-11056. [CrossRef] [PubMed]

43. Huang, H.W. Action of antimicrobial peptides: Two-state model. Biochemistry 2000, 39, 8347-8352. [CrossRef] [PubMed]

44. Wimley, W.C. Describing the mechanism of antimicrobial peptide action with the interfacial activity model. ACS Chem. Biol. 2010, 5, 905-917. [CrossRef] [PubMed]

45. Fuertes, G.; Gimenez, D.; Esteban-Martin, S.; Sanchez-Munoz, O.L.; Salgado, J. A lipocentric view of peptide-induced pores. Eur. Biophys. J. 2011, 40, 399-415. [CrossRef] [PubMed]

46. Pasupuleti, M.; Schmidtchen, A.; Malmsten, M. Antimicrobial peptides: Key components of the innate immune system. Crit. Rev. Biotechnol. 2012, 32, 143-171. [CrossRef] [PubMed]

47. Sumi, C.D.; Yang, B.W.; Yeo, I.-C.; Hahm, Y.T. Antimicrobial peptides of the genus Bacillus: A new era for antibiotics. Can. J. Microbiol. 2014, 61, 93-103. [CrossRef] [PubMed]

48. Stevenson, C.L. Advances in peptide pharmaceuticals. Curr. Pharm. Biotechnol. 2009, 10, 122-137. [CrossRef] [PubMed]

49. Marques, M.A.; Citron, D.M.; Wang, C.C. Development of Tyrocidine A analogues with improved antibacterial activity. Bioorg. Med. Chem. 2007, 15, 6667-6677. [CrossRef] [PubMed]

50. Mosges, R.; Baues, C.M.; Schroder, T.; Sahin, K. Acute bacterial otitis externa: Efficacy and safety of topical treatment with an antibiotic ear drop formulation in comparison to glycerol treatment. Curr. Med. Res. Opin. 2011, 27, 871-878. [CrossRef] [PubMed]

51. Rabanal, F.; Cajal, Y. Recent advances and perspectives in the design and development of polymyxins. Nat. Prod. Rep. 2017, 34, 886-908. [CrossRef] [PubMed]

52. Awais, M.; Shah, A.A.; Hameed, A.; Hasan, F. Isolation, identification and optimization of Bacitracin produced by Bacillus sp. Pak. J. Bot. 2007, 39, 1303-1312.

53. Bacitracin. Available online: http://www.drugbank.ca/drugs/DB00626. (accessed on 18 August 2017).

54. Deegan, L.H.; Cotter, P.D.; Hill, C.; Ross, P. Bacterlocins: Biological tools for bio-preservation and shelf-life extension. Int. Dairy J. 2006, 16, 1058-1071. [CrossRef]

55. Humphries, R.M.; Pollett, S.; Sakoulas, G. A current perspective on daptomycin for the clinical microbiologist. Clin. Microbiol. Rev. 2013, 26, 759-780. [CrossRef] [PubMed]

56. Drug-drug Interaction Study to Investigate Interaction Between Amikacin and POL7080. Available online: https: / / clinicaltrials.gov / ct2/show / NCT02897869?term=pol7080\&rank=4 (accessed on 18 August 2017).

57. A First in Human Study of the Safety and Tolerability of Single and Multiple Doses of SPR741 in Healthy Volunteers. Available online: https:/ / clinicaltrials.gov/ct2/show /NCT03022175?term=spr741\&rank=1 (accessed on 18 August 2017).

58. Spero Therapeutics to Unveil Data on Potentiator Platform at ASM Microbe 2016. Available online: https: / sperotherapeutics.com/news/press-releases/spero-therapeutics-unveil-data-potentiatorplatform-asm-microbe-2016/ (accessed on 18 August 2017).

59. Greber, K.E.; Dawgul, M. Antimicrobial Peptides Under Clinical Trials. Curr. Top. Med. Chem. 2017, 17, 620-628. [CrossRef] [PubMed] 
60. Kosikowska, P.; Lesner, A. Antimicrobial peptides (AMPs) as drug candidates: A patent review (2003-2015). Expert Opin. Ther. Pat. 2016, 26, 689-702. [CrossRef] [PubMed]

61. Sierra, J.M.; Fusté, E.; Rabanal, F.; Vinuesa, T.; Viñas, M. An overview of antimicrobial peptides and the latest advances in their development. Expert Opin. Biol. Ther. 2017, 17, 663-676. [CrossRef] [PubMed]

62. Crowther, G.S.; Baines, S.D.; Todhunter, S.L.; Freeman, J.; Chilton, C.H.; Wilcox, M.H. Evaluation of NVB302 versus vancomycin activity in an in vitro human gut model of Clostridium difficile infection. J. Antimicrob. Chemother. 2013, 68, 168-176. [CrossRef] [PubMed]

63. Velden, W.J.; van Iersel, T.M.; Blijlevens, N.M.; Donnelly, J.P. Safety and tolerability of the antimicrobial peptide human lactoferrin 1-11 (hLF1-11). BMC Med. 2009, 7, 44. [CrossRef] [PubMed]

64. Zhang, W.; Li, Y.; Qian, G.; Wang, Y.; Chen, H.; Li, Y.Z.; Liu, F.; Shen, Y.; Du, L. Identification and characterization of the anti-methicillin-resistant Staphylococcus aureus WAP-8294a2 biosynthetic gene cluster from Lysobacter enzymogenes OH11. Antimicrob. Agents Chemother. 2011, 55, 5581-5589. [CrossRef] [PubMed]

65. C16G2 STAMP Program. Available online: http://www.c3jtherapeutics.com/technologies/c16g2/ (accessed on 18 August 2017).

66. Kaplan, C.W.; Sim, J.H.; Shah, K.R.; Kolesnikova-Kaplan, A.; Shi, W.Y.; Eckert, R. Selective membrane disruption: Mode of action of $\mathrm{C} 16 \mathrm{G} 2$, a specifically targeted antimicrobial peptide. Antimicrob. Agents Chemother. 2011, 55, 3446-3452. [CrossRef] [PubMed]

67. Soligenix Inc. SGX9 executive summary. Available online: http://www.soligenix.com/wp-content/ uploads/sgx94_executive_summary_032216.pdf (accessed on 18 August 2017).

68. A Study of DPK-060 to Investigate Clinical Safety and Efficacy in Patients With Acute External Otitis. Available online: https: / clinicaltrials.gov/ct2/show /NCT01447017?term=DPK-060\&rank=1 (accessed on 18 August 2017).

69. Study of PXL01 Versus Placebo to Inhibit Adhesion Formation After Flexor Tendon Surgery (PHSU02). Available online: https: / clinicaltrials.gov / ct2/show / NCT01022242?term=PXL01\&rank=1 (accessed on 18 August 2017).

70. Study of the Effects of Brilacidin Oral Rinse on Radiation-induced Oral Mucositis in Patients with Head and Neck Cancer (Brilacidin). Available online: https:/ clinicaltrials.gov / ct2/show / NCT02324335?term= Brilacidin\&rank=1 (accessed on 18 August 2017).

71. Phase 2B Dose-Ranging Study of PAC113 Mouthrinse in HIV Seropositive Individuals With Oral Candidiasis. Available online: https: / clinicaltrials.gov / ct2/show / NCT00659971?term=PAC113\&rank=1 (accessed on 18 August 2017).

72. Murepavavadin (POL7980). Available online: http://www.polyphor.com/products/pol7080 (accessed on 18 August 2017).

73. Pharmacokinetics, Safety and Efficacy of POL7080 in Patients With Ventilator Associated Pseudomonas Aeruginosa Pneumonia. Available online: https://clinicaltrials.gov/ct2/show / NCT02096328?term= pol7080\&rank=1 (accessed on 18 August 2017).

74. A Phase II Study to Evaluate the Efficacy and Safety of Two Doses of LTX-109 in Impetigo. Available online: https:/ / clinicaltrials.gov/ct2/show / NCT01803035 (accessed on 18 August 2017).

75. Saravolatz, L.D.; Pawlak, J.; Johnson, L.; Bonilla, H.; Saravolatz, L.D.; Fakih, M.G.; Fugelli, A.; Olsen, W.M. In vitro activities of LTX-109, a synthetic antimicrobial peptide, against methicillin-resistant, vancomycin-intermediate, vancomycin-resistant, daptomycin-nonsusceptible, and linezolid-nonsusceptible Staphylococcus aureus. Antimicrob. Agents Chemother. 2012, 56, 4478-4482. [CrossRef] [PubMed]

76. Nilsson, A.C.; Janson, H.; Wold, H.; Fugelli, A.; Andersson, K.; Hakangard, C.; Olsson, P.; Olsen, W.M. LTX-109 is a novel agent for nasal decolonization of methicillin-resistant and -sensitive Staphylococcus aureus. Antimicrob. Agents Chemother. 2015, 59, 145-151. [CrossRef] [PubMed]

77. Dr. Reddy's Laboratories Ltd. Available online: http://www.drreddys.com/ (accessed on 18 August 2017).

78. Malanovic, N.; Leber, R.; Schmuck, M.; Kriechbaum, M.; Cordfunke, R.A.; Drijfhout, J.W.; de Breij, A.; Nibbering, P.H.; Kolb, D.; Lohner, K. Phospholipid-driven differences determine the action of the synthetic antimicrobial peptide OP-145 on Gram-positive bacterial and mammalian membrane model systems. Biochem. Biophys. Acta Biomembr. 2015, 1848, 2437-2447. [CrossRef] [PubMed]

79. PXL01-Prevention of Post-Surgical Adhesions. Available online: http://www.promorepharma.com/en/ px101-prevention-of-post-surgical-adhesions / (accessed on 18 August 2017). 
80. Gronberg, A.; Mahlapuu, M.; Stahle, M.; Whately-Smith, C.; Rollman, O. Treatment with LL-37 is safe and effective in enhancing healing of hard-to-heal venous leg ulcers: A randomized, placebo-controlled clinical trial. Wound Repair Regen. 2014, 22, 613-621. [CrossRef] [PubMed]

81. Novexatin ${ }^{\circledR}$ (NP213) is a Novel Cationic Antifungal Peptide that Has been Formulated as a Brush-on-Treatment for Onychomycosis (Fungal nail Infection). Available online: https:/ /www.novabiotics. co.uk/pipeline/novexatin-np213 (accessed on 18 August 2017).

82. Phase III Efficacy and Safety Study of AB103 in the Treatment of Patients With Necrotizing Soft Tissue Infections (ACCUTE). Available online: https:/ clinicaltrials.gov/ct2/show /NCT02469857?term=p2TA\& rank=1 (accessed on 18 August 2017).

83. Kollef, M.; Pittet, D.; Sanchez Garcia, M.; Chastre, J.; Fagon, J.Y.; Bonten, M.; Hyzy, R.; Fleming, T.R.; Fuchs, H.; Bellm, L.; et al. A randomized double-blind trial of iseganan in prevention of ventilator-associated pneumonia. Am. J. Respir. Crit. Care Med. 2006, 173, 91-97. [CrossRef] [PubMed]

84. Trial of Iseganan in Prevention of Ventilator-Associated Pneumonia. Available online: https://clinicaltrials. gov / ct2/show / NCT00118781?term=Iseganan\&rank=1 (accessed on 18 August 2017).

85. Lipsky, B.A.; Holroyd, K.J.; Zasloff, M. Topical versus systemic antimicrobial therapy for treating mildly infected diabetic foot ulcers: A randomized, controlled, double-blinded, multicenter trial of pexiganan cream. Clin. Infect. Dis. 2008, 47, 1537-1545. [CrossRef] [PubMed]

86. Melo, M.N.; Dugourd, D.; Castanho, M.A. Omiganan pentahydrochloride in the front line of clinical applications of antimicrobial peptides. Recent Pat. Anti-Infect. Drug Discov. 2006, 1, 201-207. [CrossRef]

87. Knight-Connoni, V.; Mascio, C.; Chesnel, L.; Silverman, J. Discovery and development of surotomycin for the treatment of Clostridium difficile. J. Ind. Microbiol. Biotechnol. 2016, 43, 195-204. [CrossRef] [PubMed]

88. Nti-851 (Ramoplanin ${ }^{\mathrm{TM}}$ ). Available online: http://www.nanotherapeutics.com/ramoplanin/ (accessed on 18 August 2017).

89. Stiefel, U.; Pultz, N.J.; Helfand, M.S.; Donskey, C.J. Efficacy of oral ramoplanin for inhibition of intestinal colonization by vancomycin-resistant Enterococci in mice. Antimicrob. Agents Chemother. 2004, 48, 2144-2148. [CrossRef] [PubMed]

90. Oragenics-Intrexon Collaboration Announces Significant Progress towards Commercial Production of Lead Lantibiotic MU1140. Available online: http:/ / www.oragenics.com/news-media/press-releases/detail/13/ oragenics-intrexon-collaboration-announces-significant (accessed on 18 August 2017).

91. Ghobrial, O.G.; Derendorf, H.; Hillman, J.D. Pharmacodynamic activity of the lantibiotic MU1140. Int. J. Antimicrob. Agents 2009, 33, 70-74. [CrossRef] [PubMed]

92. Anti-Infective. Available online: http://helixbiomedix.com/antiinfective.html (accessed on 18 August 2017).

93. Novarifyn ${ }^{\circledR}$ (NP432) is antibacterial peptide with a number of key benefits over conventional antibiotic therapies and the clear potential to succeed where existing treatments for a number of bacterial infections, including those caused by MRSA, P. aeruginosa, and C. difficile, are failing. Available online: http://www. novabiotics.co.uk/pipeline/novarifyn-np432 (accessed on 18 August 2017).

94. Arenecin. Available online: https:/ / adeniumbiotech.com/arencin/ (accessed on 18 August 2017).

95. Andra, J.; Jakovkin, I.; Grotzinger, J.; Hecht, O.; Krasnosdembskaya, A.D.; Goldmann, T.; Gutsmann, T.; Leippe, M. Structure and mode of action of the antimicrobial peptide arenicin. Biochem. J. 2008, 410, 113-122. [CrossRef] [PubMed]

96. Adenium Biotech Pipeline. Available online: https://adeniumbiotech.com/pipeline/ (accessed on 18 August 2017).

97. Avidocin ${ }^{\mathrm{TM}} \&$ Purocin $^{\mathrm{TM}}$ proteins. Available online: https://avidbiotics.com/technology/avidocinproteins / (accessed on 18 August 2017).

98. Gebhart, D.; Lok, S.; Clare, S.; Tomas, M.; Stares, M.; Scholl, D.; Donskey, C.J.; Lawley, T.D.; Govoni, G.R. A modified r-type bacteriocin specifically targeting Clostridium difficile prevents colonization of mice without affecting gut microbiota diversity. mBio 2015, 6, e02368-14. [CrossRef] [PubMed]

99. Avan, I.; Hall, C.D.; Katritzky, A.R. Peptidomimetics via modifications of amino acids and peptide bonds. Chem. Soc. Rev. 2014, 43, 3575-3594. [CrossRef] [PubMed]

100. Andersson, D.I.; Hughes, D.; Kubicek-Sutherland, J.Z. Mechanisms and consequences of bacterial resistance to antimicrobial peptides. Drug. Resist. Updates 2016, 26, 43-57. [CrossRef] [PubMed]

101. Nizet, V. Antimicrobial peptide resistance mechanisms of human bacterial pathogens. Curr. Issues Mol. Biol. 2006, 8, 11-26. [PubMed] 
102. Maria-Neto, S.; de Almeida, K.C.; Macedo, M.L.R.; Franco, O.L. Understanding bacterial resistance to antimicrobial peptides: From the surface to deep inside. Biochim. Biophys. Acta 2015, 1848, 3078-3088. [CrossRef] [PubMed]

103. Habets, M.G.; Brockhurst, M.A. Therapeutic antimicrobial peptides may compromise natural immunity. Biol. Lett. 2012, 8, 416-418. [CrossRef] [PubMed]

104. Bechinger, B.; Gorr, S.U. Antimicrobial peptides: mechanisms of action and resistance. J. Dent. Res. 2017, 96, 254-260. [CrossRef] [PubMed]

105. Nawrocki, K.L.; Crispell, E.K.; McBride, S.M. Antimicrobial peptide resistance mechanisms of Gram-positive bacteria. Antibiotics 2014, 3, 461-492. [CrossRef] [PubMed]

106. Gruenheid, S.; Le Moual, H. Resistance to antimicrobial peptides in Gram-negative bacteria. FEMS Microbiol. Lett. 2012, 330, 81-89. [CrossRef] [PubMed]

107. Kubicek-Sutherland, J.Z.; Lofton, H.; Vestergaard, M.; Hjort, K.; Ingmer, H.; Andersson, D.I. Antimicrobial peptide exposure selects for Staphylococcus aureus resistance to human defence peptides. J. Antimicrob. Chemother. 2017, 72, 115-127. [CrossRef] [PubMed]

108. Nuri, R.; Shprung, T.; Shai, Y. Defensive remodeling: How bacterial surface properties and biofilm formation promote resistance to antimicrobial peptides. Biochim. Biophys. Acta 2015, 1848, 3089-3100. [CrossRef] [PubMed]

109. Jahnsen, R.D.; Haney, E.F.; Franzyk, H.; Hancock, R.E. Characterization of a proteolytically stable multifunctional host defense peptidomimetic. Chem. Biol. 2013, 20, 1286-1295. [CrossRef] [PubMed]

110. Hein-Kristensen, L.; Franzyk, H.; Holch, A.; Gram, L. Adaptive Evolution of Escherichia coli to an alpha-peptide/beta-peptoid peptidomimetic induces stable resistance. PLoS ONE 2013, 8, e73620. [CrossRef] [PubMed]

111. Methods for Dilution Antimicrobial Susceptibility Tests for Bacteria that Grow Aerobically; Approved Standard, 9th ed.; CLSI: Wayne, PA, USA, 2012.

112. Wiegand, I.; Hilpert, K.; Hancock, R.E. Agar and broth dilution methods to determine the minimal inhibitory concentration (MIC) of antimicrobial substances. Nat. Protoc. 2008, 3, 163-175. [CrossRef] [PubMed]

113. Citterio, L.; Franzyk, H.; Palarasah, Y.; Andersen, T.E.; Mateiu, R.V.; Gram, L. Improved in vitro evaluation of novel antimicrobials: Potential synergy between human plasma and antibacterial peptidomimetics, amps and antibiotics against human pathogenic bacteria. Res. Microbiol. 2016, 167, 72-82. [CrossRef] [PubMed]

114. Mohamed, M.F.; Abdelkhalek, A.; Seleem, M.N. Evaluation of short synthetic antimicrobial peptides for treatment of drug-resistant and intracellular Staphylococcus aureus. Sci. Rep. 2016, 6, 29707. [CrossRef] [PubMed]

115. Bonapace, C.R.; Bosso, J.A.; Friedrich, L.V.; White, R.L. Comparison of methods of interpretation of checkerboard synergy testing. Diagn. Microbiol. Infect. Dis. 2002, 44, 363-366. [CrossRef]

116. Hsieh, M.H.; Yu, C.M.; Yu, V.L.; Chow, J.W. Synergy assessed by checkerboard-A critical analysis. Diagn. Microbiol. Infect. Dis. 1993, 16, 343-349. [CrossRef]

117. Ceri, H.; Olson, M.E.; Stremick, C.; Read, R.R.; Morck, D.; Buret, A. The calgary biofilm device: New technology for rapid determination of antibiotic susceptibilities of bacterial biofilms. J. Clin. Microbiol. 1999, 37, 1771-1776. [PubMed]

118. Harrison, J.J.; Stremick, C.A.; Turner, R.J.; Allan, N.D.; Olson, M.E.; Ceri, H. Microtiter susceptibility testing of microbes growing on peg lids: A miniaturized biofilm model for high-throughput screening. Nat. Protoc. 2010, 5, 1236-1254. [CrossRef] [PubMed]

119. Oddo, A.; Hansen, P.R. Hemolytic activity of antimicrobial peptides. Methods Mol. Biol. 2017, 1548, $427-435$. [CrossRef] [PubMed]

120. Jahnsen, R.D.; Sandberg-Schaal, A.; Vissing, K.J.; Nielsen, H.M.; Frimodt-Møller, N.; Franzyk, H. Tailoring cytotoxicity of antimicrobial peptidomimetics with high activity against multidrug-resistant Escherichia coli. J. Med. Chem. 2014, 57, 2864-2873. [CrossRef] [PubMed] 
121. Riss, T.L.; Moravec, R.A.; Niles, A.L.; Duellman, S.; Benink, H.A.; Worzella, T.J.; Minor, L. Cell viability assays. In Assay Guidance Manual; [Internet: Last updated, March 31, 2017]; Sittampalam, G.S., Coussens, N.P., Brimacombe, K., Grossman, A., Arkin, M., Auld, D., Austin, C., Baell, J., Bejcek, B., Chung, T.D.Y., et al., Eds.; Eli Lilly \& Company and the National Center for Advancing Translational Sciences: Bethesda, MD, USA, 2004.

122. Cory, A.H.; Owen, T.C.; Barltrop, J.A.; Cory, J.G. Use of an aqueous soluble tetrazolium formazan assay for cell-growth assays in culture. Cancer Commun. 1991, 3, 207-212. [PubMed]

123. Pohjala, L.; Tammela, P.; Samanta, S.K.; Yli-Kauhaluoma, J.; Vuorela, P. Assessing the data quality in predictive toxicology using a panel of cell lines and cytotoxicity assays. Anal. Biochem. 2007, 362, 221-228. [CrossRef] [PubMed]

124. Gallardo-Godoy, A.; Muldoon, C.; Becker, B.; Elliott, A.G.; Lash, L.H.; Huang, J.X.; Butler, M.S.; Pelingon, R.; Kavanagh, A.M.; Ramu, S.; et al. Activity and Predicted Nephrotoxicity of Synthetic Antibiotics Based on Polymyxin B. J. Med. Chem. 2016, 59, 1068-1077. [CrossRef] [PubMed]

125. Tew, G.N.; Scott, R.W.; Klein, M.L.; Degrado, W.F. De novo design of antimicrobial polymers, foldamers, and small molecules: From discovery to practical applications. Acc. Chem. Res. 2010, 43, 30-39. [CrossRef] [PubMed]

126. Thaker, H.D.; Cankaya, A.; Scott, R.W.; Tew, G.N. Role of amphiphilicity in the design of synthetic mimics of antimicrobial peptides with Gram-negative activity. ACS Med. Chem. Lett. 2013, 4, 481-485. [CrossRef] [PubMed]

127. Thaker, H.D.; Sgolastra, F.; Clements, D.; Scott, R.W.; Tew, G.N. Synthetic mimics of antimicrobial peptides from triaryl scaffolds. J. Med. Chem. 2011, 54, 2241-2254. [CrossRef] [PubMed]

128. Flemming, K.; Klingenberg, C.; Cavanagh, J.P.; Sletteng, M.; Stensen, W.; Svendsen, J.S.; Flaegstad, T. High in vitro antimicrobial activity of synthetic antimicrobial peptidomimetics against staphylococcal biofilms. J. Antimicrob. Chemother. 2009, 63, 136-145. [CrossRef] [PubMed]

129. Haug, B.E.; Stensen, W.; Kalaaji, M.; Rekdal, Ø.; Svendsen, J.S. Synthetic antimicrobial peptidomimetics with therapeutic potential. J. Med. Chem. 2008, 51, 4306-4314. [CrossRef] [PubMed]

130. Hansen, T.; Alst, T.; Havelkova, M.; Strøm, M.B. Antimicrobial activity of small $\beta$-peptidomimetics based on the pharmacophore model of short cationic antimicrobial peptides. J. Med. Chem. 2009, 53, 595-606. [CrossRef] [PubMed]

131. Ahn, M.; Gunasekaran, P.; Rajasekaran, G.; Kim, E.Y.; Lee, S.J.; Bang, G.; Cho, K.; Hyun, J.K.; Lee, H.J.; Jeon, Y.H.; et al. Pyrazole derived ultra-short antimicrobial peptidomimetics with potent anti-biofilm activity. Eur. J. Med. Chem. 2017, 125, 551-564. [CrossRef] [PubMed]

132. Ahn, M.; Jacob, B.; Gunasekaran, P.; Murugan, R.N.; Ryu, E.K.; Lee, G.H.; Hyun, J.K.; Cheong, C.; Kim, N.H.; Shin, S.Y.; et al. Poly-lysine peptidomimetics having potent antimicrobial activity without hemolytic activity. Amino Acids 2014, 46, 2259-2269. [CrossRef] [PubMed]

133. Ahn, M.; Murugan, R.N.; Jacob, B.; Hyun, J.K.; Cheong, C.; Hwang, E.; Park, H.N.; Seo, J.H.; Srinivasrao, G.; Lee, K.S.; et al. Discovery of novel histidine-derived lipo-amino acids: Applied in the synthesis of ultra-short antimicrobial peptidomimetics having potent antimicrobial activity, salt resistance and protease stability. Eur. J. Med. Chem. 2013, 68, 10-18. [CrossRef] [PubMed]

134. Ibrahim, M.A.; Panda, S.S.; Oliferenko, A.A.; Oliferenko, P.V.; Girgis, A.S.; Elagawany, M.; Kucukbay, F.Z.; Panda, C.S.; Pillai, G.G.; Samir, A.; et al. Macrocyclic peptidomimetics with antimicrobial activity: Synthesis, bioassay, and molecular modeling studies. Org. Biomol. Chem. 2015, 13, 9492-9503. [CrossRef] [PubMed]

135. Srinivas, N.; Moehle, K.; Abou-Hadeed, K.; Obrecht, D.; Robinson, J.A. Biaryl amino acid templates in place of D-pro-L-pro in cyclic $\beta$-hairpin cationic antimicrobial peptidomimetics. Org. Biomol. Chem. 2007, 5, 3100-3105. [CrossRef] [PubMed]

136. Wales, S.M.; Hammer, K.A.; Somphol, K.; Kemker, I.; Schroder, D.C.; Tague, A.J.; Brkic, Z.; King, A.M.; Lyras, D.; Riley, T.V.; et al. Synthesis and antimicrobial activity of binaphthyl-based, functionalized oxazole and thiazole peptidomimetics. Org. Biomol. Chem. 2015, 13, 10813-10824. [CrossRef] [PubMed]

137. Lapidot, I.; Albeck, A.; Gellerman, G.; Shatzmiller, S.; Grynszpan, F. 1,4-dihydropyridine cationic peptidomimetics with antibacterial activity. Int. J. Pept. Res. Ther. 2015, 21, 243-247. [CrossRef]

138. Lohan, S.; Cameotra, S.S.; Bisht, G.S. Antibacterial evaluation of structurally amphipathic, membrane active small cationic peptidomimetics: Synthesized by incorporating 3-amino benzoic acid as peptidomimetic element. Eur. J. Med. Chem. 2014, 83, 102-115. [CrossRef] [PubMed] 
139. Ghosh, C.; Haldar, J. Membrane-active small molecules: Designs inspired by antimicrobial peptides. ChemMedChem 2015, 10, 1606-1624. [CrossRef] [PubMed]

140. Liskamp, R.M.J.; Rijkers, D.T.S.; Kruijtzer, J.A.W.; Kemmink, J. Peptides and proteins as a continuing exciting source of inspiration for peptidomimetics. ChemBioChem 2011, 12, 1626-1653. [CrossRef] [PubMed]

141. Zuckermann, R.N.; Kodadek, T. Peptoids as potential therapeutics. Curr. Opin. Mol. Ther. 2009, 11, $299-307$. [PubMed]

142. Culf, A.S.; Ouellette, R.J. Solid-phase synthesis of $N$-substituted glycine oligomers ( $\alpha$-peptoids) and derivatives. Molecules 2010, 15, 5282-5335. [CrossRef] [PubMed]

143. Fowler, S.A.; Blackwell, H.E. Structure-function relationships in peptoids: Recent advances toward deciphering the structural requirements for biological function. Org. Biomol. Chem. 2009, 7, 1508-1524. [CrossRef] [PubMed]

144. Hansen, P.R.; Munk, J.K. Synthesis of antimicrobial peptoids. Methods Mol. Biol. 2013, 1047, 151-159. [CrossRef] [PubMed]

145. Sun, J.; Zuckermann, R.N. Peptoid polymers: A highly designable bioinspired material. ACS Nano 2013, 7, 4715-4732. [CrossRef] [PubMed]

146. Trabocchi, A.; Guarna, A. Peptoids. In Peptidomimetics in Organic and Medicinal Chemistry: The Art of Transforming Peptides in Drugs; John Wiley \& Sons, Ltd.: Chichester, UK, 2014. [CrossRef]

147. Zuckermann, R.N. Peptoid origins. Pept. Sci. 2011, 96, 545-555. [CrossRef] [PubMed]

148. Corson, A.E.; Armstrong, S.A.; Wright, M.E.; McClelland, E.E.; Bicker, K.L. Discovery and characterization of a peptoid with antifungal activity against Cryptococcus neoformans. ACS Med. Chem. Lett. 2016, 7, 1139-1144. [CrossRef] [PubMed]

149. Luo, Y.; Bolt, H.L.; Eggimann, G.A.; McAuley, D.F.; McMullan, R.; Curran, T.; Zhou, M.; Jahoda, C.A.B.; Cobb, S.L.; Lundy, F.T. Peptoid efficacy against polymicrobial biofilms determined by using propidium monoazide-modified quantitative PCR. ChemBioChem 2017, 18, 111-118. [CrossRef] [PubMed]

150. Kapoor, R.; Eimerman, P.R.; Hardy, J.W.; Cirillo, J.D.; Contag, C.H.; Barron, A.E. Efficacy of antimicrobial peptoids against Mycobacterium tuberculosis. Antimicrob. Agents Chemother. 2011, 55, 3058-3062. [CrossRef] [PubMed]

151. Eggimann, G.A.; Bolt, H.L.; Denny, P.W.; Cobb, S.L. Investigating the anti-leishmanial effects of linear peptoids. ChemMedChem 2015, 10, 233-237. [CrossRef] [PubMed]

152. Huang, W.; Seo, J.; Willingham, S.B.; Czyzewski, A.M.; Gonzalgo, M.L.; Weissman, I.L.; Barron, A.E. Learning from host-defense peptides: Cationic, amphipathic peptoids with potent anticancer activity. PLoS ONE 2014, 9, e90397. [CrossRef] [PubMed]

153. Gangloff, N.; Ulbricht, J.; Lorson, T.; Schlaad, H.; Luxenhofer, R. Peptoids and polypeptoids at the frontier of supra- and macromolecular engineering. Chem. Rev. 2016, 116, 1753-1802. [CrossRef] [PubMed]

154. Lee, B.-C.; Zuckermann, R.N. Protein side-chain translocation mutagenesis via incorporation of peptoid residues. ACS Chem. Biol. 2011, 6, 1367-1374. [CrossRef] [PubMed]

155. Unciti-Broceta, A.; Diezmann, F.; Ou-Yang, C.Y.; Fara, M.A.; Bradley, M. Synthesis, penetrability and intracellular targeting of fluorescein-tagged peptoids and peptide-peptoid hybrids. Bioorg. Med. Chem. 2009, 17, 959-966. [CrossRef] [PubMed]

156. Chen, X.; Wu, J.; Luo, Y.; Liang, X.; Supnet, C.; Kim, M.W.; Lotz, G.P.; Yang, G.; Muchowski, P.J.; Kodadek, T.; et al. Expanded polyglutamine-binding peptoid as a novel therapeutic agent for treatment of Huntington's disease. Chem. Biol. 2011, 18, 1113-1125. [CrossRef] [PubMed]

157. Seo, J.; Ren, G.; Liu, H.G.; Miao, Z.; Park, M.; Wang, Y.H.; Miller, T.M.; Barron, A.E.; Cheng, Z. In vivo biodistribution and small animal PET of ${ }^{64} \mathrm{Cu}$-labeled antimicrobial peptoids. Bioconj. Chem. 2012, 23, 1069-1079. [CrossRef] [PubMed]

158. Szekely, T.; Roy, O.; Faure, S.; Taillefumier, C. From glycopeptides to glycopeptoids. Eur. J. Org. Chem. 2014, 2014, 5641-5657. [CrossRef]

159. Mao, J.; Bong, D. Synthesis of DNA-binding peptoids. Synlett 2015, 26, 1581-1585. [CrossRef]

160. De Cola, C.; Manicardi, A.; Corradini, R.; Izzo, I.; De Riccardis, F. Carboxyalkyl peptoid PNAs: Synthesis and hybridization properties. Tetrahedron 2012, 68, 499-506. [CrossRef]

161. Bolt, H.L.; Cobb, S.L. A practical method for the synthesis of peptoids containing both lysine-type and arginine-type monomers. Org. Biomol. Chem. 2016, 14, 1211-1215. [CrossRef] [PubMed] 
162. Mojsoska, B.; Zuckermann, R.N.; Jenssen, H. Structure-activity relationship study of novel peptoids that mimic the structure of antimicrobial peptides. Antimicrob. Agents Chemother. 2015, 59, 4112-4120. [CrossRef] [PubMed]

163. Simon, R.J.; Kania, R.S.; Zuckermann, R.N.; Huebner, V.D.; Jewell, D.A.; Banville, S.; Ng, S.; Wang, L.; Rosenberg, S.; Marlowe, C.K. Peptoids: A modular approach to drug discovery. Proc. Natl. Acad. Sci. USA 1992, 89, 9367-9371. [CrossRef] [PubMed]

164. Zuckermann, R.N.; Kerr, J.M.; Kent, S.B.H.; Moos, W.H. Efficient method for the preparation of peptoids (oligo( $N$-substituted glycines)) by submonomer solid-phase synthesis. J. Am. Chem. Soc. 1992, 114, 10646-10647. [CrossRef]

165. Tal-Gan, Y.; Freeman, N.S.; Klein, S.; Levitzki, A.; Gilon, C. Synthesis and structure-activity relationship studies of peptidomimetic PKB/Akt inhibitors: The significance of backbone interactions. Bioorg. Med. Chem. 2010, 18, 2976-2985. [CrossRef] [PubMed]

166. Vézina-Dawod, S.; Derson, A.; Biron, E. N-substituted arylsulfonamide building blocks as alternative submonomers for peptoid synthesis. Tetrahedron Lett. 2015, 56, 382-385. [CrossRef]

167. Li, S.; Bowerman, D.; Marthandan, N.; Klyza, S.; Luebke, K.J.; Garner, H.R.; Kodadek, T. Photolithographic synthesis of peptoids. J. Am. Chem. Soc. 2004, 126, 4088-4089. [CrossRef] [PubMed]

168. Meyer, J.-P.; Davis, P.; Lee, K.B.; Porreca, F.; Yamamura, H.I.; Hruby, V.J. Synthesis using a Fmoc-based strategy and biological activities of some reduced peptide bond pseudopeptide analogs of dynorphin A1. J. Med. Chem. 1995, 38, 3462-3468. [CrossRef] [PubMed]

169. Horn, T.; Lee, B.-C.; Dill, K.A.; Zuckermann, R.N. Incorporation of chemoselective functionalities into peptoids via solid-phase submonomer synthesis. Bioconjug. Chem. 2004, 15, 428-435. [CrossRef] [PubMed]

170. Rene, A.; Martinez, J.; Cavelier, F. N-substituted glycines with functional side-chains for peptoid synthesis. Eur. J. Org. Chem. 2014, 8142-8147. [CrossRef]

171. Caumes, C.; Hjelmgaard, T.; Remuson, R.; Faure, S.; Taillefumier, C. Highly convenient gram-scale solution-phase peptoid synthesis and orthogonal side-chain post-modification. Synthesis 2011, 257-264. [CrossRef]

172. Oddo, A.; Münzker, L.; Hansen, P.R. Peptide macrocycles featuring a backbone secondary amine: A convenient strategy for the synthesis of lipidated cyclic and bicyclic peptides on solid support. Org. Lett. 2015, 17, 2502-2505. [CrossRef] [PubMed]

173. Figliozzi, G.; Goldsmith, R.; Ng, S.; Banville, S.; Zuckermann, R. Synthesis of N-substituted glycine peptoid libraries. Methods Enzymol. 1996, 267, 437-447. [CrossRef] [PubMed]

174. Kim, S.; Biswas, G.; Park, S.; Kim, A.; Park, H.; Park, E.; Kim, J.; Kwon, Y.U. Unusual truncation of N-acylated peptoids under acidic conditions. Org. Biomol. Chem. 2014, 12, 5222-5226. [CrossRef] [PubMed]

175. Goodson, B.; Ehrhardt, A.; Ng, S.; Nuss, J.; Johnson, K.; Giedlin, M.; Yamamoto, R.; Moos, W.H.; Krebber, A.; Ladner, M.; et al. Characterization of novel antimicrobial peptoids. Antimicrob. Agents Chemother. 1999, 43, 1429-1434. [PubMed]

176. Ng, S.; Goodson, B.; Ehrhardt, A.; Moos, W.H.; Siani, M.; Winter, J. Combinatorial discovery process yields antimicrobial peptoids. Bioorg. Med. Chem. 1999, 7, 1781-1785. [CrossRef]

177. Mojsoska, B.; Carretero, G.; Larsen, S.; Mateiu, R.V.; Jenssen, H. Peptoids successfully inhibit the growth of Gram-negative E. coli causing substantial membrane damage. Sci. Rep. 2017, 7, 42332. [CrossRef] [PubMed]

178. Chongsiriwatana, N.P.; Patch, J.A.; Czyzewski, A.M.; Dohm, M.T.; Ivankin, A.; Gidalevitz, D.; Zuckermann, R.N.; Barron, A.E. Peptoids that mimic the structure, function, and mechanism of helical antimicrobial peptides. Proc. Natl. Acad. Sci. USA 2008, 105, 2794-2799. [CrossRef] [PubMed]

179. Bolt, H.L.; Eggimann, G.A.; Jahoda, C.A.B.; Zuckermann, R.N.; Sharples, G.J.; Cobb, S.L. Exploring the links between peptoid antibacterial activity and toxicity. MedChem Comm 2017, 8, 886-896. [CrossRef]

180. Czyzewski, A.M.; Jenssen, H.; Fjell, C.D.; Waldbrook, M.; Chongsiriwatana, N.P.; Yuen, E.; Hancock, R.E.W.; Barron, A.E. In vivo, in vitro, and in silico characterization of peptoids as antimicrobial agents. PLoS ONE 2016, 11, e0135961. [CrossRef] [PubMed]

181. Bang, J.K.; Nan, Y.H.; Lee, E.K.; Shin, S.Y. A novel Trp-rich model antimicrobial peptoid with increased protease stability. Bull. Korean Chem. Soc. 2010, 31, 2509-2513. [CrossRef]

182. Chongsiriwatana, N.P.; Wetzler, M.; Barron, A.E. Functional synergy between antimicrobial peptoids and peptides against Gram-negative bacteria. Antimicrob. Agents Chemother. 2011, 55, 5399-5402. [CrossRef] [PubMed] 
183. Chongsiriwatana, N.P.; Miller, T.M.; Wetzler, M.; Vakulenko, S.; Karlsson, A.J.; Palecek, S.P.; Mobashery, S.; Barron, A.E. Short alkylated peptoid mimics of antimicrobial lipopeptides. Antimicrob. Agents Chemother. 2011, 55, 417-420. [CrossRef] [PubMed]

184. Kapoor, R.; Wadman, M.W.; Dohm, M.T.; Czyzewski, A.M.; Spormann, A.M.; Barron, A.E. Antimicrobial peptoids are effective against Pseudomonas aeruginosa biofilms. Antimicrob. Agents Chemother. 2011, 55, 3054-3057. [CrossRef] [PubMed]

185. Findlay, B.; Szelemej, P.; Zhanel, G.G.; Schweizer, F. Guanidylation and tail effects in cationic antimicrobial lipopeptoids. PLoS ONE 2012, 7, e41141. [CrossRef] [PubMed]

186. Fisher, K.J.; Turkett, J.A.; Corson, A.E.; Bicker, K.L. Peptoid library agar diffusion (PLAD) assay for the high-throughput identification of antimicrobial peptoids. ACS Comb. Sci. 2016, 18, 287-291. [CrossRef] [PubMed]

187. Turkett, J.A.; Bicker, K.L. Evaluating the effect of peptoid lipophilicity on antimicrobial potency, cytotoxicity, and combinatorial library design. ACS Comb. Sci. 2017, 19, 229-233. [CrossRef] [PubMed]

188. Huang, M.L.; Shin, S.B.Y.; Benson, M.A.; Torres, V.J.; Kirshenbaum, K. A comparison of linear and cyclic peptoid oligomers as potent antimicrobial agents. ChemMedChem 2012, 7, 114-122. [CrossRef] [PubMed]

189. Huang, M.L.; Benson, M.A.; Shin, S.B.Y.; Torres, V.J.; Kirshenbaum, K. Amphiphilic cyclic peptoids that exhibit antimicrobial activity by disrupting Staphylococcus aureus membranes. Eur. J. Org. Chem. 2013, 2013, 3560-3566. [CrossRef]

190. Andreev, K.; Martynowycz, M.W.; Ivankin, A.; Huang, M.L.; Kuzmenko, I.; Meron, M.; Lin, B.H.; Kirshenbaum, K.; Gidalevitz, D. Cyclization improves membrane permeation by antimicrobial peptoids. Langmuir 2016, 32, 12905-12913. [CrossRef] [PubMed]

191. Zhu, W.L.; Park, Y.; Park, I.S.; Park, Y.S.; Kim, Y.; Hahm, K.S.; Shin, S.Y. Improvement of bacterial cell selectivity of melittin by a single Trp mutation with a peptoid residue. Protein Pept. Lett. 2006, 13, 719-725. [CrossRef] [PubMed]

192. Nan, Y.H.; Park, K.H.; Jeon, Y.J.; Park, Y.; Park, I.S.; Hahm, K.S.; Shin, S.Y. Antimicrobial and anti-inflammatory activities of a Leu/Lys-rich antimicrobial peptide with phe-peptoid residues. Protein Pept. Lett. 2007, 14, 1003-1007. [CrossRef] [PubMed]

193. Kim, J.-K.; Lee, S.-A.; Shin, S.; Lee, J.-Y.; Jeong, K.-W.; Nan, Y.H.; Park, Y.S.; Shin, S.Y.; Kim, Y. Structural flexibility and the positive charges are the key factors in bacterial cell selectivity and membrane penetration of peptoid-substituted analog of piscidin 1. Biochim. Biophys. Acta 2010, 1798, 1913-1925. [CrossRef] [PubMed]

194. Shin, S.Y. Effect of double replacement of L-pro, D-pro, D-leu or Nleu in hydrophobic face of amphipathic alpha-helical model antimicrobial peptide on structure, cell selectivity and mechanism of action. Bull. Korean Chem. Soc. 2014, 35, 3267-3274. [CrossRef]

195. Zhu, W.L.; Song, Y.M.; Park, Y.; Park, K.H.; Yang, S.T.; Kim, J.I.; Park, I.S.; Hahm, K.S.; Shin, S.Y. Substitution of the leucine zipper sequence in melittin with peptoid residues affects self-association, cell selectivity, and mode of action. Biochim. Biophys. Acta 2007, 1768, 1506-1517. [CrossRef] [PubMed]

196. Zhu, W.L.; Hahm, K.S.; Shin, S.Y. Cathelicidin-derived Trp/Pro-rich antimicrobial peptides with lysine peptoid residue (Nlys): Therapeutic index and plausible mode of action. J. Pept. Sci. 2007, 13, 529-535. [CrossRef] [PubMed]

197. Jeong, M.C.; Jeon, D.; Shin, A.; Jin, S.; Shin, S.Y.; Park, Y.S.; Kim, Y. Effects of hydrophobic peptoid substitutions on the bacterial cell selectivity and antimicrobial activity of piscidin 1. Bull. Korean Chem. Soc. 2016, 37, 1545-1551. [CrossRef]

198. Shin, A.; Lee, E.; Jeon, D.; Park, Y.G.; Bang, J.K.; Park, Y.S.; Shin, S.Y.; Kim, Y. Peptoid-substituted hybrid antimicrobial peptide derived from papiliocin and magainin 2 with enhanced bacterial selectivity and anti-inflammatory activity. Biochemistry 2015, 54, 3921-3931. [CrossRef] [PubMed]

199. Wang, P.; Bang, J.K.; Kim, H.J.; Kim, J.K.; Kim, Y.; Shin, S.Y. Antimicrobial specificity and mechanism of action of disulfide-removed linear analogs of the plant-derived Cys-rich antimicrobial peptide Ib-AMP1. Peptides 2009, 30, 2144-2149. [CrossRef] [PubMed]

200. Gobbo, M.; Benincasa, M.; Bertoloni, G.; Biondi, B.; Dosselli, R.; Papini, E.; Reddi, E.; Rocchi, R.; Tavano, R.; Gennaro, R. Substitution of the arginine/leucine residues in apidaecin Ib with peptoid residues: Effect on antimicrobial activity, cellular uptake, and proteolytic degradation. J. Med. Chem. 2009, 52, 5197-5206. [CrossRef] [PubMed] 
201. Hansen, A.M.; Bonke, G.; Larsen, C.J.; Yavari, N.; Nielsen, P.E.; Franzyk, H. Antibacterial peptide nucleic acid-antimicrobial peptide (PNA-AMP) conjugates: Antisense targeting of fatty acid biosynthesis. Bioconjug. Chem. 2016, 27, 863-867. [CrossRef] [PubMed]

202. Lin, H.; Yan, T.T.; Wang, L.; Guo, F.F.; Ning, G.S.; Xiong, M. Statistical design, structural analysis, and in vitro susceptibility assay of antimicrobial peptoids to combat bacterial infections. J. Chemom. 2016, 30, 369-376. [CrossRef]

203. Ryge, T.; Hansen, P. Novel lysine-peptoid hybrids with antibacterial properties. J. Pept. Sci. 2005, 11, 727-734. [CrossRef] [PubMed]

204. Ryge, T.S.; Frimodt-Moller, N.; Hansen, P.R. Antimicrobial activities of twenty lysine-peptoid hybrids against clinically relevant bacteria and fungi. Chemotherapy 2008, 54, 152-156. [CrossRef] [PubMed]

205. Gottschalk, S.; Ingmer, H.; Thomsen, L.E. The lysine-peptoid hybrid LP5 maintain activity under physiological conditions and affects virulence gene expression in Staphylococcus aureus. Peptides 2016, 78, 24-29. [CrossRef] [PubMed]

206. Olsen, C.A. $\beta$-peptoid "foldamers"-why the additional methylene unit? Biopolymers 2011, 96, 561-566. [CrossRef] [PubMed]

207. Laursen, J.S.; Engel-Andreasen, J.; Olsen, C.A. $\beta$-peptoid foldamers at last. Acc. Chem. Res. 2015, 48, 2696-2704. [CrossRef] [PubMed]

208. Hamper, B.C.; Kolodziej, S.A.; Scatez, A.M.; Smith, R.G.; Cortez, E. Solid phase synthesis of $\beta$-peptiods: $N$-substituted $\beta$-aminopropionic acid oligomers. J. Org. Chem. 1998, 63, 708-718. [CrossRef] [PubMed]

209. Norgren, A.S.; Zhang, S.D.; Arvidsson, P.I. Synthesis and circular dichroism spectroscopic investigations of oligomeric $\beta$-peptoids with $\alpha$-chiral side chains. Org. Lett. 2006, 8, 4533-4536. [CrossRef] [PubMed]

210. Olsen, C.A.; Lambert, M.; Witt, M.; Franzyk, H.; Jaroszewski, J.W. Solid-phase peptide synthesis and circular dichroism study of chiral $\beta$-peptoid homooligomers. Amino Acids 2008, 34, 465-471. [CrossRef] [PubMed]

211. Jahnsen, R.D.; Frimodt-Møller, N.; Franzyk, H. Antimicrobial activity of peptidomimetics against multidrug-resistant Escherichia coli: A comparative study of different backbones. J. Med. Chem. 2012, 55, 7253-7261. [CrossRef] [PubMed]

212. Shuey, S.W.; Delaney, W.J.; Shah, M.C.; Scialdone, M.A. Antimicrobial $\beta$-peptoids by a block synthesis approach. Bioorg. Med. Chem. Lett. 2006, 16, 1245-1248. [CrossRef] [PubMed]

213. Roy, O.; Faure, S.; Thery, V.; Didierjean, C.; Taillefumier, C. Cyclic $\beta$-peptoids. Org. Lett. 2008, 10, 921-924. [CrossRef] [PubMed]

214. Bonke, G.; Vedel, L.; Witt, M.; Jaroszewski, J.W.; Olsen, C.A.; Franzyk, H. Dimeric building blocks for solid-phase synthesis of $\alpha$-peptide- $\beta$-peptoid chimeras. Synthesis-Stuttgart 2008, 2008, 2381-2390. [CrossRef]

215. Olsen, C.A.; Bonke, G.; Vedel, L.; Adsersen, A.; Witt, M.; Franzyk, H.; Jaroszewski, J.W. $\alpha$-peptide/ $\beta$-peptoid chimeras. Org. Lett. 2007, 9, 1549-1552. [CrossRef] [PubMed]

216. Olsen, C.A.; Ziegler, H.L.; Nielsen, H.M.; Frimodt-Møller, N.; Jaroszewski, J.W.; Franzyk, H. Antimicrobial, hemolytic, and cytotoxic activities of $\beta$-peptoid-peptide hybrid oligomers: Improved properties compared to natural amps. ChemBioChem 2010, 11, 1356-1360. [CrossRef] [PubMed]

217. Hein-Kristensen, L.; Knapp, K.M.; Franzyk, H.; Gram, L. Bacterial membrane activity of $\alpha$-peptide/ $\beta$-peptoid chimeras: Influence of amino acid composition and chain length on the activity against different bacterial strains. BMC Microbiol. 2011, 11, 144. [CrossRef] [PubMed]

218. Jahnsen, R.O.; Sandberg-Schaal, A.; Frimodt-Moller, N.; Nielsen, H.M.; Franzyk, H. End group modification: Efficient tool for improving activity of antimicrobial peptide analogues towards Gram-positive bacteria. Eur. J. Pharm. Biopharm. 2015, 95, 40-46. [CrossRef] [PubMed]

219. Molchanova, N.; Hansen, P.R.; Damborg, P.; Nielsen, H.M.; Franzyk, H. Lysine-based $\alpha$-peptide/ $\beta$-peptoid peptidomimetics: Influence of hydrophobicity, fluorination and distribution of cationic charge on antimicrobial activity and cytotoxicity. ChemMedChem 2017, 20, 312-318. [CrossRef] [PubMed]

220. Hein-Kristensen, L.; Knapp, K.M.; Franzyk, H.; Gram, L. Selectivity in the potentiation of antibacterial activity of $\alpha$-peptide/ $\beta$-peptoid peptidomimetics and antimicrobial peptides by human blood plasma. Res. Microbiol. 2013, 164, 933-940. [CrossRef] [PubMed]

221. Vedel, L.; Bonke, G.; Foged, C.; Ziegler, H.; Franzyk, H.; Jaroszewski, J.W.; Olsen, C.A. Antiplasmodial and prehemolytic activities of $\alpha$-peptide- $\beta$-peptoid chimeras. ChemBioChem 2007, 8, 1781-1784. [CrossRef] [PubMed] 
222. Liu, Y.; Knapp, K.M.; Yang, L.; Molin, S.; Franzyk, H.; Folkesson, A. High in vitro antimicrobial activity of $\beta$-peptoid-peptide hybrid oligomers against planktonic and biofilm cultures of Staphylococcus epidermidis. Int. J. Antimicrob. Agents 2013, 41, 20-27. [CrossRef] [PubMed]

223. Skovbakke, S.L.; Larsen, C.J.; Heegaard, P.M.H.; Moesby, L.; Franzyk, H. Lipidated $\alpha$-peptide/ $\beta$-peptoid hybrids with potent antiinflammatory activity. J. Med. Chem. 2015, 58, 801-813. [CrossRef] [PubMed]

224. Holdfeldt, A.; Skovbakke, S.L.; Winther, M.; Gabl, M.; Nielsen, C.; Perez-Gassol, I.; Larsen, C.J.; Wang, J.M.; Karlsson, A.; Dahlgren, C.; et al. The lipidated peptidomimetic Lau-((S)-Aoc)-(Lys- $\beta \mathrm{Nphe}_{6}-\mathrm{NH}_{2}$ is a novel formyl peptide receptor 2 agonist that activates both human and mouse neutrophil nadph oxidase. J. Biol. Chem. 2016, 291, 19888-19899. [CrossRef] [PubMed]

225. Skovbakke, S.L.; Heegaard, P.M.H.; Larsen, C.J.; Franzyk, H.; Forsman, H.; Dahlgren, C. The proteolytically stable peptidomimetic Pam-(Lys- $\beta \mathrm{NSpe})_{6}-\mathrm{NH}_{2}$ selectively inhibits human neutrophil activation via formyl peptide receptor 2. Biochem. Pharmacol. 2015, 93, 182-195. [CrossRef] [PubMed]

226. Andreev, K.; Bianchi, C.; Laursen, J.S.; Citterio, L.; Hein-Kristensen, L.; Gram, L.; Kuzmenko, I.; Olsen, C.A.; Gidalevitz, D. Guanidino groups greatly enhance the action of antimicrobial peptidomimetics against bacterial cytoplasmic membranes. Biochim. Biophys. Acta 2014, 1838, 2492-2502. [CrossRef] [PubMed]

227. Mansour, S.C.; de la Fuente-Nunez, C.; Hancock, R.E. Peptide IDR-1018: Modulating the immune system and targeting bacterial biofilms to treat antibiotic-resistant bacterial infections. J. Pept. Sci. 2015, 21, 323-329. [CrossRef] [PubMed]

228. Skovbakke, S.L.; Winther, M.; Gabl, M.; Holdfeldt, A.; Linden, S.; Wang, J.M.; Dahlgren, C.; Franzyk, H.; Forsman, $\mathrm{H}$. The peptidomimetic Lau-(Lys- $\beta \mathrm{NSpe})_{6}-\mathrm{NH}_{2}$ antagonizes formyl peptide receptor 2 expressed in mouse neutrophils. Biochem. Pharmacol. 2016, 119, 56-65. [CrossRef] [PubMed]

229. Seebach, D.; Matthews, J.L. $\beta$-Peptides: A surprise at every turn. Chem. Commun. 1997, 2015-2022. [CrossRef]

230. Arvidsson, P.I.; Frackenpohl, J.; Ryder, N.S.; Liechty, B.; Petersen, F.; Zimmermann, H.; Camenisch, G.P.; Woessner, R.; Seebach, D. On the antimicrobial and hemolytic activities of amphiphilic $\beta$-peptides. ChemBioChem 2001, 2, 771-773. [CrossRef]

231. DeGrado, W.F.; Schneider, J.P.; Hamuro, Y. The twists and turns of $\beta$-peptides. J. Pept. Res. 1999, 54, $206-217$. [CrossRef] [PubMed]

232. Hamuro, Y.S.; Joel, P.; DeGrado, W.F. De novo design of antibacterial $\beta$-peptides. J. Am. Chem. Soc. 1999, 121, 12200-12201. [CrossRef]

233. Porter, E.A.; Wang, X.; Lee, H.-S.; Weisblum, B.; Gellman, S.H. Antibiotics: Non-haemolytic $\beta$-amino-acid oligomers. Nature 2000, 404, 565. [CrossRef] [PubMed]

234. Suresh Babu, V.V.; Gopi, H.N.; Anada, K. Homologation of $\alpha$-amino acids to $\beta$-amino acids using Fmoc-amino acid pentafluorophenyl esters. J. Pept. Res. 1999, 53, 308-313. [CrossRef]

235. Lee, H.S.; LePlae, P.R.; Porter, E.A.; Gellman, S.H. An efficient route to either enantiomer of orthogonally protected trans-3-aminopyrrolidine-4-carboxylic acid. J. Org. Chem. 2001, 66, 3597-3599. [CrossRef] [PubMed]

236. LePlae, P.R.; Umezawa, N.; Lee, H.S.; Gellman, S.H. An efficient route to either enantiomer of trans-2-aminocyclopentanecarboxylic acid. J. Org. Chem. 2001, 66, 5629-5632. [CrossRef] [PubMed]

237. Liu, D.; DeGrado, W. De novo design, synthesis, and characterization of antimicrobial $\beta$-peptides. J. Am. Chem. Soc. 2001, 123, 7553-7559. [CrossRef] [PubMed]

238. Porter, E.A.; Weisblum, B.; Gellman, S.H. Mimicry of host-defense peptides by unnatural oligomers: Antimicrobial peptides. J. Am. Chem. Soc. 2002, 124, 7324-7330. [CrossRef] [PubMed]

239. Geueke, B.; Namoto, K.; Agarkova, I.; Perriard, J.C.; Kohler, H.P.E.; Seebach, D. Bacterial cell penetration by $\beta^{3}$-oligohomoarginines: Indications for passive transfer through the lipid bilayer. ChemBioChem 2005, 6, 982-985. [CrossRef] [PubMed]

240. Serrano, G.N.; Zhanel, G.G.; Schweizer, F. Antibacterial activity of ultrashort cationic lipo- $\beta$-peptides. Antimicrob. Agents Chemother. 2009, 53, 2215-2217. [CrossRef] [PubMed]

241. Karlsson, A.J.; Pomerantz, W.C.; Weisblum, B.; Gellman, S.H.; Palecek, S.P. Antifungal activity from 14-helical $\beta$-peptides. J. Am. Chem. Soc. 2006, 128, 12630-12631. [CrossRef] [PubMed]

242. Karlsson, A.J.; Pomerantz, W.C.; Neilsen, K.J.; Gellman, S.H.; Palecek, S.P. Effect of sequence and structural properties on 14-helical $\beta$-peptide activity against candida albicans planktonic cells and biofilms. ACS Chem. Biol. 2009, 4, 567-579. [CrossRef] [PubMed] 
243. Lee, M.-R.; Raman, N.; Gellman, S.H.; Lynn, D.M.; Palecek, S.P. Hydrophobicity and helicity regulate the antifungal activity of 14-helical $\beta$-peptides. ACS Chem. Biol. 2014, 9, 1613-1621. [CrossRef] [PubMed]

244. Raman, N.; Lee, M.-R.; Lynn, D.; Palecek, S. Antifungal activity of 14 -helical $\beta$-peptides against planktonic cells and biofilms of candida species. Pharmaceuticals 2015, 8, 483-503. [CrossRef] [PubMed]

245. Mora-Navarro, C.; Caraballo-Leon, J.; Torres-Lugo, M.; Ortiz-Bermudez, P. Synthetic antimicrobial $\beta$-peptide in dual-treatment with fluconazole or ketoconazole enhances the in vitro inhibition of planktonic and biofilm Candida albicans. J. Pept. Sci. 2015, 21, 853-861. [CrossRef] [PubMed]

246. Mora-Navarro, C.; Mendez-Vega, J.; Caraballo-Leon, J.; Lee, M.R.; Palecek, S.; Torres-Lugo, M.; Ortiz-Bermudez, P. Hydrophobicity of antifungal $\beta$-peptides is associated with their cytotoxic effect on in vitro human colon Caco-2 and liver HepG2 cells. PLoS ONE 2016, 11, e0149271. [CrossRef]

247. Raman, N.; Lee, M.R.; Lopez, A.D.R.; Palecek, S.P.; Lynn, D.M. Antifungal activity of a $\beta$-peptide in synthetic urine media: Toward materials-based approaches to reducing catheter-associated urinary tract fungal infections. Acta Biomater. 2016, 43, 240-250. [CrossRef] [PubMed]

248. Raman, N.; Marchillo, K.; Lee, M.R.; Lopez, A.D.R.; Andes, D.R.; Palecek, S.P.; Lynn, D.M. Intraluminal release of an antifungal $\beta$-peptide enhances the antifungal and anti-biofilm activities of multilayer-coated catheters in a rat model of venous catheter infection. ACS Biomater. Sci. Eng. 2016, 2, 112-121. [CrossRef] [PubMed]

249. Schmitt, M.A.; Weisblum, B.; Gellman, S.H. Unexpected relationships between structure and function in $\alpha, \beta$-peptides: Antimicrobial foldamers with heterogeneous backbones. J. Am. Chem. Soc. 2004, 126, 6848-6849. [CrossRef] [PubMed]

250. Schmitt, M.A.; Weisblum, B.; Gellman, S.H. Interplay among folding, sequence, and lipophilicity in the antibacterial and hemolytic activities of $\alpha / \beta$-peptides. J. Am. Chem. Soc. 2007, 129, 417-428. [CrossRef] [PubMed]

251. Hu, Y.; Li, X.; Sebti, S.M.; Chen, J.; Cai, J. Design and synthesis of AApeptides: A new class of peptide mimics. Bioorg. Med. Chem. Lett. 2011, 21, 1469-1471. [CrossRef] [PubMed]

252. Padhee, S.; Hu, Y.; Niu, Y.; Bai, G.; Wu, H.; Costanza, F.; West, L.; Harrington, L.; Shaw, L.N.; Cao, C.; et al. Non-hemolytic $\alpha$-AApeptides as antimicrobial peptidomimetics. Chem. Commun.(Camb.) 2011, 47, 9729-9731. [CrossRef] [PubMed]

253. Niu, Y.; Padhee, S.; Wu, H.; Bai, G.; Harrington, L.; Burda, W.N.; Shaw, L.N.; Cao, C.; Cai, J. Identification of $\gamma$-AApeptides with potent and broad-spectrum antimicrobial activity. Chem. Commun. 2011, 47, 12197-12199. [CrossRef] [PubMed]

254. Hu, Y.G.; Amin, M.N.; Padhee, S.; Wang, R.S.E.; Qiao, Q.; Bai, G.; Li, Y.Q.; Mathew, A.; Cao, C.H.; Cai, J.F. Lipidated peptidomimetics with improved antimicrobial activity. ACS Med. Chem. Lett. 2012, 3, 683-686. [CrossRef] [PubMed]

255. Padhee, S.; Smith, C.; Wu, H.; Li, Y.; Manoj, N.; Qiao, Q.; Khan, Z.; Cao, C.; Yin, H.; Cai, J. The development of antimicrobial $\alpha$-AApeptides that suppress proinflammatory immune responses. ChemBioChem 2014, 15, 688-694. [CrossRef] [PubMed]

256. Niu, Y.; Padhee, S.; Wu, H.; Bai, G.; Qiao, Q.; Hu, Y.; Harrington, L.; Burda, W.N.; Shaw, L.N.; Cao, C.; et al. Lipo- $\gamma$-AApeptides as a new class of potent and broad-spectrum antimicrobial agents. J. Med. Chem. 2012, 55, 4003-4009. [CrossRef] [PubMed]

257. Wu, H.; Niu, Y.; Padhee, S.; Wang, R.E.; Li, Y.; Qiao, Q.; Bai, G.; Cao, C.; Cai, J. Design and synthesis of unprecedented cyclic $\gamma$-AApeptides for antimicrobial development. Chem. Sci. 2012, 3, 2570-2575. [CrossRef]

258. Li, Y.Q.; Smith, C.; Wu, H.F.; Padhee, S.; Manoj, N.; Cardiello, J.; Qiao, Q.; Cao, C.H.; Yin, H.; Cai, J.F. Lipidated cyclic $\gamma$-AApeptides display both antimicrobial and anti-inflammatory activity. ACS Chem. Biol. 2014, 9, 211-217. [CrossRef] [PubMed]

259. Li, Y.Q.; Wu, H.F.; Teng, P.; Bai, G.; Lin, X.Y.; Zuo, X.B.; Cao, C.H.; Cai, J.F. Helical antimicrobial sulfono- $\gamma$-AApeptides. J. Med. Chem. 2015, 58, 4802-4811. [CrossRef] [PubMed]

260. She, F.; Nimmagadda, A.; Teng, P.; Su, M.; Zuo, X.; Cai, J. Helical 1:1 $\alpha$ /sulfono- $\gamma$-AAheterogeneous peptides with antibacterial activity. Biomacromolecules 2016, 17, 1854-1859. [CrossRef] [PubMed]

261. Teng, P.; Shi, Y.; Sang, P.; Cai, J. $\gamma$-AApeptides as a new class of peptidomimetics. Chem. Eur. J. 2016, 22, 5458-5466. [CrossRef] [PubMed]

262. Shi, Y.; Teng, P.; Sang, P.; She, F.; Wei, L.; Cai, J. $\gamma$-AApeptides: Design, structure, and applications. Acc. Chem. Res. 2016, 49, 428-441. [CrossRef] [PubMed] 
263. Bolarinwa, O.; Nimmagadda, A.; Su, M.; Cai, J. Structure and function of AApeptides. Biochemistry 2017, 56, 445-457. [CrossRef] [PubMed]

264. Niu, Y.; Hu, Y.; Wu, H.; Cai, J. Synthesis of AApeptides. In Peptide Modifications to Increase Metabolic Stability and Activity; Cudic, P., Ed.; Humana Press: Totowa, NJ, USA, 2013; pp. 35-46.

265. Wu, H.; Teng, P.; Cai, J. Rapid access to multiple classes of peptidomimetics from common $\gamma$-AApeptide building blocks. Eur. J. Org. Chem. 2014, 2014, 1760-1765. [CrossRef]

266. Wu, H.; Amin, M.N.; Niu, Y.; Qiao, Q.; Harfouch, N.; Nimer, A.; Cai, J. Solid-phase synthesis of $\gamma$-AApeptides using a submonomeric approach. Org. Lett. 2012, 14, 3446-3449. [CrossRef] [PubMed]

267. Niu, Y.H.; Jones, A.; Wu, H.F.; Varani, G.; Cai, J.F. $\gamma$-AApeptides bind to RNA by mimicking RNA-binding proteins. Org. Biomol. Chem. 2011, 9, 6604-6609. [CrossRef] [PubMed]

268. Yang, Y.; Niu, Y.; Hong, H.; Wu, H.; Zhang, Y.; Engle, J.W.; Barnhart, T.E.; Cai, J.; Cai, W. Radiolabeled $\gamma$-AApeptides: A new class of tracers for positron emission tomography. Chem. Commun. 2012, 48, 7850-7852. [CrossRef] [PubMed]

269. Hu, Y.G.; Cheng, N.; Wu, H.F.; Kang, S.; Ye, R.D.; Cai, J.F. Design, synthesis and characterization of fMLF-mimicking aapeptides. ChemBioChem 2014, 15, 2420-2426. [CrossRef] [PubMed]

270. Wu, H.F.; Li, Y.Q.; Bai, G.; Niu, Y.H.; Qiao, Q.; Tipton, J.D.; Cao, C.H.; Cai, J.F. $\gamma$-AApeptide-based small-molecule ligands that inhibit $A \beta$ aggregation. Chem. Commun. 2014, 50, 5206-5208. [CrossRef] [PubMed]

271. Niu, Y.; Wu, H.; Huang, R.; Qiao, Q.; Costanza, F.; Wang, X.-S.; Hu, Y.; Amin, M.N.; Nguyen, A.-M.; Zhang, J.; et al. Nanorods formed from a new class of peptidomimetics. Macromolecules 2012, 45, 7350-7355. [CrossRef]

272. Padhee, S.; Li, Y.; Cai, J. Activity of lipo-cyclic $\gamma$-aapeptides against biofilms of Staphylococcus epidermidis and Pseudomonas aeruginosa. Bioorg. Med. Chem. Lett. 2015, 25, 2565-2569. [CrossRef] [PubMed]

273. Kaur, P.; Li, Y.; Cai, J.; Song, L. Selective membrane disruption mechanism of an antibacterial $\gamma$-AApeptide defined by epr spectroscopy. Biophys. J. 2016, 110, 1789-1799. [CrossRef] [PubMed]

274. Niu, Y.; Wu, H.; Li, Y.; Hu, Y.; Padhee, S.; Li, Q.; Cao, C.; Cai, J. AApeptides as a new class of antimicrobial agents. Org. Biomol. Chem. 2013, 11, 4283-4290. [CrossRef] [PubMed]

275. Radzishevsky, I.S.; Rotem, S.; Bourdetsky, D.; Navon-Venezia, S.; Carmeli, Y.; Mor, A. Improved antimicrobial peptides based on acyl-lysine oligomers. Nat. Biotechnol. 2007, 25, 657-659. [CrossRef] [PubMed]

276. Rotem, S.; Mor, A. Antimicrobial peptide mimics for improved therapeutic properties. Biochim. Biophys. Acta 2009, 1788, 1582-1592. [CrossRef] [PubMed]

277. Mor, A. Engineered oaks against antibiotic resistance and for bacterial detection. In Host Defense Peptides and Their Potential as Therapeutic Agents; Epand, R.M., Ed.; Springer International Publishing: Cham, Switzerland, 2016; pp. 205-226.

278. Livne, L.; Kovachi, T.; Sarig, H.; Epand, R.F.; Zaknoon, F.; Epand, R.M.; Mor, A. Design and characterization of a broad-spectrum bactericidal acyl-lysyl oligomer. Chem. Biol. 2009, 16, 1250-1258. [CrossRef] [PubMed]

279. Livne, L.; Epand, R.F.; Papahadjopoulos-Sternberg, B.; Epand, R.M.; Mor, A. OAK-based cochleates as a novel approach to overcome multidrug resistance in bacteria. FASEB J. 2010, 24, 5092-5101. [CrossRef] [PubMed]

280. Zaknoon, F.; Goldberg, K.; Sarig, H.; Epand, R.F.; Epand, R.M.; Mor, A. Antibacterial properties of an oligo-acyl-lysyl hexamer targeting Gram-negative species. Antimicrob. Agents Chemother. 2012, 56, 4827-4832. [CrossRef] [PubMed]

281. Kaneti, G.; Sarig, H.; Marjieh, I.; Fadia, Z.; Mor, A. Simultaneous breakdown of multiple antibiotic resistance mechanisms in S. aureus. FASEB J. 2013, 27, 4834-4843. [CrossRef] [PubMed]

282. Makobongo, M.O.; Kovachi, T.; Gancz, H.; Mor, A.; Merrell, D.S. In vitro antibacterial activity of acyl-lysyl oligomers against Helicobacter pylori. Antimicrob. Agents Chemother. 2009, 53, 4231-4239. [CrossRef] [PubMed]

283. Makobongo, M.O.; Gancz, H.; Carpenter, B.M.; McDaniel, D.P.; Merrell, D.S. The oligo-acyl lysyl antimicrobial peptide $C_{12} \mathrm{k}-2 \beta_{12}$ exhibits a dual mechanism of action and demonstrates strong in vivo efficacy against Helicobacter pylori. Antimicrob. Agents Chemother. 2012, 56, 378-390. [CrossRef] [PubMed]

284. Zaknoon, F.; Wein, S.; Krugliak, M.; Meir, O.; Rotem, S.; Ginsburg, H.; Vial, H.; Mor, A. Antiplasmodial properties of acyl-lysyl oligomers in culture and animal models of malaria. Antimicrob. Agents Chemother. 2011, 55, 3803-3811. [CrossRef] [PubMed]

285. Radzishevsky, I.; Krugliak, M.; Ginsburg, H.; Mor, A. Antiplasmodial activity of lauryl-lysine oligomers. Antimicrob. Agents Chemother. 2007, 51, 1753-1759. [CrossRef] [PubMed] 
286. Jammal, J.; Zaknoon, F.; Kaneti, G.; Goldberg, K.; Mor, A. Sensitization of Gram-negative bacteria to rifampin and OAK combinations. Sci. Rep. 2015, 5, 9216. [CrossRef] [PubMed]

287. Goldfeder, Y.; Zaknoon, F.; Mor, A. Experimental conditions that enhance potency of an antibacterial oligo-acyl-lysyl. Antimicrob. Agents Chemother. 2010, 54, 2590-2595. [CrossRef] [PubMed]

288. Sarig, H.; Ohana, D.; Epand, R.F.; Mor, A.; Epand, R.M. Functional studies of cochleate assemblies of an oligo-acyl-lysyl with lipid mixtures for combating bacterial multidrug resistance. FASEB J. 2011, 25, 3336-3343. [CrossRef] [PubMed]

289. Epand, R.F.; Sarig, H.; Ohana, D.; Papahadjopoulos-Sternberg, B.; Mor, A.; Epand, R.M. Physical properties affecting cochleate formation and morphology using antimicrobial oligo-acyl-lysyl peptide mimetics and mixtures mimicking the composition of bacterial membranes in the absence of divalent cations. J. Phys. Chem. B. 2011, 115, 2287-2293. [CrossRef] [PubMed]

290. Radzishevsky, I.S.; Kovachi, T.; Porat, Y.; Ziserman, L.; Zaknoon, F.; Danino, D.; Mor, A. Structure-activity relationships of antibacterial acyl-lysine oligomers. Chem. Biol. 2008, 15, 354-362. [CrossRef] [PubMed]

291. Epand, R.F.; Sarig, H.; Mor, A.; Epand, R.M. Cell-wall interactions and the selective bacteriostatic activity of a miniature oligo-acyl-lysyl. Biophys. J. 2009, 97, 2250-2257. [CrossRef] [PubMed]

292. Goldberg, K.; Sarig, H.; Zaknoon, F.; Epand, R.F.; Epand, R.M.; Mor, A. Sensitization of Gram-negative bacteria by targeting the membrane potential. FASEB J. 2013, 27, 3818-3826. [CrossRef] [PubMed]

293. Sarig, H.; Goldfeder, Y.; Rotem, S.; Mor, A. Mechanisms mediating bactericidal properties and conditions that enhance the potency of a broad-spectrum oligo-acyl-lysyl. Antimicrob. Agents Chemother. 2011, 55, 688-695. [CrossRef] [PubMed]

294. Forde, E.; Devocelle, M. Pro-moieties of antimicrobial peptide prodrugs. Molecules 2015, 20, $1210-1227$. [CrossRef] [PubMed]

295. Falciani, C.; Lozzi, L.; Scali, S.; Brunetti, J.; Bracci, L.; Pini, A. Site-specific pegylation of an antimicrobial peptide increases resistance to Pseudomonas aeruginosa elastase. Amino Acids 2014, 46, 1403-1407. [CrossRef] [PubMed]

296. Water, J.J.; Smart, S.; Franzyk, H.; Foged, C.; Nielsen, H.M. Nanoparticle-mediated delivery of the antimicrobial peptide plectasin against Staphylococcus aureus in infected epithelial cells. Eur. J. Pharm. Biopharm. 2015, 92, 65-73. [CrossRef] [PubMed]

297. Epand, R.F.; Mor, A.; Epand, R.M. Lipid complexes with cationic peptides and oaks; their role in antimicrobial action and in the delivery of antimicrobial agents. Cell. Mol. Life Sci. 2011, 68, 2177-2188. [CrossRef] [PubMed]

298. D'Angelo, I.; Casciaro, B.; Miro, A.; Quaglia, F.; Mangoni, M.L.; Ungaro, F. Overcoming barriers in Pseudomonas aeruginosa lung infections: Engineered nanoparticles for local delivery of a cationic antimicrobial peptide. Colloids Surf. B Biointerfaces 2015, 135, 717-725. [CrossRef] [PubMed]

299. De Mello, M.B.; da Silva Malheiros, P.; Brandelli, A.; Pesce da Silveira, N.; Jantzen, M.M.; de Souza da Motta, A. Characterization and antilisterial effect of phosphatidylcholine nanovesicles containing the antimicrobial peptide pediocin. Probiotics Antimicrob. Proteins 2013, 5, 43-50. [CrossRef] [PubMed]

300. Domalaon, R.; Findlay, B.; Ogunsina, M.; Arthur, G.; Schweizer, F. Ultrashort cationic lipopeptides and lipopeptoids: Evaluation and mechanistic insights against epithelial cancer cells. Peptides 2016, 84, 58-67. [CrossRef] [PubMed]

(C) 2017 by the authors. Licensee MDPI, Basel, Switzerland. This article is an open access article distributed under the terms and conditions of the Creative Commons Attribution (CC BY) license (http://creativecommons.org/licenses/by/4.0/). 